\title{
First Anthomyzidae (Diptera) from China: a new genus, six new species and new records
}

\author{
Jindřich ROHÁČEK \\ Department of Entomology, Silesian Museum, Nádražní okruh 31, CZ-746 01, Opava, Czech Republic; e-mail: rohacek@szm.cz
}

\author{
Accepted: \\ $16^{\text {th }}$ April 2018 \\ Published online: \\ $25^{\text {th }}$ April 2018
}

\begin{abstract}
The family Anthomyzidae (Diptera: Acalyptrata) is recorded from China for the first time based on 11 species, 6 of them new to science. A distinctive new genus Marshallya gen. nov. is described, based on single peculiar species, M. platythorax sp. nov. (both sexes) from Sichuan. Other new species, viz. Amygdalops sevciki sp. nov. (Hainan I.) (both sexes), Epischnomyia tkoci sp. nov. (Sichuan) (male only), Anthomyza ornata sp. nov. (Sichuan) (female only), Anthomyza sulphurea sp. nov. (Yunnan) (both sexes) and Arganthomyza hyperseta sp. nov. (Shaanxi) (male only) are described and illustrated in detail. Male-female association of two Amygdalops species is clarified by means of molecular barcoding and the female of $A$. bisinus Roháček, 2008 is correctly identified and described. Relationships of all these taxa are discussed. Five species, viz. Amygdalops bisinus (Hainan I.), Epischnomyia merzi Roháček, 2009, Anthomyza cuneata Roháček, 1987, Anthomyza trifurca Sueyoshi \& Roháček, 2003 (all from Sichuan) and Arganthomyza versitheca Roháček, 2009 (Shaanxi, Sichuan) are new additions to the Chinese fauna of Anthomyzidae. DNA sequences of the barcoding region of COI have been obtained for 3 species, Amygdalops bisinus, Amygdalops sevciki and Marshallya platythorax. Biology and distribution of all 11 species are discussed. First photographs of living Anthomyzidae from East Asia are presented. Based on knowledge of Anthomyzidae from neighbouring areas the diversity of the Chinese fauna of the family is estimated to include $50-60$ species.
\end{abstract}

Key words. Diptera, Anthomyzidae, Marshallya, biodiversity, biology, distribution, DNA barcoding, new genus, new records, new species, relationships, taxonomy, China

Zoobank: http://zoobank.org/urn:lsid:zoobank.org:pub:9808C120-13B7-43F8-B735-C13D2B6D43CA

(C) 2018 The Authors. This work is licensed under the Creative Commons Attribution-NonCommercial-NoDerivs 3.0 Licence.

\section{Introduction}

Although dipterology has recently achieved significant progress in China, flies of the family Anthomyzidae have not yet been studied in this vast territory. Representatives of this small acalyptrate family (currently 134 recent species are described in the world) are delicate slender flies related to Opomyzidae. The family Anthomyzidae is currently placed within the superfamily Opomyzoidea and is considered a sister-group of Opomyzidae (ROHÁČEK 1998, 2006, 2013). Larvae of most anthomyzids are micro(phyto)saprophagous grazers living in graminoids between the leaf base and stem, utilizing (at least partly) rotten tissues usually in plants damaged to some extent. Other species feed in a similar way on decaying soft tissues of dicotyledonous plants and a few are mycosaprophagous. For more detail on the biology and information on immatures of Anthomyzidae see ROHÁČEK $(2006,2009)$ and ROHÁČEK \& BARBER (2011). The biology of the East Palaearctic and Oriental species (including basic data about habitat and host plant association) is largely unknown (see ROHÁČEK 2008, 2009; ROHÁČEK \& PRZHIBORO 2016) and, consequently, any biological information on them is very valuable. Because China covers a vast territory comprising both Palaearctic and Oriental realms its dipterous fauna is extremely diverse. This is surely also true for Anthomyzidae despite none having been recorded from this country. However, they are known from neighbouring areas including Mongolia in the north ( 2 species of 2 genera), Far East of Russia 
(20 species of 6 genera), Japan (10 species of 4 genera) and the Korean peninsula (10 species of 5 genera) in the northeast, and Taiwan (4 Amygdalops species), Vietnam (1 Amygdalops species), Nepal (2 species of 2 genera) and India (2 Amygdalops species) in the southeast and south; for published data see SUEYoshI \& RoHÁČEK (2003), RoHÁČEK $(2006,2008,2009)$, and RohÁČ́EK \& PrZHiboro (2016). Therefore we can expect that at least some of these species also occur in China besides hitherto unknown taxa living in this territory.

In this study Anthomyzidae (a total of 11 species) are recorded from China for the first time, including one new genus and 6 new species which are described below. However, this treatment is to be considered only a first and relatively small probe into the Chinese anthomyzid fauna where we can expect not only many more species but also further surprising taxonomic discoveries (as is the peculiar new genus treated here) in the future.

\section{Material and methods}

Material. The material examined is deposited in collections as follows:

CAU Entomological Museum of China Agricultural University, Beijing, China;

CNCI Canadian National Collection of Insects, Arachnids \& Nematodes, Ottawa, Canada;

DEBU University of Guelph Insect Collection, School of Environmental Sciences, University of Guelph, Guelph, Canada;

HNHM Hungarian Natural History Museum, Budapest, Hungary;

MBP Miroslav Barták collection, Praha, Czech Republic;

NMPC National Museum, Praha, Czech Republic;

SIINH Saigusa Institute of Insect Natural History, Fukuoka, Japan;

SMOC Silesian Museum, Opava, Czech Republic;

USNM Department of Entomology, National Museum of Natural History, Smithsonian Institution, Washington D. C., U.S.A.;

ZSMC Zoologische Staatssammlung München, München, Germany.

Methods. Specimens have been examined, drawn and measured using two types of binocular stereoscopic microscopes (Reichert, Olympus SZX10). Male genitalia and female terminalia were examined after their detachment, following treatment in hot $10 \% \mathrm{KOH}$, washing in water and dissection of the whole abdomen in a drop of glycerine under a binocular microscope. Detailed examination was performed with a compound microscope (JENAVAL). After examination, all parts were transferred to a small plastic tube in glycerine and pinned below the respective specimens.

Drawing techniques and photography. Legs were drawn on squared paper using a Reichert binocular microscope with an ocular screen. Details of the male and female terminalia were drawn using Abbe's drawing apparatus on a compound microscope (JENAVAL) at higher magnification $(130-350 \times)$. Wings were photographed on the same microscope with an attached digital camera (Nikon COOLPIX 4500). For more details see RoHÁČEK (2006). Whole adult specimens and their details were photographed by M. Tkoč using Canon 5DSR digital camera with a Nikon CFI Plan 10x/0.25NA 10.5mm WD objective attached to an EF 70-200mm f/4L USM lens. The specimens were repositioned upwards between each exposure using a WeMacro Rail (http://www.wemacro. $\mathrm{com} /$, each step was 5,10 , or $20 \mu \mathrm{m}$ ) and the final photograph was compiled from multiple layers (50-150) using Helicon Focus Pro 5.3. The final images were edited in Adobe Photoshop CS6.

Measurements. Five main characteristics of adults were measured: body length (measured from anterior margin of head to end of cercus, thus excluding the antenna), wing length (from wing base to wing tip), wing width (maximum width), C-index $\left(\mathrm{Cs}_{3}: \mathrm{Cs}_{4}\right)$ (= ratio of length of 3rd costal sector : length of 4th costal sector) and index rmldm-cu : $\mathrm{dm}$-cu (= ratio of length of section between $\mathrm{rm}$ and $\mathrm{dm}$ cu on discal cell : length of dm-cu). All type specimens were measured.

Presentation of faunistic data. Label data of primary type specimens are presented strictly verbatim including information on colour of all associated labels. Data from other material examined are standardized and presented in full. Phenological and other biological information obtained from the material examined and literature are given in the Biology paragraph; data on occurrence are summarized in the Distribution paragraph.

Barcoding. The specimens used for DNA analysis were alcohol-preserved ( $80 \%$ ethanol) and/or dry-mounted. The DNA was extracted using NucleoSpin Tissue Kit (MachereyNagel, Germany) following manufacturers' protocols. Sclerotized remains of all extracted bodies (some representing type specimens) have been preserved in pinned plastic vials in glycerine, labelled with full data and deposited in SMOC. PCRs (polymerase chain reactions) were performed using specific primers for the mitochondrial COI gene barcode region, LCO1490 (5'-GGTCAACAAATCATAAAGATATTGG-3') and HCO2198 (5'-TAAACTTCAGGGTGACCAAAAAATCA-3') (FoLmer et al. 1994). All amplified products were purified using Gel/PCR DNA Fragments Extraction Kit (Geneaid, New Taipei City, Taiwan). After PCR, the amplified DNA samples were sequenced by Macrogen Europe (Netherlands). All sequences were assembled, manually inspected, and primers trimmed in SeqTrace (STUCKY 2012). For more details about molecular methods used in this study see ŠEvČíK et al. (2016). New sequences were deposited in the GenBank database and their accession numbers are given in Table 1. The dataset was analyzed using the maximum likelihood (ML) method. The node support values are given in the form of bootstrap value (BV). The analyses were conducted on the CIPRES computer cluster using RAxML-HPC BlackBox 8.2.10 (STAMATAKIS 2014). Phylogenetic trees were visualized using Interactive Tree Of Life (iTOL) (LeTUNIC \& Bork 2016). The species Fungomyza albimana (Meigen, 1830) was used as a root following the phylogenetic hypothesis of Holarctic Anthomyzidae by ROHÁČEK \& TóTHOVÁ (2014). The outgroups were represented by six species: Anagnota bicolor (Meigen, 1838), Arganthomyza carbo Roháček \& Barber, 2013, Typhamyza bifasciata (Wood, 1911), Stiphrosoma fissum Roháček, 1996, Anthomyza macra (Czerny, 1928) and F. albimana. Sequences of all these outgroup species (and also that of Amygdalops thomasseti Lamb, 1914) were taken from the GenBank database. GenBank accession numbers for all the sequences are listed in Table 1. 
Table 1. List of species with their GenBank accession numbers and localities.

\begin{tabular}{|c|c|c|}
\hline Taxa & COI & locality \\
\hline $\begin{array}{l}\text { Amygdalops bisinus Roháček, } 2008 \\
\text { (male) }\end{array}$ & MH012201 & China: Hainan I. \\
\hline $\begin{array}{l}\text { Amygdalops bisinus Roháček, } 2008 \\
\text { (female) }\end{array}$ & MH012200 & China: Hainan I. \\
\hline Amygdalops sevciki sp. nov. (male) & MH012202 & China: Hainan I. \\
\hline Amygdalops sevciki sp. nov. (female) & MH012203 & China: Hainan I. \\
\hline Amygdalops thomasseti Lamb, 1914 & KJ418529 & Greece: Crete \\
\hline Anagnota bicolor (Meigen, 1838) & KJ418530 & Czech Republic \\
\hline Anthomyza macra Czerny, 1928 & KJ418533 & Austria \\
\hline $\begin{array}{l}\text { Arganthomyza carbo Roháček \& } \\
\text { Barber, } 2013\end{array}$ & KJ418561 & Canada: Ontario \\
\hline $\begin{array}{l}\text { Fungomyza albimana (Meigen, } \\
1830 \text { ) }\end{array}$ & KJ418547 & Czech Republic \\
\hline $\begin{array}{l}\text { Marshallya platythorax sp. nov. } \\
\text { (male) }\end{array}$ & MH012199 & China: Sichuan \\
\hline Stiphrosoma fissum Roháček, 1996 & KJ418541 & South Korea \\
\hline Typhamyza bifasciata (Wood, 1911) & KJ418544 & Austria \\
\hline
\end{tabular}

Morphological terminology follows that used in monographs of Anthomyzidae by RoHÁčeK (2006) and/or ROHÁČEK \& BARBER (2016) including terms of the male hypopygium and female terminalia. For male genitalia terminology, the 'hinge' hypothesis of the origin of the eremoneuran hypopygium (see ZATWARNICKI 1996), has been adopted. The following synonymous terms of the male genitalia, emanating from other hypotheses and used in Diptera manuals (e.g. Cumming \& Wood 2010), need to be listed (terms used here first): aedeagus = phallus; ejacapodeme $=$ ejaculatory apodeme; epandrium $=$ periandrium; gonostylus $=$ surstylus; medandrium $=$ bacilliform sclerite, intraepandrial or intraperiandrial sclerite; phallapodeme $=$ aedeagal apodeme; postgonite $=$ gonite, paramere. Morphological terms of the male postabdomen and genitalia are depicted in Figs 8-22, 45-50, those of the female postabdomen in Figs 23-30. Characters in the generic diagnosis are numbered following the system used by ROHÁČEK $(2006,2009)$ and ROHÁČEK \& BARBER (2016).

Abbreviations of morphological terms used in text and/ or figures:

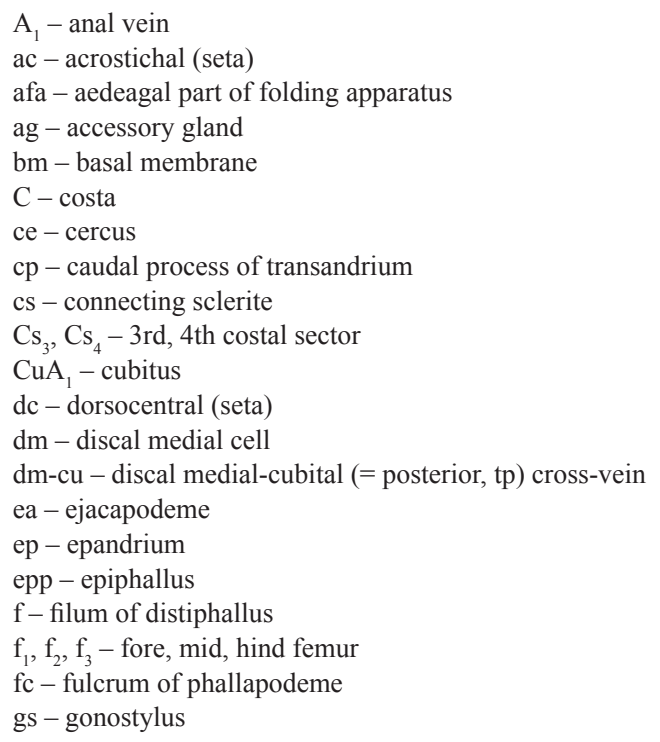

hl - hypandrial lobe

hu - humeral (= postpronotal) (seta)

hy - hypandrium

is - internal sclerite(s)

$\mathrm{M}$ - media

ma-medandrium

$\mathrm{npl}$ - notopleural (seta)

oc - ocellar (seta)

ors - orbital (seta)

pa - postalar (seta)

$\mathrm{pg}$ - postgonite

pha - phallapodeme

$\mathrm{pp}$ - phallophore

ppl - propleural (= proepisternal) (seta)

prg - pregonite

prs - presutural (seta)

pvt - postvertical (seta)

$\mathrm{R}_{1}-1$ st branch of radius

$\mathrm{R}_{2+3}-2 \mathrm{nd}$ branch of radius

$\mathrm{R}_{4+5}^{2+3}-3$ rd branch of radius

$\mathrm{r}-\mathrm{m}$ - radial-medial (= anterior, ta) cross-vein

$\mathrm{s}-$ saccus of distiphallus

S2-S10 - abdominal sterna

sa - supraalar (seta)

sc - scutellar (seta)

$\mathrm{Sc}-$ subcosta

sp - spermatheca

stpl - sternopleural (= katepisternal) (seta)

T1-T10 - abdominal terga

$\mathrm{t}_{1}, \mathrm{t}_{2}, \mathrm{t}_{3}-$ fore, mid, hind tibia

ta - transandrium

vi - vibrissa

$\mathrm{vr}$ - ventral receptacle

vte - outer vertical (seta)

vti - inner vertical (seta)

wpha - wing-shaped lobes of phallapodeme

\section{Results}

\section{Marshallya gen. nov.}

Type species. Marshallya platythorax sp. nov., here designated.

Diagnosis. (1) Head slightly longer than high. (2) Eye large, very convex, elongately ellipsoid, with longest diameter oblique. (3) Frons narrow, flattened and medially slightly depressed; (4) frontal triangle short and shining. (5) Frontal lunule reduced, indistinct. (6) Occiput strongly concave. (7) Vertex with silvery grey microtomentose stripes lateral to ocellar triangle. (8) Antenna geniculate between pedicel and 1st flagellomere; pedicel simple, 1st flagellomere strongly compressed laterally. (9) Arista ciliate (not pectinate) (Fig. 2). (10) Palpus slender, with 1 distinct subapical seta and 2 apical setulae. Cephalic chaetotaxy: (11) pvt small, convergent to parallel; (12) vte and/or posterior ors longest of cephalic setae; (13) vti shorter than vte but longer than oc; (14) 2 long ors, widely spaced - posterior in the middle of orbit, anterior close to fore margin of frons; 1 setula and 1 microsetula just in front of anterior ors; (15) postocular setulae minute, in single row; (16) 1 long vi and 1 subequally long subvibrissa; (17) peristomal setulae sparse but at least twice as long as postoculars. (18) Posteroventral corner of head (postgena) almost rectangled (Fig. 3). (19) Antenna and face of similar colouring in both sexes (only slightly darker in female). 
(20) Thorax narrower than head, subshining. (21) Mesonotum (but not scutellum) dorsally flattened (Fig. 7). (22) Pleuron with dark longitudinal band at dorsal margin. Thoracic chaetotaxy: (23) $1 \mathrm{hu}, 2 \mathrm{npl}$ (anterior longer); (24) 0 prs; (25) 0 sa, 1 short pa; (26) 2 postsutural dc, both in prescutellar portion of scutum, only posterior long, anterior small; (27) ac microsetae in 4 rows in front of suture; (28) 2 sc, apical long, laterobasal short and weak; (29) $0 \mathrm{ppl}$; (30) $2 \mathrm{stpl}$, anterior almost as long as posterior, and a few setulae in dorsal half of sternopleuron. Legs: (31) femora and tibiae with dark annulus near knee; (32) $\mathrm{f}_{1}$ of both sexes without ctenidial spine but with a comb of short anteroventral setae in distal two-fifths; (33) $t_{2}$ with distinct ventroapical seta; (34) $f_{3}$ of both sexes with posteroventral and anteroventral row of setae some of which in distal half are shortened and thickened. (35) Wing long and narrow; (36) wing membrane darkened, particularly subapically (Fig. 1); (37) C with distinct spinulae among fine setulae on $\mathrm{Cs}_{2}$ (Fig. 4); (38) $\mathrm{R}_{2+3}$ long, slightly sinuous, ending about twice as far from apex of $\mathrm{R}_{4+5}$ than does $\mathrm{M}$ and bent towards C apically; (39) $\mathrm{R}_{4+5}$ slightly bent apically; (40) $\mathrm{R}_{4+5}$ and $\mathrm{M}$ distinctly convergent preapically but parellel apically; (41) M slightly sinuous; (42) dm cell narrow and relatively long; cross-vein $\mathrm{r}-\mathrm{m}$ situated near its basal two-fifths to third; (43) $\mathrm{CuA}_{1}$ medium long and almost reaching wing margin; (44) $\mathrm{A}_{1}$ short but almost reaching wing margin; (45) anal lobe and alula reduced, both very narrow.

(46) Male abdomen very narrow, elongate. (47) T1 separate from T2; (48) T2-T5 large, long and broad, reaching laterally onto ventral aspect of abdomen, uniformly dark-pigmented. (49) S1-S5 narrower and very pale-pigmented. Male postabdomen: (50) T6 not developed (membranous); (51) S6-S8 fused dorsolaterally to form asymmetrical synsclerite; (52) S6 and S7 strongly asymmetrical, firmly fused and situated laterally, both without setae. (53) S8 very long, setose, less asymmetrical and situated dorsally.

Male genitalia (Figs 8, 9, 11-22). (54) Epandrium relatively large, hemispherical, wider than long, densely setose, with 2 pairs of markedly longer setae. (55) Anal fissure large, high but relatively narrow. (56) Medandrium broad, not high, with submembranous dorsal part; (57) cercus medium-sized, sclerotized but dorsoventrally flattened, finely setose. (58) Gonostylus long, slender, with tapered apex and strongly bent medially, setose mainly on inner side, with micropubescence covering most of outer side. (59) Hypandrium robust, with flat lateral lobes well developed; (60) transandrium (Figs 14, 15, 17) formed by simple medial sclerite, but its lateral robust part projecting in caudal process which is peculiarly connected with both pregonite and postgonite. (61) Pregonite elongate, very low, with 2 groups of setae, fused to hypandrium, only its anterior part projecting medially (see Fig. 15), posterior part very simple but fused with postgonite (and lateral caudal process of transadrium). (62) Postgonite unique because of its lateral position, absence of basal sclerite, short and complex form with several processes and fusion with pregonite and caudal process. (63) Basal membrane without sclerotized structures and ventrally incised. (64) Aedeagal part of folding apparatus (Fig. 22) relatively short, provided with dark, radially arranged tubercles; (65) connecting sclerite (Fig. 22) extremely robust and heavily sclerotized, distally dilated, darkened and angular. (66) Phallapodeme with basal part expanded into large flat wing-like lobes (Fig. 19) embracing base of distiphallus. Aedeagus with (67) medium long (posteriorly projecting) phallophore and (68) distiphallus composed of voluminous largely membranous saccus and slender sclerotized filum. (69) Membrane of saccus overgrown by fine spines, mainly on its right side; (70) filum formed by 2 long, dark, slender and twisted band-like sclerites, but one of them shortened and ending far from apex. (71) Ejacapodeme small, with slender digitiform projection.

(72) Female abdomen also very elongate but with somewhat broader terga (T2-T5) and sterna (S2-S5) than in male. (73) Postabdomen (Figs 23-25) relatively long, with terga and sterna (except S6) well sclerotized and dark-pigmented. (74) T6 and S6 relatively large, T6 dark, S6 pale. (75) T7 laterally extended and reaching ventral aspect but not fused with $\mathrm{S} 7$ and 7 th spiracles free in pleural membrane; (76) S7 much smaller than S6, rounded, characteristically pigmented; (77) T8 simple, flat, with rounded corners; (78) S8 protruding posteromedially, with very small posteromedial incision. (79) Internal sclerotization of female genital chamber (uterus) well developed (Figs 28, 30), formed by very complex (but symmetrical) posterior sclerites being posteroventrally fused to inner side of S8 and (80) 1 anteroventral, simply transversely ellipsoid annular sclerite. (81) Anterior part of uterus with voluminous vesicular kidney-shaped ventral receptacle (Fig. 28). (82) Accessory glands of usual form, on short simple (non-dilated) ducts. (83) Spermathecae $(1+1)$ shortly pyriform (Figs 28, 29), with well-developed sclerotized cervix and some grain-like spinulae on smooth body surface; spermathecal duct relatively short. (84) T10 relatively large, rounded, partly dark, with 1 pair of dorsomedial setae; (85) S10 slightly smaller than T10, simply semicircular, micropubescent besides fine setulae. (86) Cerci moderate but robust, with comparatively short, fine and abundant setae, none of which is enlarged.

Discussion. The combination of diagnostic characters of Marshallya gen. nov. (as listed above) is unique within the Anthomyzidae. These characters include external features shared with Amygdalops Lamb, 1914 and its relatives (while lacking most of their synapomorphies in the male and female terminalia), plesiomorphies widespread among anthomyzid genera and, most significantly, apomorphies unique within the whole family Anthomyzidae.

The type species of Marshallya externally closely resembles species of the Old World tropical genus Amygdalops and the related Afrotropical genus Margdalops Roháček \& Barraclough, 2003 in having very convex ellipsoid eyes, narrow frons, 2 long widely spaced ors, strongly concave occiput, pleuron with dark dorsal band, wing with subapical darkening, narrow and relatively short $\mathrm{dm}$ cell, reduced anal lobe and alula etc. With Amygdalops it also shares vti shorter than vte, reduced 
frontal lunule, dc macrosetae in prescutellar position and shortened $\mathrm{CuA}_{1}$ (cf. ROHÁČEK 2004, 2008), and with Margdalops vertex with silvery microtomentose stripes and the ciliate (not pectinate) arista (see RoHÁČEK \& BarRaclough 2003). However, more detailed study of the type species of Marshallya revealed substantive morphological dissimilarities with both genera discussed above, particularly with unique structures of the male and female terminalia (see below). The new genus differs from them also in several external characters,
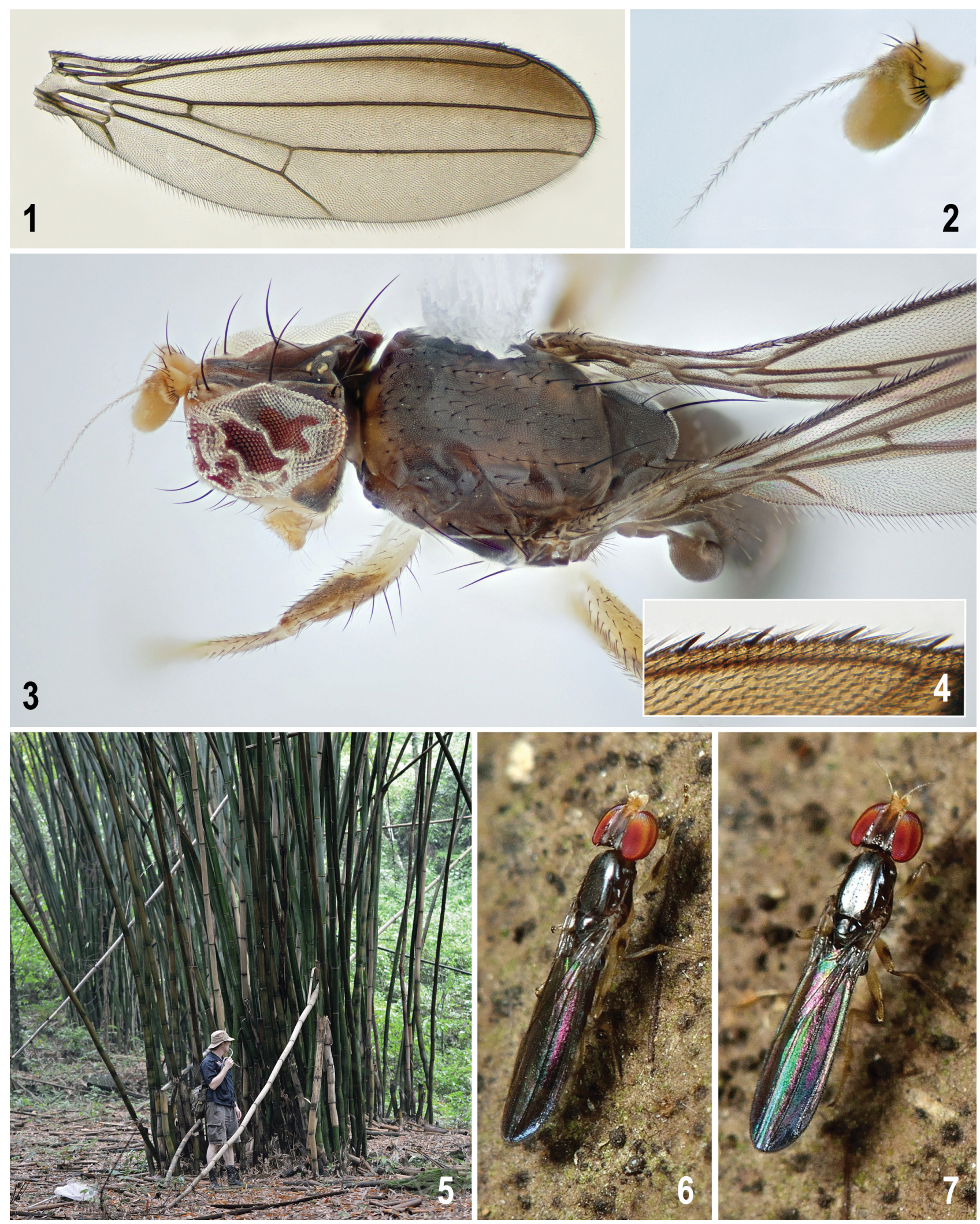

Figs 1-7. Marshallya platythorax sp. nov. and its habitat (China: Sichuan). 1 - wing (length ca. $3 \mathrm{~mm}$ ); 2 - antenna, laterally; 3 - head and thorax, laterodorsally; 4 - detail of $\mathrm{C}$ with spine-like setae; 5 - copse of bamboo, habitat and probable host plant in the type locality (with Owen Lonsdale in front of it); 6, 7 - living adults on bamboo stem (body length ca $3.1 \mathrm{~mm}$ ). Figs 1, 4 based on male paratype, Figs 2, 3 on male holotype. Photos by J. Roháček $(1,4)$, M. Tkoč $(2,3)$ and S. A. Marshall (5-7). 
particularly in having the dorsally flattened mesonotum, reduced thoracic chaetotaxy (prs, sa, ppl absent, pa short), both male and female with rows of shortened thickened setae on $\mathrm{f}_{1}$ (anteroventrally) and $\mathrm{f}_{3}$ (both anteroventrally and posteroventrally), $\mathrm{C}$ with distinct spine-like setae among fine setulae and very elongate slender abdomen. It is notable that some of these characters can be found as homoplasies in distinctly non-related genera, e. g. the flattened mesonotum in the genus Typhamyza Roháček, 1992, the reduced thoracic chaetotaxy in Anagnota Becker, 1902 and Cercagnota Roháček \& Freidberg, 1993 (see ROHÁČEK 2006) and $f_{1}$ with anteroventral row of thicker setae in the Afrotropical genus Barbarista Roháček, 1993 (see ROHÁČEK 1993).

Nevertheless, the most important autapomorphies that characterize Marshallya can be seen in the male genitalia and female postabdomen as follows: (58) gonostylus elongate but strongly bent medially (Fig. 9); (60) transandrium with robust lateral parts, each projecting in caudal process which is uniquely connected with both pregonite and postgonite; (62) postgonite in unusual lateral position, lacking the basal sclerite, of short and complex form with several processes and fused with (posterior part of) pregonite and (lateral) caudal process (see Figs 16, 17); (63) basal membrane without sclerotized structures and ventrally incised; (65) connecting sclerite (Fig. 22) extremely robust and heavily sclerotized, distally dilated, darkened and angular; (66) phallapodeme basally with large symmetrical flat wing-like lobes embracing base of distiphallus (Figs 19, 22); (70) filum of distiphallus with (plesiomorphic) 2 long band-like sclerites, but one them shortened and ending far from apex (Fig. 21); (79) internal sclerotization of female genital chamber (Figs 28, 30) well developed, formed by very complex (but symmetrical) posterior sclerites which are posteroventrally fused to inner side of S8 and (80) an anteroventral, simply transversely ellipsoid annular sclerite; (81) ventral receptacle voluminous, vesicular, kidney-shaped (Fig. 28).

The relationships of the genus Marshallya have not yet been resolved. It is probable that its sister-group will be discovered among the largely unknown Oriental taxa of Anthomyzidae. Morphological and molecular distance (see Fig. 31) of M. platythorax to the externally similar Amygdalops species proved to be too large to demonstrate their close alliance. The new genus could possibly be a more distant relative of the Amygdalops clade (comprising Amygdalops, Margdalops and an unnamed Neotropical genus, cf. RoHÁčEK 2008) as is indicated by the shared external characters discussed above despite large molecular dissimilarity in the barcoding region of COI (Fig. 31).

Species included. Marshallya platythorax sp. nov. (described below).

Etymology. The new genus Marshallya is dedicated to my friend, Steve A. Marshall (University of Guelph), the collector of its type species, world renowned Canadian dipterist and insect photographer. The name is an abbreviated conjunction of Marshall $+[m] y a$, gender feminine.

\section{Marshallya platythorax sp. nov.}

$$
\text { (Figs 1-4, 6-30) }
$$

Type material. Hоцотүре: 3 , labelled: 'China: Sichuan: Emeishan, 19.v.2016, 800-900m, N 29³4'10.42” E 10323'27.98”, S. A. Marshall' and 'Holotypus đે, Marshallya platythorax sp. n., J. Roháček det. 2017' (red label). The specimen is intact, dried from ethanol and mounted on a pinned paper point, with only left mid leg removed and glued to the specimen pin (CAU). PARATYPES: $1 \delta 1$, with same label data as the holotype, only second (type) label is yellow and has 'Paratypus' instead of 'Holotypus'; the male body (without abdomen, one wing and hind leg) was used for DNA extraction and subsequently placed (partly dissected) in glycerine in a pinned plastic microvial; abdomen of both male and female cleared, dissected and preserved in glycerine in a pinned plastic tube but that of male with the removed wing and hind leg in addition (DEBU, 1 ; ; SMOC, 1 ).

Description. Male. Total body length $3.02-3.18 \mathrm{~mm}$. Body elongate and very slender (Figs 6, 7), bicolourous, dark brown and whitish yellow. Head slightly longer than high; frons flattened and dorsomedially depressed. Occiput distinctly concave, dark but not entirely (ochreous to ochreous yellow dorsally, particularly behind eyes), subshining and greyish microtomentose (most densely medially above foramen). Vertex with narrow silvery grey microtomentose stripes between ocellar triangle and posterior part of orbit. Frontal triangle very short (only in posterior third of frons) and roughly equilateral, shiny because of very sparse microtomentum, including ocellar triangle. Ocelli large and close to each other. Frons largely dark brown, dark grey microtomentose and dull, only its narrow medial band pale brown to ochreous yellow (anteriorly) and anterior half of orbit yellow. Orbit dark brown and shining in posterior half but becoming lighter anteriorly to dirty yellow and whitish grey microtomentose in anterior third. Frontal lunule very reduced, not visible in dry specimens. Face dark ochreous laterally, brown and distinctly concave medially; parafacialia and (most of) gena whitish yellow, with silvery white microtomentum but both pale brown margined (on anterior part of gena most broadly); postgena with posteroventral corner almost rectangled (Fig. 3) but rounded, whitish yellow, dorsally concolourous with adjacent dark brown part of occiput. Mouthparts relatively small, dirty yellow including somewhat darker clypeus. Cephalic chaetotaxy (Fig. 3): pvt small but distinct, convergent (usually) to parallel; vti distinctly shorter than vte (about two-thirds of the latter); vte and/or posterior ors longest of cephalic setae; oc strongly proclinate, only about as long as vti, situated outside line connecting ocelli; 2 widely spaced and long ors, posterior as long as or longer than vte, anterior only slightly shorter; 1 setula and 1 much smaller microsetula in front of anterior ors; 2 pairs of microsetulae in interfrontal position in anterior third of frons; 1 relatively weak vi (about as long as oc) and 1 almost equal subvibrissa; peristomal setulae (6-7) fine, becoming longer anteriorly, the foremost about half length of vi; postocular setulae very minute, in single row behind dorsal half of posterior eye margin; palpus whitish yellow, with usual subapical (as long as foremost peristomal) and 2 smaller setulae on apex. Eye large, orange red (when alive, cf. Figs 6, 7), ellipsoid (almond-shaped) as in Amygdalops species and covering most of head profile, 
very convex, with longest diameter about 1.6 times as long as shortest one. Gena very narrow; its shortest height 0.08 times as long as shortest eye diameter. Antenna (Fig. 2) yellow, strongly geniculate; scape and pedicel of usual form and setosity; 1st flagellomere strongly laterally flattened, entirely yellow, at most with slightly darker margin around base of arista, shortly whitish ciliate on apex. Arista also yellowish, including short and thick basal segment, about 2.2 times as long as antenna, with medium long whitish ciliation (Fig. 2).

Thorax narrower than head (with eyes), bicolourous, dark brown dorsally and yellowish white ventrally. Dorsal part of thorax sparsely microtomentose and relatively shining, pleural part duller. Mesonotum dorsally flattened (see Figs 6, 7), largely dark brown but with paler ochreous brown anterior spots adjacent to humeral callus and also dorsocentral lines somewhat paler (Fig 3). Humeral (postpronotal) callus pale brown and also notopleural area somewhat lighter than surrounding sclerites; pleural part of thorax with rather broad (covering entire propleuron and dorsal half of mesopleuron) blackish brown dorsal band extending from propleuron to haltere and sharply delimited from yellowish white ventral portion of pleuron. Scutellum slightly convex (not flat) and blackish brown, as are the well developed (bulging) postscutellum and metapleuron. Thoracic chaetotaxy (Fig. 3) reduced: ppl, prs and sa absent; 1 relatively weak hu, $2 \mathrm{npl}$ (anterior slightly longer than hu, posterior short), 2 (both postsutural) dc arising close to scutellum; anterior dc short (only twice the length of dc microsetae) and situated immediately in front of the long posterior dc, the latter only slightly shorter than apical sc; ac microsetae small and sparse, in 4 rows on suture, in 2 rows between dc macrosetae and reaching to prescutellar position; 1 short pa (not longer than laterobasal sc); $2 \mathrm{sc}$, apical long and strong (the longest thoracic seta), laterobasal small, less than one third of length of apical sc and situated rather far from base of scutellum; 2 stpl, posterior only slightly longer than anterior; 5-6 microsetae below stpl and number (about 10) of fine setae on ventral corner of sternopleuron. Scutellum rounded triangular, about 1.5 times as wide as long. Legs bicolourous, largely yellow to yellowish white (coxae lightest) but femora with diffuse brown darkening in distal third to half (except for yellow apical part at knees) and with tibiae similarly (somewhat paler) brown-darkened in proximal fourth to third (cf. Figs $3,10,27)$. Pedal chaetotaxy: $f_{1}$ with usual posterodorsal and posteroventral row of longer setae but also with an anteroventral comb of short and thicker setae (3-4 usually more robust than others) in distal two-fifth (see Fig. 27); $f_{2}$ without peculiarities, only with some slightly longer and erect ventral setae in proximal third; $f_{3}$ with posteroventral row of setae along entire length (4-5 of them in distal half shortened and thickened) and with an additional anteroventral row of several (yet shorter) thickened setae (see Fig. 10). $t_{1}$ and $t_{3}$ uniformly setulose; $t_{2}$ with usual ventroapical seta, distinctly longer than maximum width of tibia; basitarsi of all legs with 1-3 longer and somewhat thicker ventrobasal setulae, being larger (2-3) on hind basitarsus which also bears a series of thicker ventral setulae among fine setulae. Wing (Fig. 1) with distinctly brown darkened membrane, darkest along distal half of $\mathrm{R}_{2+3}$ and between apices of the latter and $\mathrm{R}_{4+5}$; veins dark brown. $\mathrm{C}$ (unlike Amygdalops species) with thicker spine-like, widely spaced, setae on dorsal side (cf. Figs 3, 4). Sc well developed, free proximally, attached to $\mathrm{R}_{1}$ distally and forming with the latter a very distinct preapical kink at subcostal break. $\mathrm{R}_{2+3}$ very long, running close to $\mathrm{C}$, distally slightly sinuate and apically upcurved to $\mathrm{C} . \mathrm{R}_{4+5}$ distally slightly bent and converging preapically to slightly sinuate vein $M$ and ending in parallel. Discal (dm) cell narrow but relatively long (longer than in most of Amygdalops species); r-m situated around basal two-fifths to third of dm cell; apical section of $\mathrm{CuA}_{1}$ more than twice longer than $\mathrm{dm}$ and almost ending in wing margin; bm and cup cells small and narrow; $\mathrm{A}_{1}$ short but almost reaching wing margin due to reduced anal lobe of wing. Alula small and very narrow (as in Amygdalops species). Wing measurements: length 2.98-3.02 mm, width 0.83-0.93 mm, $\mathrm{Cs}_{3}: \mathrm{Cs}_{4}=2.08-2.19$, $\mathrm{r}-\mathrm{m} \backslash \mathrm{dm}-\mathrm{cu}: \mathrm{dm}-\mathrm{cu}=3.89-4.06$. Haltere with brown stem and large dark brown knob.

Abdomen elongate and very narrow (about 4.6 times as long as wide), blackish brown, greyish microtomentose and subshiny dorsally, pale (whitish) ochreous ventrally. Preabdominal terga large, bent onto lateral to ventrolateral aspects (hence pleural part of segments reduced), uniformly blackish brown and relatively densely but shortly and finely setose. T1 distinctly separate and about half length of T2; T2 slightly shorter than T3 and/or T4 (these subequal); T5 shorter than T2 but widest of preabdominal terga. T6 not developed (membranous). Preabdominal sterna very pale, finely sparsely setose, becoming somewhat wider posteriorly, S5 the widest. S1 shorter than wide, bare; S2 with brownish stripe along anterior margin, slightly shorter than S3 and/or S4 (these subequal) and all distinctly longer than wide; S5 widest but shorter, about as long as wide. S6-S8 asymmetrical, dorsolaterally fused; both S6 and S7 lighter brown, subequal in length, each with anterior darkened marginal ledge-like stripe and situated on left side of postabdomen; S6 ventrally shortened, transversely band-like, laterally dilated, subrhomboidal, bare except for 2 microsetulae; S7 of pentagonal outline, bare, with fusion line with S6 thickened and darkened and its dorsal part embedding large 7th spiracle; 6th spiracle situated in membrane above dorsal corner of S6. S8 situated dorsally, blackish brown, long (almost 3 times as long as S7) and with a number of relatively short setae in posterior half.

Genitalia of distinctive construction. Epandrium relatively large (compared to postabdominal sclerites), hemispherical, not long (Fig. 8) but broad (markedly wider than long, cf. Fig. 9), rather densely setose, with 1 dorsomedial and 1 laterocaudal (this longest and thickest) long setae; anal opening relatively large, high, narrowly semi-ellipsoid (Fig. 9). Cercus characteristically formed, not small but only half length of gonostylus, strongly (dorsoventrally) flattened and hidden in anal fissure (hence not visible in lateral view), with longer setae mainly in dorsal half. Medandrium (Figs 9, 11) comparatively broad, having only lateral parts well-sclerotized; dorsomedial connecti- 


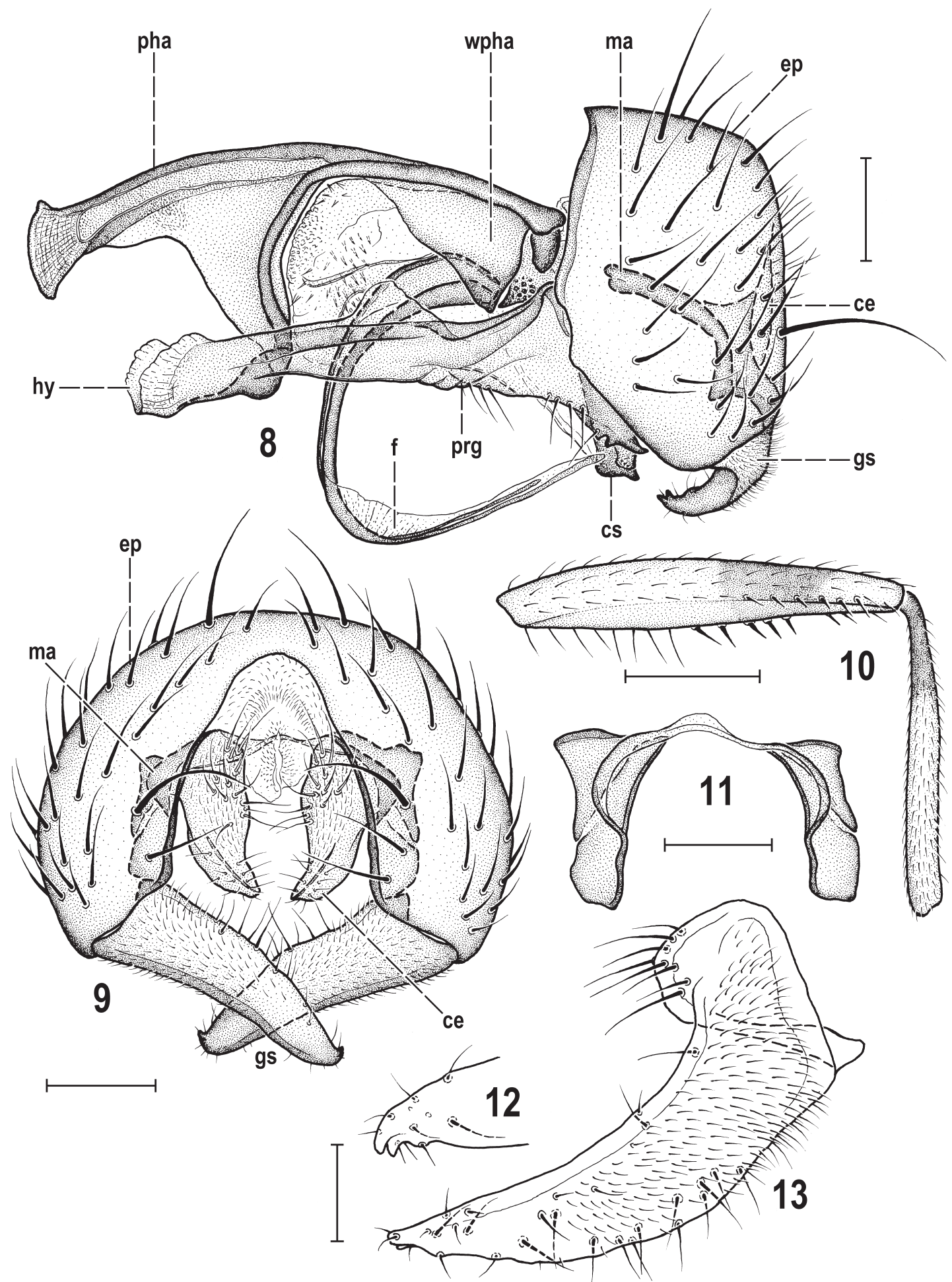

Figs 8-13. Marshallya platythorax sp. nov., male paratype (China: Sichuan). 8 - genitalia, laterally; 9 - external genitalia, caudally; $10-\mathrm{f}_{3}$ and $\mathrm{t}_{3}$ anteriorly; 11 - medandrium, anteriorly; 12 - apex of gonostylus, anterolaterally (widest extension); 13 - gonostylus, lateroventrally (widest extension). Scales $=0.5 \mathrm{~mm}$ (Fig. 10), $0.05 \mathrm{~mm}$ (Figs 12,13), $0.1 \mathrm{~mm}$ (others). For abbreviations see p. 37 .

on slender and submembranous. Gonostyli symmetrical, strongly bent medially (cf. Fig. 9), with apices crossed or appressed in rest position. Gonostylus (Figs 8, 9, 13) long and relatively slender, roughly sickle-shaped in widest extension view (Fig. 13); its anterior (basal) part with a group of longer fine setae ventrally, most of outer side covered by micropubescence, otherwise finely setose on inner side near posterior margin; apex of gonostylus with a pair of denticles (visible only at a limited viewing angle-Fig. 12). Hypandrial complex (Figs 14, 15) of unique construction. Hypandrium robust (both in lateral and ventral view), with well developed dorsally projecting flat lateral lobes (Figs 14, 15, hl). Transandrium (Figs 14, 15, 17) formed by simple medial sclerite (lacking medial caudal process, 


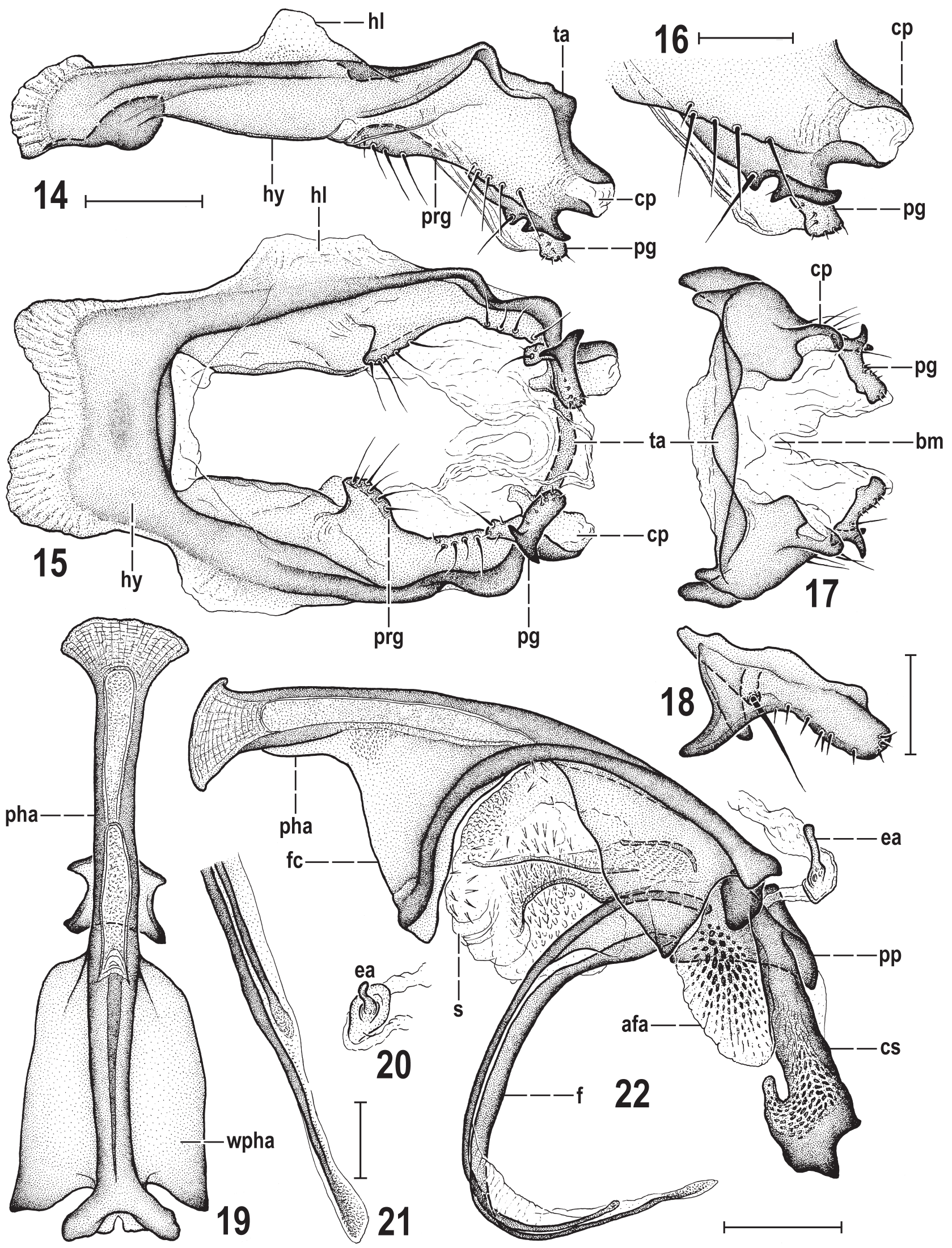

Figs 14-22. Marshallya platythorax sp. nov., male paratype (China: Sichuan). 14-15 - hypandrial complex (14-laterally; 15 - ventrally); 16 - postgonite and associated structures, laterally; 17 - transandrium, caudally; 18 - postgonite, caudally; 19 - phallapodeme, dorsally; 20 - ejacapodeme, different view than in Fig. 22; 21 - apex of filum, sublaterally; 22 - aedeagal complex, laterally. Scales $=0.05 \mathrm{~mm}$ (Fig. 16), $0.03 \mathrm{~mm}$ (Figs 18, 21), $0.1 \mathrm{~mm}$ (others). For abbreviations see p. 37. 


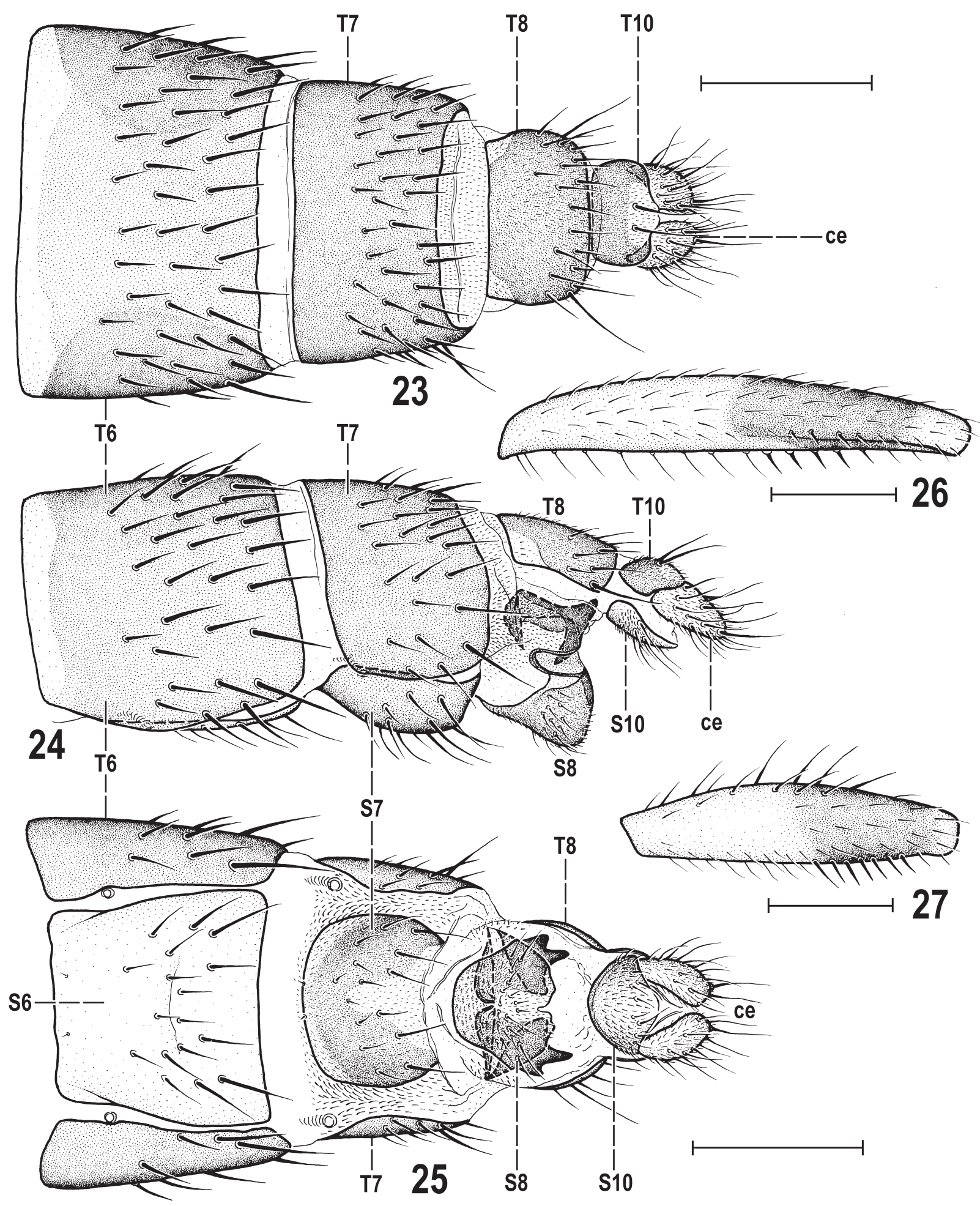

Figs 23-27. Marshallya platythorax sp. nov., female paratype (China: Sichuan). 23-25 - postabdomen (23 - dorsally; 24 - laterally; 25 - ventrally); 26 - female $\mathrm{f}_{3}$, anteriorly; $27-$ female $_{1}$, anteriorly. Scales $=0.2 \mathrm{~mm}$. For abbreviations see p. 37 .

see Fig. 17) connecting robust lateral parts each projecting into a peculiar stump-like (caudal) process being anteroventrally connected with both postgonite and posterior part of pregonite (see Figs 14-17, cp). Pregonite (Figs 14, 15), elongate and low, incurved, only its anterior part somewhat projecting medially (Fig. 15, prg) and bearing a group of 5-6 setae; its inconspicuous posterior part with 4-5 setae. Postgonite (Figs 14-18,pg) very unusual, shifted laterally, lacking basal sclerite but anterodorsally fused to pregonite and posterodorsally to lateral caudal process of transandrium. Its form is uniquely short and complex, with several teeth (one of them with a distinct seta) and main lobe with series of setiform sensilla (cf. Fig. 18). Basal membrane (Fig. 17, bm) also peculiar in lacking any armature and being ventrally incised. Aedeagal part of folding apparatus (Fig. 22, afa) submembranous, relatively short and its external side with medium to small dark tubercles arranged in radial pattern; connecting sclerite (Fig. 22, cs) 


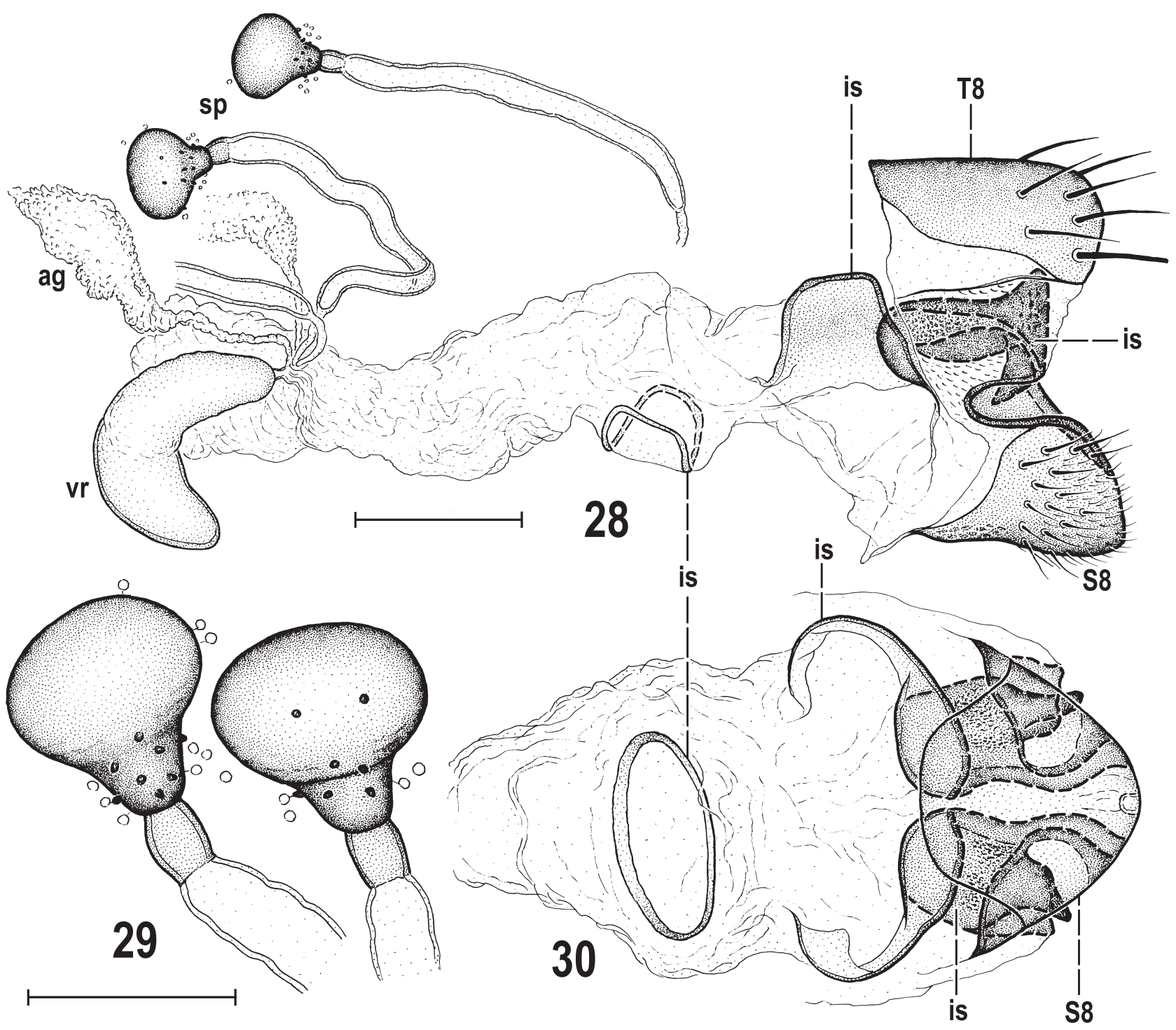

Figs 28-30. Marshallya platythorax sp. nov., female paratype (China: Sichuan). 28 - genital chamber with 8th abdominal segment, laterally; 29 spermathecae; 30 - internal sclerites of genital chamber and S8 (with setosity omitted), ventrally. Scales $=0.05 \mathrm{~mm}$ (Fig. 29) and 0.1 mm (others). For abbreviations see p. 37.

extremely robust, heavily sclerotized, proximally slender but becoming thicker in middle part, distally dilated and somewhat hook-like, with robust blackish angular apex projecting below hypandrial complex (see Fig. 8, cs). Aedeagal complex (Fig. 22). Phallapodeme relatively robust, having basal part with peculiar (symmetrical) wing-like but ventrally somewhat bent lobes (Fig. 19) embracing basal part of distiphallus (see Fig. 22), apex distinctly widened and lateroventrally projecting; fulcrum also relatively robust. Aedeagus of ancestrally looking type (Fig. 22). Phallophore relatively long, subtriangular in profile, darkest on dorsal corner, with posterior corner more projecting and slightly bent ventrally. Distiphallus composed of short but relatively voluminous saccus and long slender filum. Saccus largely membranous except some sclerotization in basal and middle part, and provided with numerous fine spines, mostly on right side of distal membranous part (see Fig. 22). Filum of distiphallus (Fig. 22) very slender, formed by 2 dark stripe-like twisted sclerites being attenuated distally but (unlike all other taxa) one of them shortened (ending far from end of filum), and the other terminating in slightly dilated and flattened submembranous apex (see Fig. 21). Ejacapodeme relatively small, with slender finger-like projection (Figs 20, 22).

Female. Similar to male but differing as follows. Total body length $3.14 \mathrm{~mm}$. Face and clypeus somewhat darker; antenna distinctly darker, ochreous including 1 st flagellomere and arista with somewhat longer cilia. Very unusually $f_{1}$ and $f_{3}$ (see Figs 26,27 ) with combs of shortened thicker setae as in male. $t_{2}$ with ventroapical seta somewhat longer and thicker. Wing measurements: length $3.02 \mathrm{~mm}$, width $0.87 \mathrm{~mm}, \mathrm{Cs}_{3}: \mathrm{Cs}_{4}=2.04, \mathrm{r}-\mathrm{m} \backslash$ $\mathrm{dm}-\mathrm{cu}: \mathrm{dm}-\mathrm{cu}=4.00$. Abdomen very elongate (slender) as in male, about 4.5 times as long as its maximum width but having preabdominal terga shorter, slightly more transverse; also preabdominal sterna somewhat wider. T1-T3 becoming wider posteriorly, T3 largest and widest; T4 slightly and T5 distinctly narrower and shorter than 
T3. S1 and S2 as in male but S3-S5 subequal in length and width, all longer than wide.

Postabdomen (Figs 23-25) relatively long. T6 large (but smaller than T5), distinctly wider and much longer than T7 (Fig. 23), slightly tapering posteriorly, with numerous dense, short setae in posterior two-thirds, darker laterally than dorsally and with narrow pale anterior margin. S6 (Fig. 25) distinctly shorter than S5, about as long as wide, slightly widened posteriorly, all pale whitish ochreous, sparsely setose in posterior two-thirds. T7 (Figs 23, 24) narrower and darker than T6, uniformly blackish brown, densely setose as is T6. S7 much smaller than S6, convex, with rounded sides (Figs 24, 25), with characteristic dark brown pattern leaving only anterior marginal stripe and posteromedial wedge-shaped area pale-pigmented; it is sparsely setose, with longest setae in posterior third of sclerite. T8 relatively flat, transversely suboblong with rounded corners, dark brown except for anterior corners (Fig. 23), with fine but longer setae in posterior third, longest in posterior corners. S8 (Figs 24, 25, 28) smaller than S7, very convex (bulging posteroventrally, cf. Fig. 24), finely setulose, having small posteromedial incision (best visible in Fig. 25) in pale-pigmented posterior part and peculiar in being fused with internal sclerites of female genital chamber situated anterodorsally to S8. Internal sclerotization of genital chamber very conspicuous (see Figs 24, 25, 28, 30, is). Posterior sclerotization complex, formed by 1 pair of lighter bent anterior sclerites which are posteriorly fused to heavily sclerotized and dark-pigmented but symmetrical complex of sclerites projecting posteriorly on each side in 2 processes and being posteroventrally fused with (invaginated parts? of) S8; annular sclerite also unusual, rather simple, forming a transversely ellipsoid ring situated rather far in front of posterior sclerites (Figs 28, 30). Ventral receptacle (Fig. 28) unusually voluminous but weakly sclerotized and pale-pigmented, of slender kidney-shaped form with smooth surface. Accessory gland on relatively short and slender (non-dilated) duct. Spermathecae (1+1) shortly pyriform (Figs 28, 29), blackish brown, each with a few grain-like spines (mainly on narrowed basal part); duct cervix well developed, comparatively long, pigmented; spermathecal duct relatively short (cf. Fig. 28). T10 (Fig. 23) relatively large and broad (shorter than wide), of suboblong rounded outline, dark brown in anterior two-thirds, and with a pair of long medial setae beyond middle. S10 (Figs 24, 25) slightly smaller than T10, semicircular, pale brown, micropubescent, with fine setulae at posterior margin. Cerci (Figs 23-25) mediumsized but robust, with abundant fine setae none of which is particularly longer or thicker.

Discussion. This new species is peculiar in many characters (see above under the genus Marshallya) but in external appearance it is reminiscent of a large and very slender species of Amygdalops. It particularly resembles some Amygdalops species having a brown-darkened annulus on the femora and tibiae, such as those known from the East Palaearctic and Oriental Regions (see RoHÁčEK 2008, 2009). However, it can be easily distinguished from all known species of the latter genus in having the finely ciliate (not pectinate) arista, the dorsally flattened mesonotum, no prs and sa, short pa, $\mathrm{f}_{1}$ with a comb of short thickened anteroventral setae, $\mathrm{f}_{3}$ of both sexes(!) with 2 rows (anteroventral and posteroventral) of thickened and shortened setae and wing with distinct costal spine-like setae among fine setulae. The species of the Afrotropical genus Margdalops are also externally similar to $M$. platythorax, particularly in their ciliate arista and dark wing pattern (cf. ROHÁČEK \& BARRACLOUGH 2003) but they differ (even more distinctly than Amygdalops spp.) in cephalic, thoracic and pedal chaetotaxies. The striking genital and postabdominal differences from Amygdalops, Margdalops and species of other genera of Anthomyzidae have been discussed above under the genus Marshallya and need not be repeated here.

Etymology. The name (a Greek noun in apposition) of the new species refers to the strikingly dorsally flattened thorax (mesonotum).

Biology. The type specimens were photographed (Figs $6,7)$ and subsequently collected by Steve Marshall on stems in a copse of bamboo (Poaceae) (documented by photograph, Fig. 5) on Emei Mountain (at about 800-900 $\mathrm{m})$ on 19 May. Because these peculiar anthomyzids were reasonably abundant in this habitat (but only 3 specimens were collected; S. A. Marshall, personal communication, 2018 ) it is plausible that this bamboo species is the host plant of $M$. platythorax.

Distribution. Hitherto known only from the type specimens from China (Sichuan).

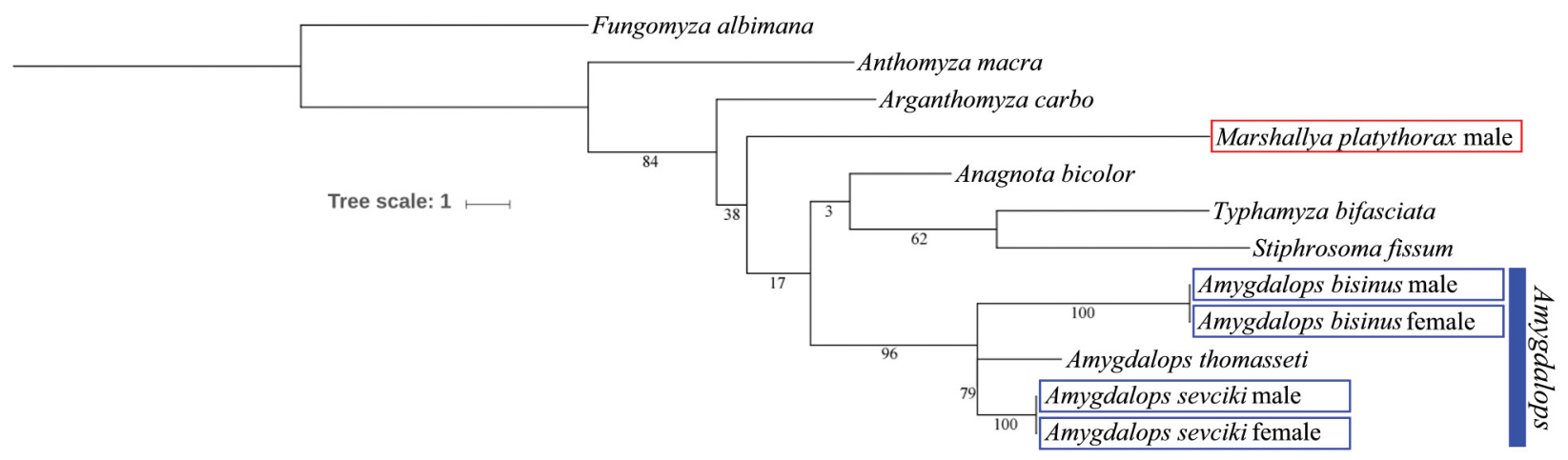

Fig. 31. Maximum likelihood tree outlining similarities of Amygdalops species and Marshallya platythorax based on the barcode region of COI. 


\section{Amygdalops Lamb, 1914}

The genus Amygdalops Lamb, 1914 is the most diverse group of Anthomyzidae in the tropical belt of the Afrotropical (ROHÁČEK 2004) and Oriental Regions (ROHÁČEK 2008) and a few species of Amygdalops also extend into the Palaearctic Region (RoHÁčEK 2006, 2009). Therefore, several species have been expected to occur in China, particularly in its Oriental part. The two species recorded below from Hainan Island. clearly belong to the Oriental fauna of Amygdalops. Their syntopic occurrence on this island revealed not only a new species but also a mistake in the previous affiliation of the female sex of Amygdalops bisinus Roháček, 2008. Under the latter name, two species were mixed by RоHÁČEK (2008: 341-345) due to similarity of the distinctively sinuate male gonostyli and, moreover, the female described by him as A. bisinus belongs to another (new) species because the true female of $A$. bisinus was unknown at that time. To address the problem of correct male-female affiliation, the specimens from Hainan I. were studied using the barcoding area of COI (see material and methods and Fig. 31). Results of this analysis revealed that the female with more complex structures of the terminalia belongs to A. bisinus (described below) while the other female is conspecific with the male of a new species, A. sevciki sp. nov. Subsequently, all paratypes of A. bisinus as originally labelled by RонÁČEK (2008), have been revised and those belonging to $A$. sevciki removed and included in the type series of the latter species.

\section{Amygdalops bisinus Roháček, 2008}

$$
\text { (Figs 36-44, 62) }
$$

Amygdalops bisinus Roháček, 2008: 341 (partim, male only).

Type material examined. HоLотуре: $\partial$, labelled: 'THAILAND: Bangkok, Huaykwang, Aug.-Sept. 1962, J. Scanlon -light' (USNM, genit. prep.) and 'Holotypus Amygdalops bisinus sp. n., J. Roháček det. 2007' (red label). Paratype: VIETNAM: Cuc phuong, Ninh binh, 6.-18.v.1966, $1 \delta$, Topál leg. (HNHM, genit. prep.). Paratype with same type label as the holotype but it is yellow and has 'Paratypus' instead of 'Holotypus'. Additional material examined. CHINA: HaInAN I.: Sanya $30 \mathrm{~km}$

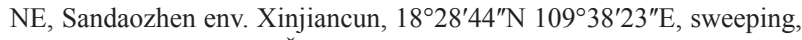
22.v.2016, $1 \hat{\jmath} 1$ q, J. Ševčík leg. (SMOC, both dissected and after being used for DNA extraction remnants of their bodies are preserved in glycerine in plastic pinned microvials, genit. prep.).

Addition to description. Male. Total body length 1.82-1.96 mm. $\mathrm{f}_{3}$ with 5-7 short and thickened setae in distal third of posteroventral row but these setae distinctly longer and more widely spaced than in A. sevciki. Wing measurements: length $1.71-1.91 \mathrm{~mm}$, width $0.50-0.54 \mathrm{~mm}$, $\mathrm{Cs}_{3}: \mathrm{Cs}_{4}=2.05-2.23, \mathrm{r}-\mathrm{m} \backslash \mathrm{dm}-\mathrm{cu}: \mathrm{dm}-\mathrm{cu}=3.38-3.56$. T5 always with small semicircular, pale ochreous to yellowish, anterolateral spot on each side. Preabdominal sterna pale ochreous, contrasting with dark brown terga. Male genitalia as in Figs 32-37.

Female (first description). Similar to male (for description see ROHÁČEK 2008: 341 and the above addition) but differing as follows. Total body length $2.32 \mathrm{~mm}$ (measured in ethanol). $\mathrm{f}_{3}$ simply setulose, without thickened posteroventral setae. Wing (Fig. 62) with pattern generally paler than in most other Amygdalops species, thus with preapical brownish spot and stripe along $\mathrm{R}_{4+5}$ faded and less distinct, and area between $\mathrm{R}_{4+5}$ and $\mathrm{C}$ only a little lighter. $\mathrm{R}_{4+5}$ and $\mathrm{M}$ subparallel or slightly converging preapically and then running parallel apically to margin; r-m situated at middle or slightly in front of midpoint of $\mathrm{dm}$ cell. Wing measurements: length $2.14 \mathrm{~mm}$, width $0.64 \mathrm{~mm}, \mathrm{Cs}_{3}: \mathrm{Cs}_{4}=2.05$, $\mathrm{r}-\mathrm{m} \backslash \mathrm{dm}-\mathrm{cu}: \mathrm{dm}-\mathrm{cu}=3.23$. Preabdominal terga wider and more transverse, dark brown but T4 and T5 with small (and short) yellowish white anterolateral spots, those on T4 being distinctly shorter. Preabdominal sterna paler than in male, yellowish white; S1 short, transverse and bare, S2-S5 finely and sparsely setose. S2 and S3 narrow, longer than broad; S4 and S5 wider than S3, about as long as broad; S5 slightly narrower than S6.

Postabdomen (Figs 38-40) relatively short and broad (at 6th segment). T6 large, broad, relatively shortly but not densely setose (with most robust setae at posterior margin), dark brown with small pale-pigmented anterolateral areas being medially connected by transverse stripe (Fig. 38). S6 whitish yellow, relatively large although narrower than $\mathrm{T} 7$, with fine and sparse setae (Fig. 40). T7 transversely suboblong, much narrower and darker brown than T6, anteriorly with pale-pigmented emargination, and covered by dense short setae in posterior half (Figs 38, 39). S7 of distinctive shape with rounded sides, brown-pigmented and finely setose only in middle third; its anterior third pale and micropubescent, and posterior third also pale-pigmented but bare (Figs 39, 40). T8 transversely suboblong and flat (Fig. 38), smaller and paler than $\mathrm{T} 7$, with sparse fine setae at posterior margin. S8 (Figs 39, 40, 42, 43) peculiarly modified and markedly different from those of all relatives, relatively short but of complex shape, with dark inclinate digitiform projection on each side, posteromedially narrowly incised, with crescent-shaped dark pigmentation and finely setose in middle part, and its pale-pigmented dorsolateral parts with more robust micropubescence. Internal sclerotization of genital chamber very weak, largely unpigmented and poorly visible; annular sclerite many times twisted, thicker and best recognized ventrally (Fig. 43); vaginal part of chamber provided with minute thorn-like spines near genital opening (Figs 42, 43). Ventral receptacle (Fig. 41) submembranous, vesiculate but terminally projecting in a beak-shaped process. Spermathecae shortly pear-shaped (Fig. 44), narrowed at duct insertion, with relatively dense and short irregular spines inserted on basal half of spermatheca; duct cervix poorly developed and short. T10 (Fig. 38) small and relatively short, pale, somewhat darkened only laterally, centrally with a spot of sparse and fine micropubescence and with a pair of longer setae. S10 (Fig. 40) slightly wider and darker than T10, micropubescent, with setulae at posterior margin. Cerci (Figs 38, 39) relatively small and short, micropubescent, finely and shortly setose.

Discussion. As noted above, the original description of Amygdalops bisinus Roháček, 2008 involved a mixture of two species, $A$. bisinus and $A$. sevciki sp. nov., and the female described as this species belonged to the latter species. Therefore, the interpretation of $A$. bisinus is corrected above, with the first description of its true female. The knowledge of the female postabdominal structures also helped to clarify the relationships of $A$. bisinus. Especially, 

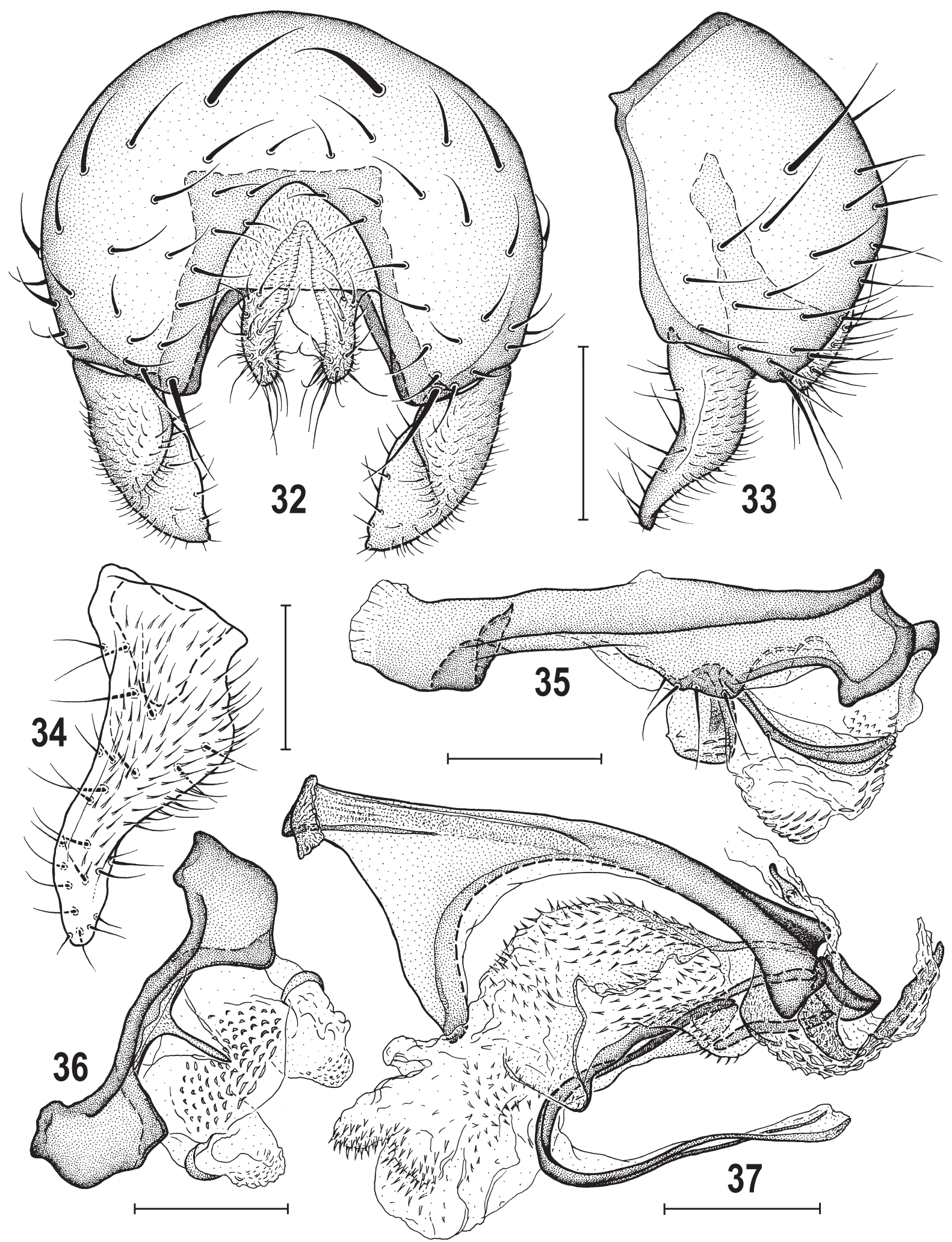

Figs 32-37. Amygdalops bisinus Roháček, 2008, male holotype (Thailand). 32-33 - external genitalia (32 - caudally; 33 - laterally); 34 - gonostylus, lateroventrally (widest extension); 35 - hypandrial complex, laterally; 36 - transandrium, caudally; 37 - aedeagal complex, laterally. Scales $=0.05 \mathrm{~mm}$ (Fig. 34), 0.1 mm (others). Adapted from RонÁČEK (2008: Figs 26-31).

the pyriform spermathecae with thick spines indicate a closer affinity to some species of the A. nigrinotum subgroup of ROHÁČEK (2008), particularly to A. nigrinotum Sueyoshi \& Roháček, 2003 and A. geniculatus de Meijere, 1916. It also shares larger basal sclerite of postgonite with $A$. nig- rinotum (cf. RoHÁČEK 2008: Fig. 104). The relationships of $A$. bisinus cannot be solved definitively this time inasmuch as the male of $A$. geniculatus is unknown and $A$. bisinus displays some peculiar modifications in the male hypandrial complex (posteroventrally expanded hypandrium and 


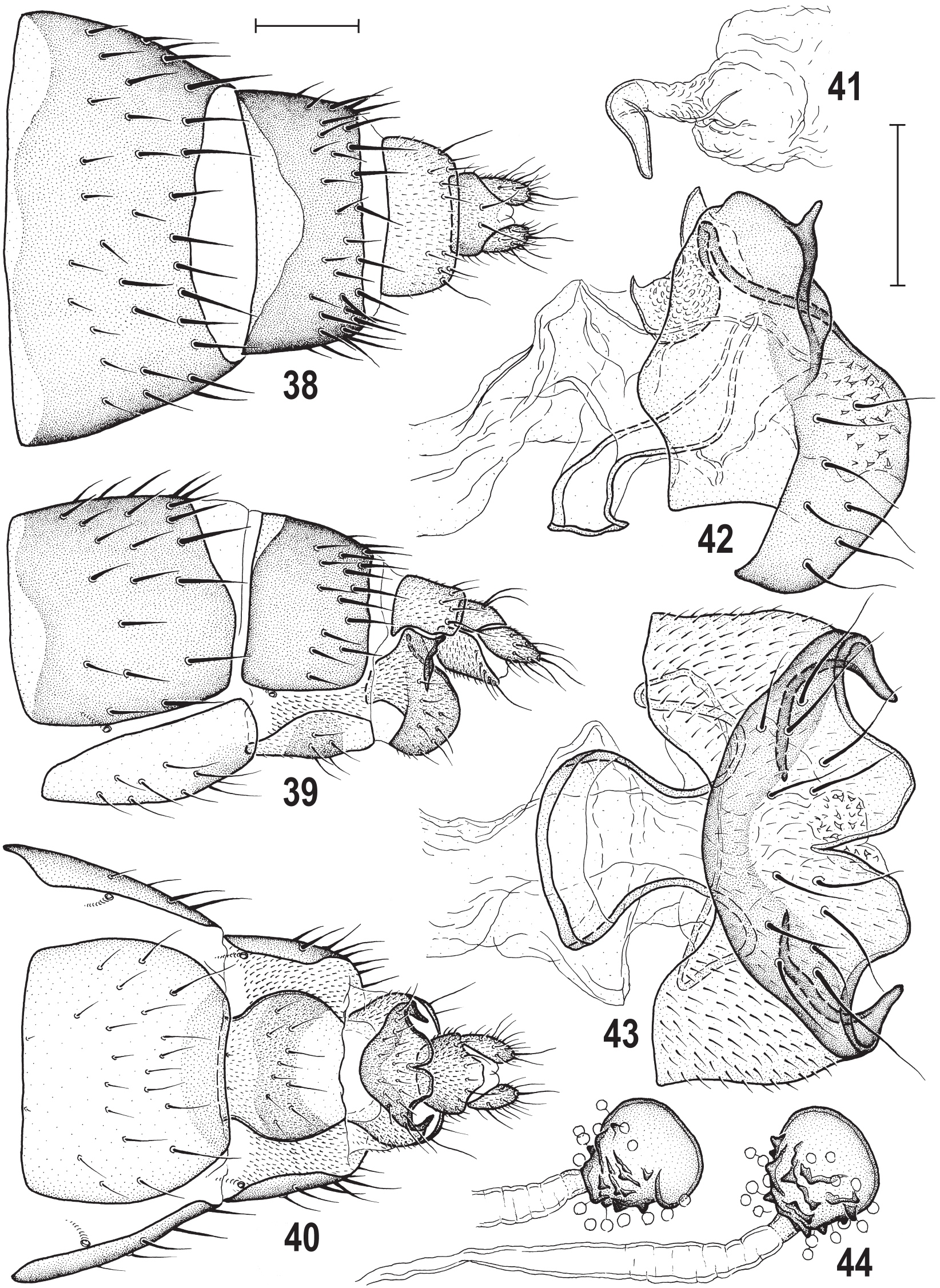

Figs 38-44. Amygdalops bisinus Roháček, 2008, female (China: Hainan I.). 38-40 - postabdomen (38 - dorsally; 39 - laterally; 40 - ventrally); 41 - ventral receptacle, laterally; 42-43 - S8 (micropubescence omitted) and associated structures in posterior part of genital chamber (42 - laterally; 43 ventrally); $44-$ spermathecae. Scales $=0.1 \mathrm{~mm}$ (Figs 38-40), $0.05 \mathrm{~mm}$ (others). 
caudal process of transandrium in particular, see Figs 35, 36) as well as in the formation of the female S8 (Figs 42, 43) which is unique within the genus Amygdalops.

Differences between $A$. bisinus and the externally (including the form of the gonostylus) similar $A$. sevciki are stressed below under the latter species. A. bisinus can also be distinguished from the latter species in having differently modified posteroventral setae on the male $\mathrm{f}_{3}$, small pale lateral spots on $\mathrm{T} 5$ in the male and on T4 and $\mathrm{T} 5$ in the female, a distinctively formed female S7 and pyriform spermathecae. However, the peculiarities in the male hypandrium and female S8 are the best diagnostic characters of $A$. bisinus.

Biology. Largely unknown because of the small number of recorded specimens. The holotype was collected at a light and the pair from Hainan I. was swept together with a pair of $A$. sevciki from low vegetation under longan (Dimocarpus longan Lour., Sapindaceae) trees (Fig. 65). The few known specimens were collected in May, August and September.

Distribution. Known only from three neighbouring countries in the Oriental Region: Thailand, Vietnam (ROHÁČEK 2008) and China (Hainan I.) (first record).

\section{Amygdalops sevciki sp. nov. (Figs 45-61, 63)}

Amygdalops bisinus (misidentification): RoHÁČEK (2008: 341) (partim, females only).

Type material. Holotype: $\delta$, labelled: 'CHINA: Hainan I.: Sanya 30 km NE, Sandaozhen env. Xinjiancun, 22.v.2016, 18²8'44"N 109³8'23"E, sweeping, J. Ševčík leg.' and 'Holotypus đ̂, Amygdalops sevciki sp. n., J. Roháček det. 2017' (red label). The specimen is dissected and (after being used for DNA extraction) preserved in glycerine in a pinned plastic microvial; its abdomen is detached and preserved with dissected genitalia in glycerine in a plastic tube pinned on the same pin (SMOC).

PARATYPES: 1 , with same data, dissected, prepared, partly used for DNA extraction and preserved in glycerine as in the holotype including the abdomen (SMOC). Three further paratypes (originally misidentified and designated as paratypes of Amygdalops bisinus by ROHÁČEK 2008: 341): THAILAND: Mae Fang N. P., No. 14, over \& along forest brook, 1.xi.2004, 1 q, L. Papp \& M. Földvári leg. (HNHM, genit. prep.). INDONESIA: Isle Flores: 8,49 S, 121,02 E, eastern periphery of village Mataloko, ca $10 \mathrm{~km}$ ESE Badjawa, 200-300 m E mission church and school, X 859, creek valley, open cultivated land (vegetables, manioc, diverse herb. vegetation ( $2 \mathrm{~m}$ height), grazed by buffaloes, 24.ix.1992, $1 \lesssim 1$, M. v. Tschirnhaus leg. (ZSMC, both dried from ethanol, genit. prep.). All paratypes with same type label as the holotype but it is yellow and has 'Paratypus' instead of 'Holotypus'.

Description. Male. Total body length 1.86-1.99 mm. Body bicolourous, brown and yellow. Head slightly longer than high. Occiput concave, entirely blackish brown, subshining, with a pair of large greyish microtomentose spots laterodorsal to foramen. Frontal triangle very long and narrow, almost reaching to anterior margin of frons, with very acute anterior corner, largely bare and shiny, including ocellar triangle. Frons almost entirely dark, paler brown only in anterior fifth or fourth; stripes delimiting frontal triangle from orbits somewhat depressed, darker, greyish microtomentose and dull. Orbit largely dark brown and shining, with anterior fourth somewhat paler and only its foremost part lateral to base of antenna whitish yellow and dull. Face dark yellow to (ventrally) ochreous; parafacialia and gena almost white, with silvery white microtomentum but both pale-brown to ochreous margined (very narrowly on gena); postgena with only ventral corner whitish yellow, otherwise concolourous with dark brown occiput. Mouthparts dirty yellow including clypeus and palpus. Cephalic chaetotaxy (partly reconstructed from paratypes): pvt small but distinct and crossed; vti relatively short, only about 1.5 times as long as but thicker than pvt; vte (together with posterior ors) longest of cephalic setae; oc relatively short but somewhat longer than vti; 2 long ors, posterior as long as vte, anterior only slightly shorter; 2 microsetulae in front of anterior ors, anterior microsetula only slightly shorter than posterior; 2 pairs of microsetulae at sides of anterior thirds to fourth of frontal triangle; 1 relatively weak vi and 1 subvibrissa about three-fourths of vi; peristomal setulae sparse, only 4-5, being somewhat longer anteriorly, shorter posteriorly; postocular setulae very minute; palpus with usual subapical seta. Eye large, covering most of head profile, very convex, with longest diameter about 1.5 times as long as shortest one. Gena anteriorly very narrow; its shortest height 0.05 times as long as shortest eye diameter. Antenna strongly geniculate between pedicel and 1st flagellomere, with yellowish white scape and pedicel but the latter narrowly orange ochreous at anterior margin; 1st flagellomere dirty yellowish white but distinctly brown darkened in dorsal half, darkest around base of arista, whitish long ciliate on apex. Arista blackish brown, about 1.9 times as long as antenna, long-pectinate.

Thorax distinctly narrower than head, bicolourous, dark brown and pale yellow. Mesonotum including scutellum brown to dark brown but somewhat lighter than head. Humeral and notopleural areas ochreous yellow; pleural part of thorax with broad (covering entire propleuron and most of mesopleuron) dark brown dorsal band extending from propleuron to haltere and sharply delimited from whitish yellow ventral portion of pleura. Thoracic chaetotaxy: 1 relatively short hu, $2 \mathrm{npl}$ (anterior stronger than hu), 1 very small and fine prs; only 1 (posterior) long dc about as long as apical sc and situated close to scutellum (anterior dc reduced to microseta); ac microsetae sparse, in 4 rows on suture, in 2 rows between posterior dc; sa shorter than pa, both relatively short; 2 sc, apical long and strong (together with posterior dc longest thoracic setae), laterobasal sc about half length of apical sc; ppl reduced, not visible; 2 stpl, posterior longer and thicker; only 3 additional setae on ventral part of sternopleuron. Scutellum rounded triangular with slightly convex dorsal surface; postscutellum well developed, convex, blackish brown. Legs bicolourous, largely yellow to pale yellow, with femora diffusely brownish darkened in distal fourth to third (except for yellow knees) and with tibiae similarly but less darkened in proximal fourth; these brownish markings less distinct on $f_{1}$ and $t_{1}$. Pedal chaetotaxy: $f_{1}$ with usual posterodorsal and posteroventral row of longer setae, those posteroventral in distal half longest; $f_{2}$ without peculiarities and $t_{2}$ with usual ventroapical seta; $f_{3}$ with posteroventral row of setae along entire length but only 5 of them in distal fifth to third shortened, thickened and in denser comb (Fig. 51). Wing (Fig. 63) with simplified pattern, thus with only 


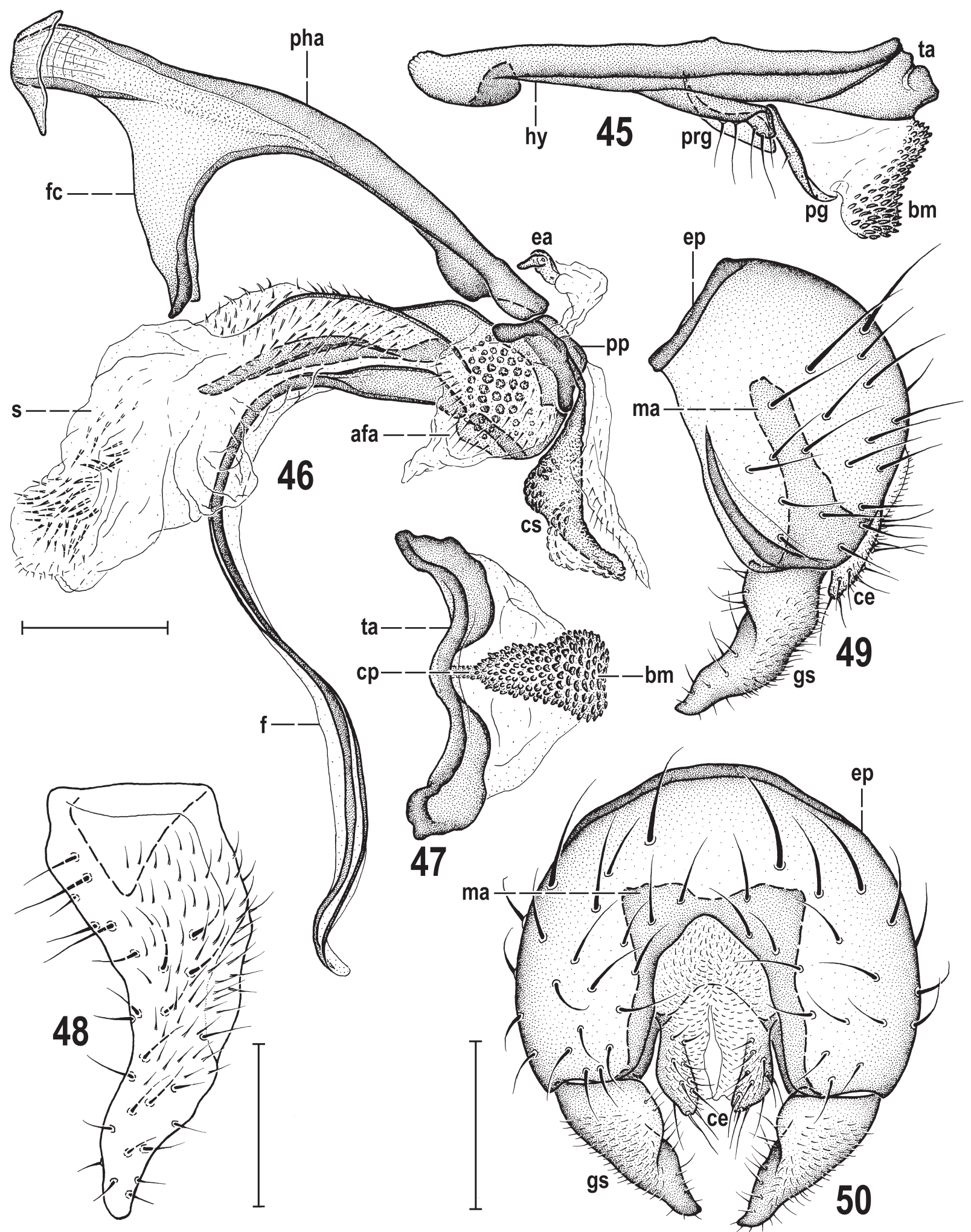

Figs 45-50. Amygdalops sevciki sp. nov., male holotype (China: Hainan I.). 45 - hypandrial complex, laterally; 46 - aedeagal complex, laterally; 47 - transandrium, caudally; 48 - gonostylus, lateroventrocaudally (widest extension); 49-50 - external genitalia (49 - laterally; 50 - caudally). Scales $=0.05 \mathrm{~mm}$ (Fig. 48), $0.1 \mathrm{~mm}$ (others). For abbreviations see p. 37 .

preapical spot darker brownish (but paler than in most relatives), rest of wing membrane almost unicolourous, with area between $\mathrm{R}_{4+5}$ and $\mathrm{C}$ only a little lighter. $\mathrm{R}_{4+5}$ and $\mathrm{M}$ subparallel, with very slight preapical convergence; $r-m$ situated near middle (slightly in front of midpoint of) dm cell. Anal lobe and alula reduced. Wing measurements: length $1.78-2.02 \mathrm{~mm}$, width $0.53-0.58 \mathrm{~mm}, \mathrm{Cs}_{3}: \mathrm{Cs}_{4}=$ $1.68-1.82, \mathrm{r}-\mathrm{m} \backslash \mathrm{dm}-\mathrm{cu}: \mathrm{dm}-\mathrm{cu}=3.54-4.00$. Haltere with pale brown stem and dark brown knob.

Abdomen. Preabdominal terga large, with short and 


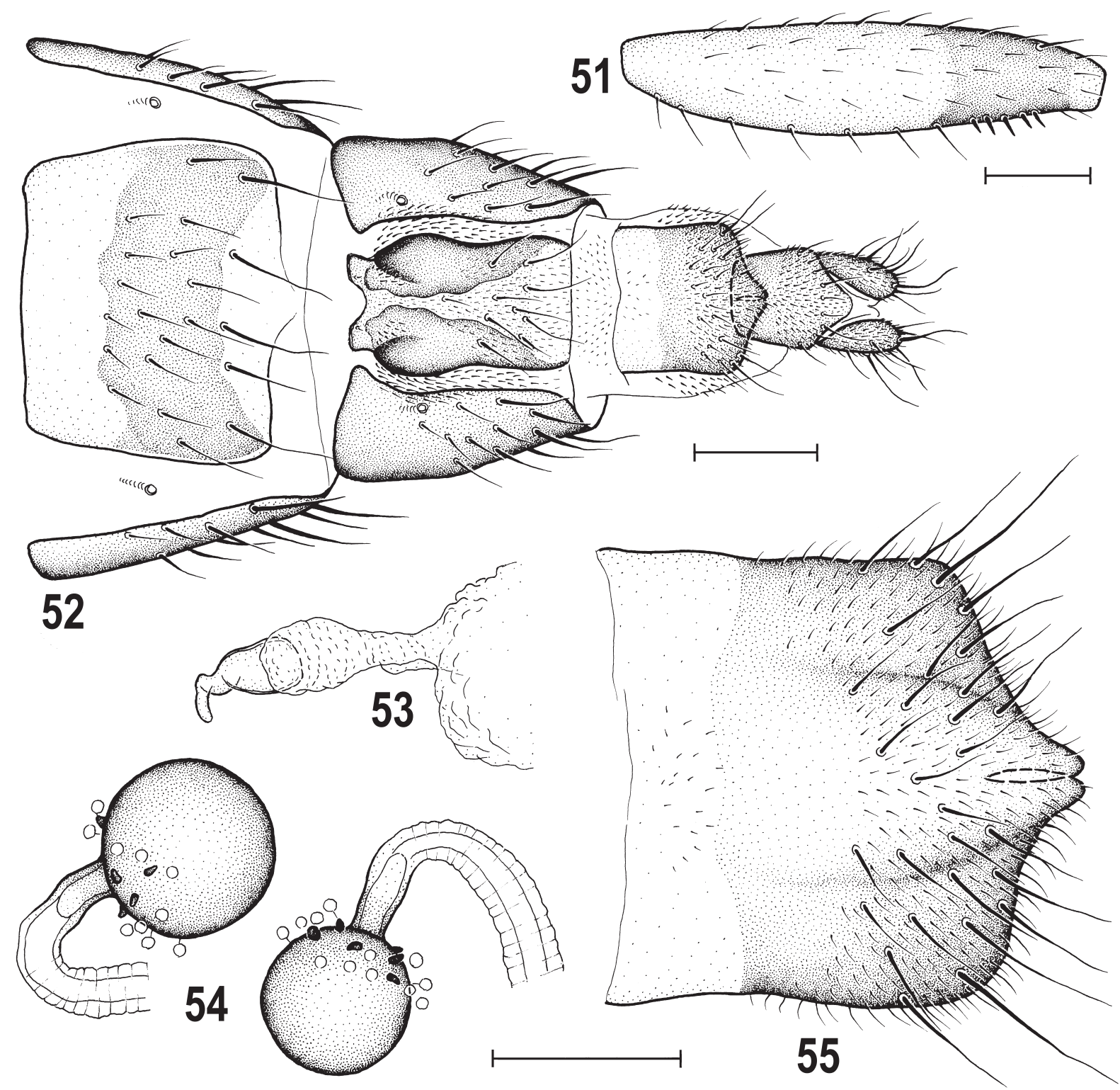

Figs 51-55. Amygdalops sevciki sp. nov., male holotype and female paratype (China: Hainan I.). 51 - male right $\mathrm{f}_{3}$, posteriorly; 52 - female postabdomen, ventrally; 53 - ventral receptacle, laterally; 54 - spermathecae; 55 - female S8, ventrally. Scales $=0.1 \mathrm{~mm}$ (Figs 51, 52), $0.05 \mathrm{~mm}$ (others).

relatively thick setae, uniformly brown to dark brown, thus without paler laterobasal spots on T4 and/or T5. T6 submembranous, short, bare and very pale. Preabdominal sterna relatively narrow, and finely setose, paler brown than terga, and becoming somewhat wider posteriorly, hence S5 the largest. S6-S8 dark brown, dorsolaterally fused; S6 ventrally shortened, transversely band-like; S7 almost twice as long as than S6, somewhat rectangular, with ventral side shorter than dorsal; both S6 and S7 with anterior darkened marginal ledge-like stripe (thicker in S6) and each with 2 or 3 small setae; S8 relatively long, with thicker setae (as in T5) in posterior half.

Genitalia. Epandrium hemispherical, medium-long (Figs 49, 50), rather sparsely setose, with 1 dorsomedial and/or 1 dorsolateral pair of longer setae; anal opening relatively small, narrowly subpentagonal (Fig. 50). Cercus small, distinctly shorter than gonostylus, finely setose. Medandrium (Figs 49, 50) comparatively high and narrow, ventrally narrower than that of $A$. bisinus. Gonostylus (Fig.
48-50) relatively small (much shorter than epandrial height), sinuous in profile and hence somewhat resembling that of A. bisinus but differing from the latter in having distal half more robust in lateral view (Fig. 48) and more tapered in caudal view (Fig. 50); also micropubescent pattern of outer side of gonostylus similar to that of $A$. bisinus including bare anterior margin and apex; setosity of inner side of gonostylus also similar in both species. Hypandrial complex (Fig. 45) markedly different from that of $A$. bisinus: hypandrium slender (also anteriorly), with reduced (membranous) internal lobes; transandrium (Fig. 47) simple, relatively slender laterally (not projecting ventrolaterally - cf. Fig. 45), more narrowly concave ventromedially (Fig. 47); caudal process small, narrow, inconspicuous and short, transient to spinulose basal membrane, thus somewhat resembling that of $A$. cuspidatus Roháček, 2008 (cf. RoHÁČEK 2008: 347, Fig. 41) although medially undivided. Pregonite (Fig. 45), low, incurved, slightly posteroventrally projecting and shortly separated by narrow posterior incision, with about 5 setae 


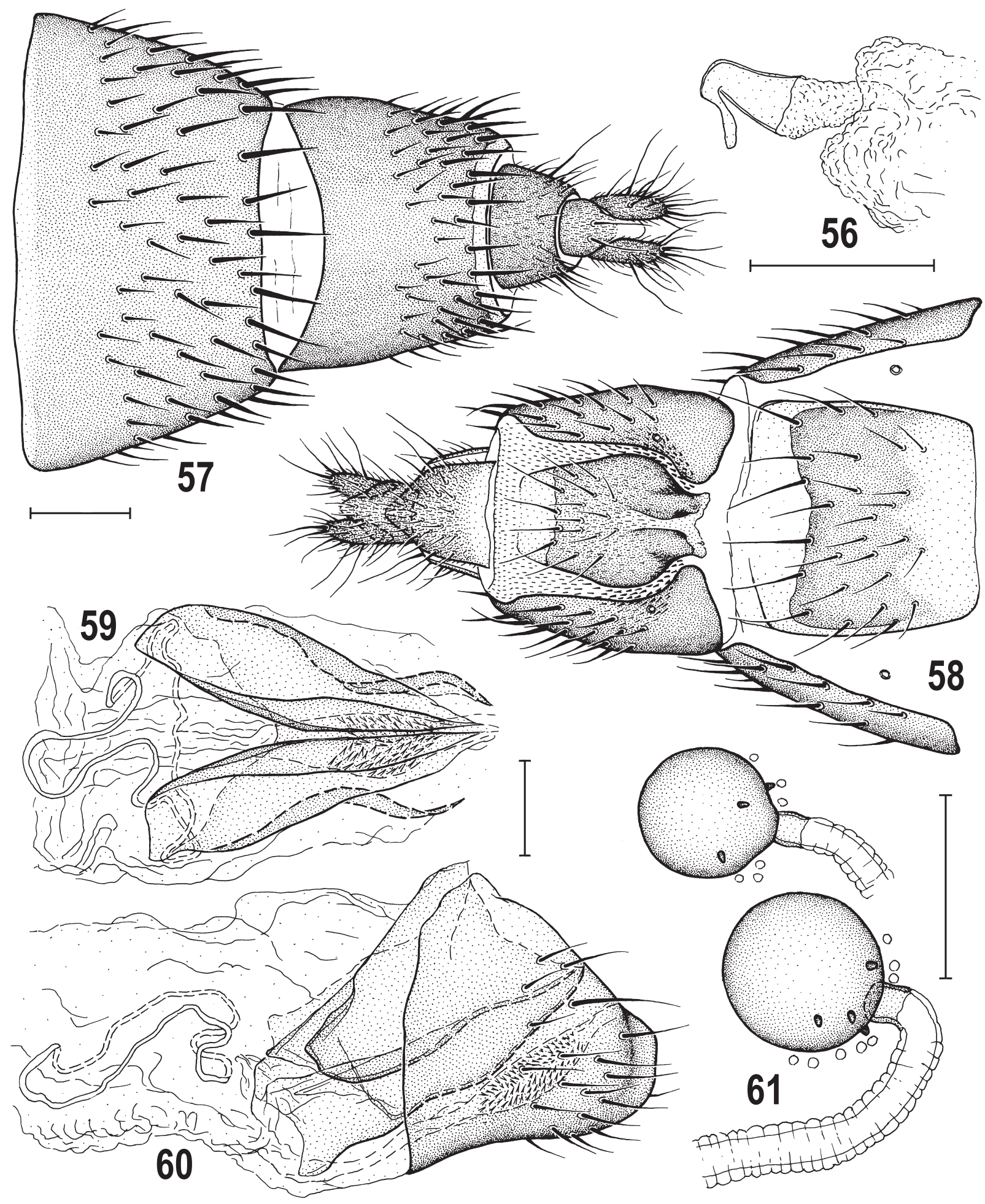

Figs 56-61. Amygdalops sevciki sp. nov., female paratype (Indonesia: Flores I.). 56 - ventral receptacle, laterally; 57 - postabdomen, dorsally; 58 - the same, ventrally; 59 - internal sclerites of genital chamber, ventrally; 60 - the same $+\mathrm{S} 8$, laterally; $61-$ spermathecae. Scales $=0.1 \mathrm{~mm}($ Figs 57,58$)$, $0.05 \mathrm{~mm}$ (others). Adapted from RонÁČ́̌ (2008: Figs 33-37, as A. bisinus sp. nov.).

along posterior half of its ventral side. Postgonite (Fig. 45) very slender, knife-shaped, apically slightly bent and acutely pointed, having a few sensilla on outer side and 1 seta near middle of anterior margin; basal sclerite of postgonite markedly different from that of $A$. bisinus (cf. Fig. 35), slender and about as long as postgonite. Aedeagal part of folding apparatus (Fig. 46) not darkened dorsally, relatively short and its external side with rather small flat tubercles (resembling that of $A$. cuspidatus); connecting sclerite well-sclerotized, proximally slender, triangularly dilated in middle part but distally attenuated and with series of small tubercles. Basal membrane (Figs 45, 47) with dense short spines arranged narrowly dorsomedially but more widely ventrally (cf. Fig. 47). Aedeagal complex (Fig. 46) of the 
A. cuspidatus type. Phallapodeme relatively slender, but with somewhat dilated and bifurcate base and its apex with well-developed lateral projections; also fulcrum relatively slender. Aedeagus with short frame-like phallophore closely resembling that of $A$. cuspidatus (cf. ROHÁČEK 2008: Fig. 42) and large distiphallus. Saccus of distiphallus relatively voluminous, membranous except for very short basal part and provided with two groups of fine spines, one in basal half, the other on right side of apex of the membranous part (see Fig. 46). Filum of distiphallus very slender, formed by 2 dark stripe-like twisted sclerites which are closely attached except for distal third and terminate in a rounded membranous apex. Ejacapodeme small, short, with slender finger-like projection.

Female. Similar to male unless mentioned otherwise. Total body length $2.22-2.50 \mathrm{~mm}$. Face somewhat darker, ochreous to pale brown; also mouthparts darker, with clypeus brown and palpus ochreous-brown; 1st antennal flagellomere more extensively brownish. $t_{2}$ with ventroapical seta longer and thicker; $f_{3}$ posteroventrally simply finely setulose, lacking a group of shortened ventral setae. Wing measurements: length $2.22-2.42 \mathrm{~mm}$, width $0.67-0.73 \mathrm{~mm}$, $\mathrm{Cs}_{3}: \mathrm{Cs}_{4}=1.75-2.15, \mathrm{r}-\mathrm{m} \backslash \mathrm{dm}-\mathrm{cu}: \mathrm{dm}-\mathrm{cu}=3.57-3.92$. Abdomen with preabdominal terga shorter, more transverse and all uniformly dark brown. T3-T6 becoming narrower posteriorly. Preabdominal sterna smaller, narrower and paler than in male, pale ochreous-yellow, only lateral margins of S3-S5 may be narrowly darkened; S3 and S4 subequal (or S3 slightly narrower) and distinctly narrower than S5; the latter as broad as S6 but longer.

Postabdomen (Figs 52, 57-58) moderately long. T6 large, markedly wider and slightly longer than T7, tapering posteriorly, with numerous dense, short and thick setae (Fig. 57), dark brown with pale anterior margin. S6 (Figs 52, 58) narrower than $\mathrm{T} 7$, pale ochreous both anteriorly and posteriorly and characteristically brown-darkened in the middle part, finely setose. T7 (Fig. 57) blackish brown, anteriorly shallowly emarginate and with anterolateral corners extended onto ventral aspect and embedding 7th spiracle (see Figs 52, 58), densely setose like T6 but mainly in posterior half. S7 relatively small and narrow, abruptly tapered anteriorly (Figs 52, 58) and sometimes gradually narrowed posteriorly (Fig. 58), with characteristic pattern composed of light narrow medial area bordered by larger brown lateral parts being anteriorly blackish brown patterned; fine setae concentrated in front of posterior pale-pigmented part of S7. T8 dark brown and unusually narrow (Fig. 57), tapering posteriorly due to ventrally bent sides, with a few (1 longer) fine setae in posterior third. S8 (Figs 52, 55, 58, 60) relatively long and narrow, brown in posterior two-thirds to four-fifths and setose in posterior third to half, and with prominent posteromedial bulge (Fig. 55) having the usual mediodorsal incision very narrow. Internal sclerotization of genital chamber formed by 2 pairs of fused flat bent pale brown sclerites being widened anteriorly (Fig. 59); annular sclerite very thin and twisted several times; vaginal area finely spinulose (see Figs 59, 60). Ventral receptacle vesiculate, submembranous, roughly bell-shaped, with smooth surface and digitiform, somewhat variably bent (Figs 53,
56) terminal projection. Spermathecae spherical (Figs 54, 61 ), relatively large (one distinctly larger than other) each with a few grain-like spines in basal part; duct cervix short to medium long. T10 (Fig. 57) small and narrow, about as long as wide, brown, with scattered microtomentum and 1 pair of longer posteromedial setae. S10 (Figs 52, 58) also small, slightly larger than T10, brown, micropubescent, posteromedially projecting, with fine setulae at posterior margin. Cerci (Figs 52, 57) medium-sized, brown, with moderately long fine setae.

Discussion. Although Amygdalops sevciki sp. nov. strikingly resembles $A$. bisinus Roháček, 2008 in the form of the gonostylus and some external characters (which led to previous confusion of these two species by ROHÁčEK 2008) these two species proved not to be closely related (see also their dissimilarity in COI, Fig. 31). This new species belongs to the A. cuspidatus subgroup of RoHÁČEK (2008). This can be demonstrated by a number of similarities in the construction of the male internal genitalia (cf. pregonite, basal sclerite of postgonite, caudal process of transandrium, armature of basal membrane and aedeagal part of folding apparatus, connecting sclerite) as well as in the female terminalia (cf. structure of S7, spherical spermathecae with short blunt spines). Amygdalops sevciki sp. nov. seems to be particularly related to $A$. cuspidatus Roháček, 2008 resembling the latter in most of the above male characters and to $A$. sp. cf. cuspidatus of RoHÁčEK (2008: Figs 52-57) from Taiwan in the shape of the female S7 and spermathecae. Actually, the latter (hitherto unnamed) species is possibly the closest relative of $A$. sevciki but this can only be demonstrated as and when its male is found and described. Female $A$. sp. cf. cuspidatus differs distinctly from that of $A$. sevciki sp. nov. in having yellow legs, broad and maculate S6 and wider, more transverse T6, T7, T8, T10, S8 and S10 (cf. ROHÁČEK 2008: Figs 53, 54). Amygdalops sevciki can also be easily distinguished from $A$. cuspidatus by the sinuate lateral outline of the gonostylus, the more slender hypandrium and some detail in armature of the basal membrane and saccus of the distiphallus (for these structures in A. cuspidatus see ROHÁČEK 2008: Figs 38-43), and (in female) also by the shape and pigmentation of T7, T8, S6, S7, S8, S10 and the more densely spinulose spermathecae (cf. ROHÁČEK 2008: Figs 45, 46, 48).

Externally, A. sevciki is diagnosed by its very long and narrow frontal triangle, only 1 (posterior) dc seta, femora and tibiae with brownish annulus (in contrast to uniformly yellow legs in other species of the A. cuspidatus subgroup), male $\mathrm{f}_{3}$ with a comb of only 5 short thickened posteroventral setae (Fig. 51), simplified wing pattern (Fig. 63) and both male and female preabdominal terga unicolourous brown, without paler lateral spots. Nevertheless, for its safe identification the examination of the male and female terminalia is recommended because the existence of further unnamed and similarly coloured species in the Oriental Region cannot be excluded.

Etymology. The species is named in honour of Jan Ševčík (Ostrava, Czech Republic), my friend, research colleague in dipterology and collector of this and other anthomyzids on Hainan Island. 
Biology. The male holotype and female paratype of $A$. sevciki were netted by J. Ševčík on Hainan I. together with a pair of $A$. bisinus from lush vegetation near growth of longan (Dimocarpus longan) trees (Fig. 65). Other paratypes were found on herbaceous (sometimes partly grazed) vegetation beside streams in forested valleys. Adult occurrence was confirmed in May, September and November.

Distribution. The species is widespread in the Oriental Region: China (Hainan I.), Thailand and Indonesia (Flores I.).
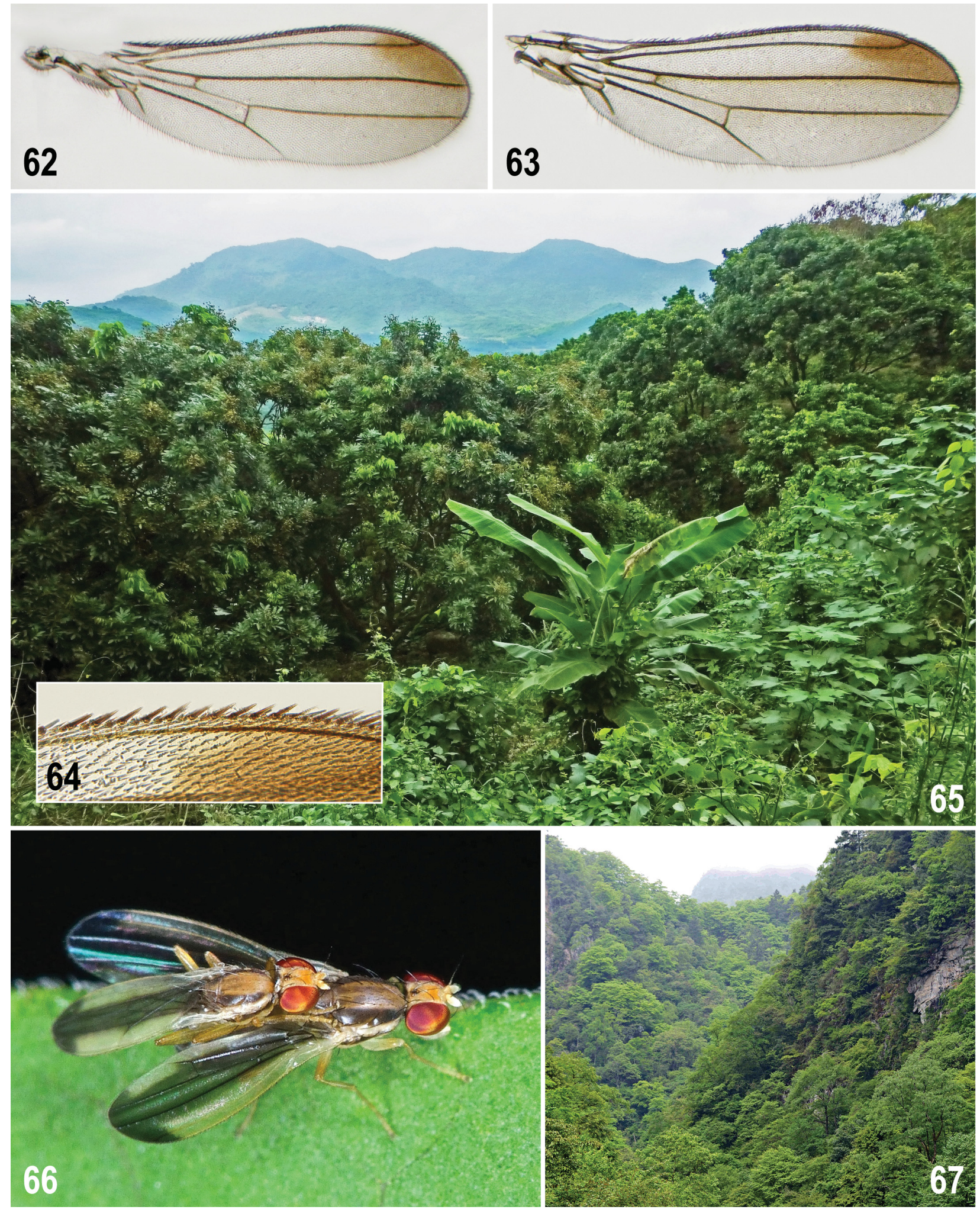

Figs 62-67. Amygdalops and Epischnomyia species and their habitats. 62 - A. bisinus Roháček, 2008, female (China: Hainan I.), wing (length 2.1 mm); $63-A$. sevciki sp. nov., female paratype (China: Hainan I.), wing (length $2.3 \mathrm{~mm}$ ); 64 - same specimen, detail of costal setosity; 65 - habitat of $A m y g d a-$ lops species in the type locality of A. sevciki; 66 - mating pair of E. merzi Roháček, 2009 (body length of male $3.1 \mathrm{~mm}$, of female $3.8 \mathrm{~mm}$ ); 67 - habitat of E. merzi in Sichuan: Laohegou. Photos by J. Roháček (62-64), J. Ševčík (65) and S. A. Marshall (66, 67). 


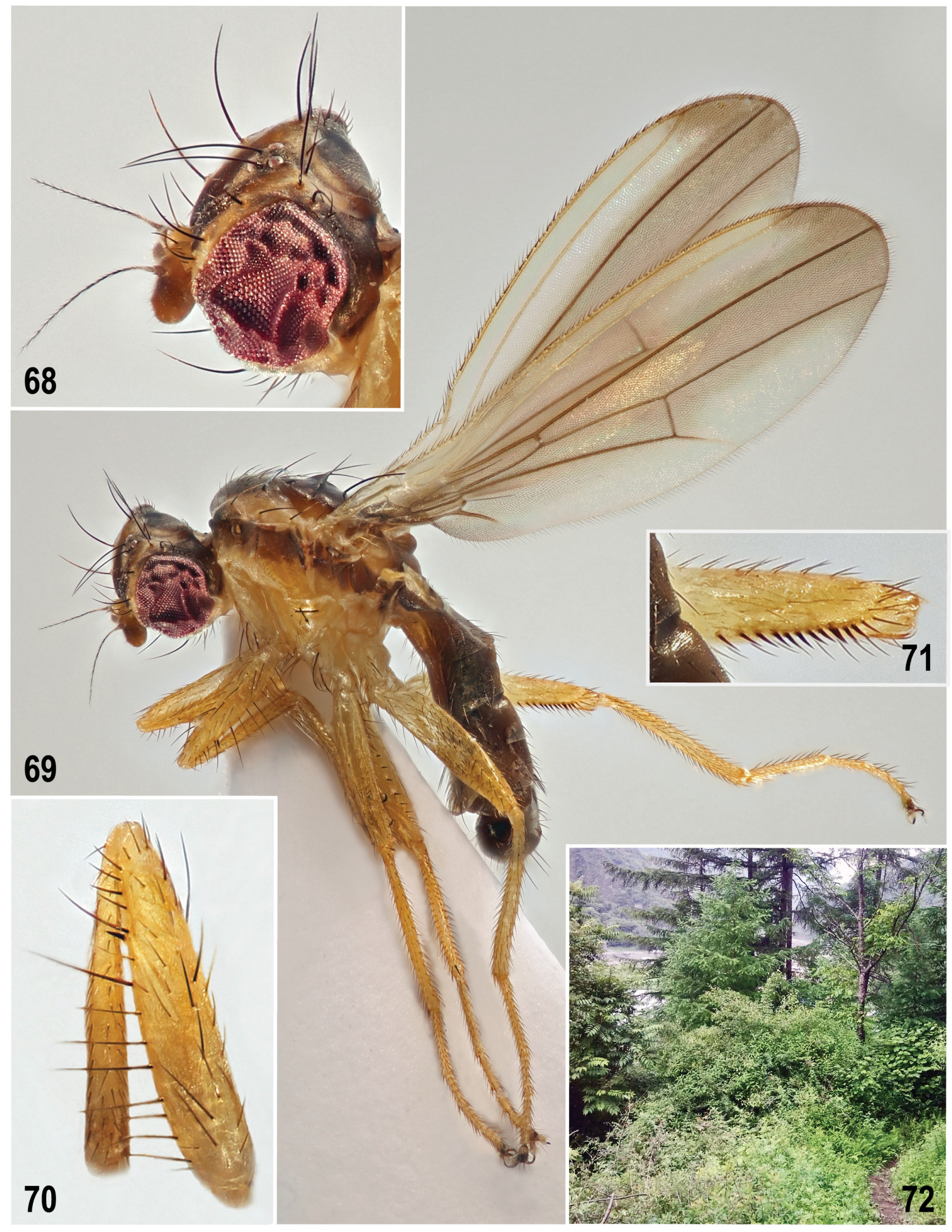

Figs 68-72. Epischnomyia tkoci sp. nov. and its habitat. 68-71 - E. tkoci sp. nov., male holotype (China: Sichuan): 68 - head, dorsolaterally; 69 - holotype before dissection, laterally (body length $2.9 \mathrm{~mm}$ ); $70-\mathrm{f}_{1}$ and $\mathrm{t}_{1}$, posteriorly; 71 - distal half of $\mathrm{f}_{3}$, posteriorly; 72 - habitat of $E$. tkoci in the type locality. Photos by M. Tkoč. 


\section{Epischnomyia merzi Roháček, 2009 (Fig. 66)}

Material examined. CHINA: Sichuan: Pingwu Co., Mianyang, Laohegou (= Old Creek), Xiaogou (= Small Valley), $32^{\circ} 29^{\prime} 02.47^{\prime \prime} \mathrm{N}$ $104^{\circ} 42^{\prime} 21.17^{\prime \prime}$ E, 15.v.2016, $1814 \mathrm{~m}, 1$ o 1 in copula on leaf, S. + S. Marshall leg. (DEBU, dried from ethanol and mounted on triangular pinned card, both genit. prep. but female body lost during drying process so only its abdomen is preserved).

Remarks. The pair of specimens examined belong to the pale form of E. merzi as described by RoHÁČEK (2009: 80) having frons and medial part of mesonotum largely yellow although the latter has a pair of faint vittae in the female (see Fig. 66). This form closely resembles in colour the species E. triarmigera (Sueyoshi \& Roháček, 2003) but detailed study of characters of the male and female terminalia confirmed the identity of the above Chinese specimens as E. merzi.

Biology. Very little known. The type specimens were found in South Korea in forests at higher altitudes (750-1200 $\mathrm{m}$ ) in the second half of June (RoHÁčEK 2009). The specimens from Sichuan were photographed on a small shrub in a slightly open hilltop (1814 m) surrounded by dense forest (as in Fig. 67) in May (S. A. Marshall, personal communication, 2018). The first habitat photos (see also that of E. tkoci below, Fig. 72) of Epischnomyia species in China indicate that members of this genus could be associated with dicotyledonous plants in the undergrowth of leafy forests.

Distribution. South Korea (RoHÁČEK 2009), China: Sichuan (new record).

\section{Epischnomyia tkoci sp. nov.} (Figs 68-71,73-81)

Type material. Holotyp: $\hat{\alpha}$, labelled: 'CHINA, Sichuan prov., Wenchuan, Aba, Wolong, Wolong Nature Reserve, forested slope, 2050m, $31^{\circ} 01^{\prime} 32^{\prime \prime} \mathrm{N}, 103^{\circ} 10^{\prime} 15^{\prime \prime} \mathrm{E}$, sweep. vegetation, indiv. coll., 24.vi. 2014, J. Hájek, J. Růžička \& M. Tkoč lgt.' and 'Holotypus đ̂, Epischnomyia tkoci sp.n., J. Roháček det. 2017’ (red label) (NMPC, genit. prep.).

Description. Male. Total body length $2.90 \mathrm{~mm}$; body bicolourous (Fig. 69), brown (mainly dorsally) and yellow to yellowish white (ventrally), most resembling the dark form of $E$. merzi but a bit darker. Head (Fig. 68) somewhat higher than long, also bicolourous but largely brown, with some parts yellow to whitish yellow. Occiput dorsomedially slightly concave, largely dark brown, with only subtriangular (tapered ventrally) medial area between vti, pvt and foramen dirty yellow and silvery white microtomentose but, in contrast to $E$. merzi, having a medial brown stripe continuing from ocellar triangle, tapering towards foramen and ending immediately above the latter; ventrolateral (dark brown) part of occiput sharply delimited from yellowish white postgena. Frons pattern similar to that of dark form of $E$. merzi - brown-darkened (darkest anteriorly), dull and distinctly striated between frontal triangle and orbits; frontal triangle very small, narrow (not wider than ocellar triangle), dark yellow and whitish microtomentose, reaching to middle of frons; ocellar triangle relatively small, dark brown and grey microtomentose; ocelli large.
Orbit yellow to whitish yellow, whitish microtomentose, slightly tapered anteriorly and widened posteriorly where confluent with yellow medial area on occiput. Frontal lunule reduced, small, orange yellow. Face very narrow, medially less sclerotized, concave, brown and grey microtomentose, laterally with dark brown, relatively broad and bare marginal stripe (reaching onto ventral margin of gena). Parafacialia (very narrow) and gena (except dark marginal stripe) yellow, both with strikingly glittering silvery white microtomentum. Postgena whitish yellow, whitish microtomentose and contrasting with dark brown ventrolateral part of occiput. Mouthparts yellow (clypeus) to whitish yellow (ventrally); palpus dark brown at least in distal two-thirds. Cephalic chaetotaxy: all macrosetae long (Fig. 68); pvt also long and strongly crossed; vti longest of cephalic setae; vte shorter than vti and exclinately curved; oc subparallel, proclinate, only slightly shorter than vti and subequal to posterior ors; 3 ors, 2 posterior strong (hindmost ors as long as oc, middle about as long as vte), 1 anterior small, about one-third of middle ors; 1 additional microsetula in front of the foremost short ors; 3 pairs of medial microsetulae in the anterior half of frons; 1-2 inclinate setulae behind vte; postocular setulae short, numerous (10-11), in single row; postgena with several setulae and 1 longer posteroventral seta; 1 long vi (about as long as vte) but subvibrissa very reduced (or absent?), weak, shorter than anterior peristomal setula; 4 proclinate peristomal setulae. Palpus small, slender, with 2 (1 subapical, 1 ventral) dark setae and a few shorter ventral and lateral setulae. Eye suboval, with longest diameter slightly oblique and about 1.5 times as long as shortest. Gena low, its shortest height about 0.11 times as long as shortest eye diameter. Antenna slightly geniculate, with scape and pedicel yellow but 1st flagellomere largely brownish darkened (dirty yellowish only dorsally in front of base of arista and on posteroventral margin), elongately oval, laterally flattened and densely long white ciliate on anterior margin. Arista brown, with basal segments paler, only 1.8 times as long as antenna and relatively shortly ciliate.

Thorax slightly narrower than head, yellow and brown (Fig. 69), and dull due to relatively dense greyish microtomentum. Mesonotum similarly coloured to that of dark form of E. merzi, largely brown but laterally with yellow longitudinal band reaching from posterior end of humeral callus to sides of postnotum and medially with very narrow and faint ochreous dorsocentral lines fading in front of suture and interrupted between both posterior dc macrosetae; scutellum largely brown with only small spots around bases of apical and laterobasal sc ochreous. Humeral callus largely brown but notopleural area yellow to yellowish white (ventrally). Pleural part of thorax whitish yellow, with brown dorsal band extended from cervix to base of abdomen and its width equalling dorsal half of mesopleuron. Postscutellum and postnotum brown except for yellowish ochreous lateral areas of the latter. Thoracic chaetotaxy (Fig. 69): 1 long hu; 2 long npl (anterior longer); 1 prs, 1 sa, 1 pa, all 3 very long, subequal in length; 3 postsutural dc, 1 anterior short (about twice as long as 
dc microseta in front of it), middle dc slightly shorter than prs, hindmost dc very long, as long as apical sc; only 2 rows + single seta of a 3 rd row of ac microsetae on suture, 2 rows more posteriorly with hindmost pair of ac microsetae situated slightly behind the level of middle dc; $2 \mathrm{sc}$, laterobasal short and weak (much shorter than middle dc), apical sc very long; 1 ppl, weak but as long as half height of propleuron; 2 long stpl, anterior distinctly shorter, 1 setula in front of them and 5 below the latter; ventral part of sternopleuron with 3 pairs of longer setae. Scutellum elongately triangular, flat dorsally as in congeners. Legs yellow (coxae and trochanters yellowish white), only apical half of last tarsal segment brown. $f_{1}$ (Fig. 70) with ctenidial spine small, distinctly shorter than width of $t_{1}$ and with a number of long hair-like setae in posteroventral (longer setae) and posterodorsal row. $\mathrm{f}_{2}$ with posteroventral row of erect setae, those in middle third thicker and shorter and those in distal fourth denser. $t_{2}$ with very weak ventroapical seta, hardly longer than maximum width of tibia; $f_{3}$ with dense posteroventral row of setae along entire length, 9-10 in proximal half longer and slender and 11-12 in distal half shortened, thickened and densely arranged (see Fig. 71), thus with more and much denser thickened setae than in both congeners (4-7 in E. merzi, 7-8 in E. triarmigera). Fore and hind basitarsus with somewhat prolonged golden yellow setulae ventrobasally and mid basitarsus with a row of ventral setulae proximal of which may be thicker. Wing (Fig. 69) long, slightly narrower than in E. merzi, with very similar brown and white longitudinal pattern but the dark band somewhat narrower (particularly when compared with that of E. merzi which has brown area distinctly expanded beyond dm cell, see RoHÁČEK 2009: Fig. 106). Veins dark brown, except for whitish yellow $\mathrm{Sc}, \mathrm{R}_{1}, \mathrm{R}_{2+3}$ and most (from base to apex of $\mathrm{R}_{2+3}$ ) of $\mathrm{C}$. $\mathrm{C}$ with distinct spinulae between apices of $\mathrm{R}_{1}$ and $\mathrm{R}_{2+3}$. Shape of $\mathrm{R}_{2+3}$ and $\mathrm{R}_{4+5}$ as in other Epischnomyia species; $\mathrm{M}$ very slightly divergent from $\mathrm{R}_{4+5}$ apically; $\mathrm{r}$-m situated in basal two-fifths of $\mathrm{dm}$ cell; $\mathrm{dm}, \mathrm{CuA}_{1}, \mathrm{~A}_{1}$, alula and anal lobe also very similar to those of congeners. Wing measurements: length $3.22 \mathrm{~mm}$, width $1.01 \mathrm{~mm}, \mathrm{Cs}_{3}: \mathrm{Cs}_{4}=1.49$ (slightly lower than in relatives), $\mathrm{rm} \backslash \mathrm{dm}-\mathrm{cu}: \mathrm{dm}-\mathrm{cu}=3.33$ (somewhat higher than in relatives). Haltere relatively small, with dirty yellowish stem and pale brown knob.

Abdomen long, with dark brown T1-T5, S6-S8 and (darkest) epandrium; S1-S5 brown (as in E. triarmigera), all abdominal sclerites sparsely greyish microtomentose and more shining than thorax. Preabdominal terga large, broad, reaching far onto ventrolateral aspect of abdomen, of similar shape to those of congeners, with setae on more posterior terga denser and longer. Preabdominal sterna markedly narrower than terga, all somewhat trapezoidal, becoming distinctly wider posteriorly (S4 slightly wider than long, S5 distinctly wider than long and largest sternum). Postabdomen large and constructed similarly to that of other Epischnomyia species, with membranous, unpigmented and bare T6, large S7 (almost as long as S8), both S6 and S7 laterally bulging and anteriorly with dark marginal ledge but S6 not as large and without anterior internal lobe. S6 with 2 (1 longer) distinct setae, S7 with only 1 seta apart from a pair of setiform sensilla at anterior margin. S8 as long as epandrium and with sparse (7 or 8) setae at posterior margin.

Genitalia. Epandrium (Figs 73, 74) slightly wider than high, longer than that of both relatives, with relatively dense and long setae, including 2 pairs of long and robust setae. Anal fissure narrowed in dorsal half (Fig. 73) so differing from that of congeners but cercus similar, small, pale-pigmented and finely setose. Medandrium distinctly lower and with sides sinuate, not rectangular as in that of other Epischnomyia species. Gonostylus (Figs 73, 74, 76) dissimilar to that of relatives, slender and elongate, only basally broader, with distal three-fourths narrow, slightly bent medially and posteriorly and with apex terminating in 2 blunt denticles (Fig. 76); its chaetotaxy also different, with denser internal setae and micropubescence reduced, restricted to subbasal area of outer side (see Fig. 76). Hypandrium (Fig. 77) robust but less asymmetrical and less bent than in relatives, also differing in having larger internal submembranous leaf-like lobes. Transandrium (Fig. 78) including inconspicuous short and flat caudal process also similarly formed but its dark dorsal ledge more sinuate; also basal membrane closely resembling those of congeners with its armature formed by small spine-like tubercles (Fig. 78). Pregonites (Fig. 77) less asymmetrical than those of congeners, each with anterior lobe bent internally and its posterior part bulging ventrally being narrower in caudal view (see Fig. 78, with setae omitted); anterior part of pregonite with 4 setae becoming longer ventrally and its posterior bulging part with 4 subequal setae, thus both with chaetotaxy dissimilar to that of relatives. Postgonite (Fig. 77) very similar to that of E. merzi including long seta in proximal third and minute setiform sensilla externally. Aedeagal part of folding apparatus (Fig. 81) with asymmetrical armature different from that of both relatives, on left side composed of dark robust elongate spines ( 2 anterodorsal, and a group of 3 fused posteroventral) and fine striae (Fig. 81), and on (larger) right side with an area of dense flat short spines and 1 elongate sclerotized posteroventral band terminating in 2 fused dark spines (Fig. 75); connecting sclerite closely resembling those of other Epischnomyia species, short, heavily sclerotized and dark-spinose. Phallapodeme and aedeagus of the same general construction as in Epischnomyia species but basal fork of phallapodeme less deep and less asymmetrical; also phallophore similarly projecting into robust epiphallus but its distal part longer (Fig. 81). Saccus with armature distinctly different (Fig. 81), having 4 (only 1 robust, others smaller) spikes distally and some flat or rounded processes subbasally (the latter absent in relatives) (cf. Fig. 80). Filum (Figs 80, 81) formed by homogenous elongate and curved sclerite as in congeners and having apex of filum (Fig. 79) shortly lanceolate, with small subapical denticle and reduced distal membranous lobe. Ejacapodeme slightly bigger than in relatives, with longer digitiform projection (Fig. 81).

Female unknown.

Discussion. Epischnomyia tkoci sp. nov. is the third species of the genus. Its congeners, viz. E. triarmigera (Sueyoshi 


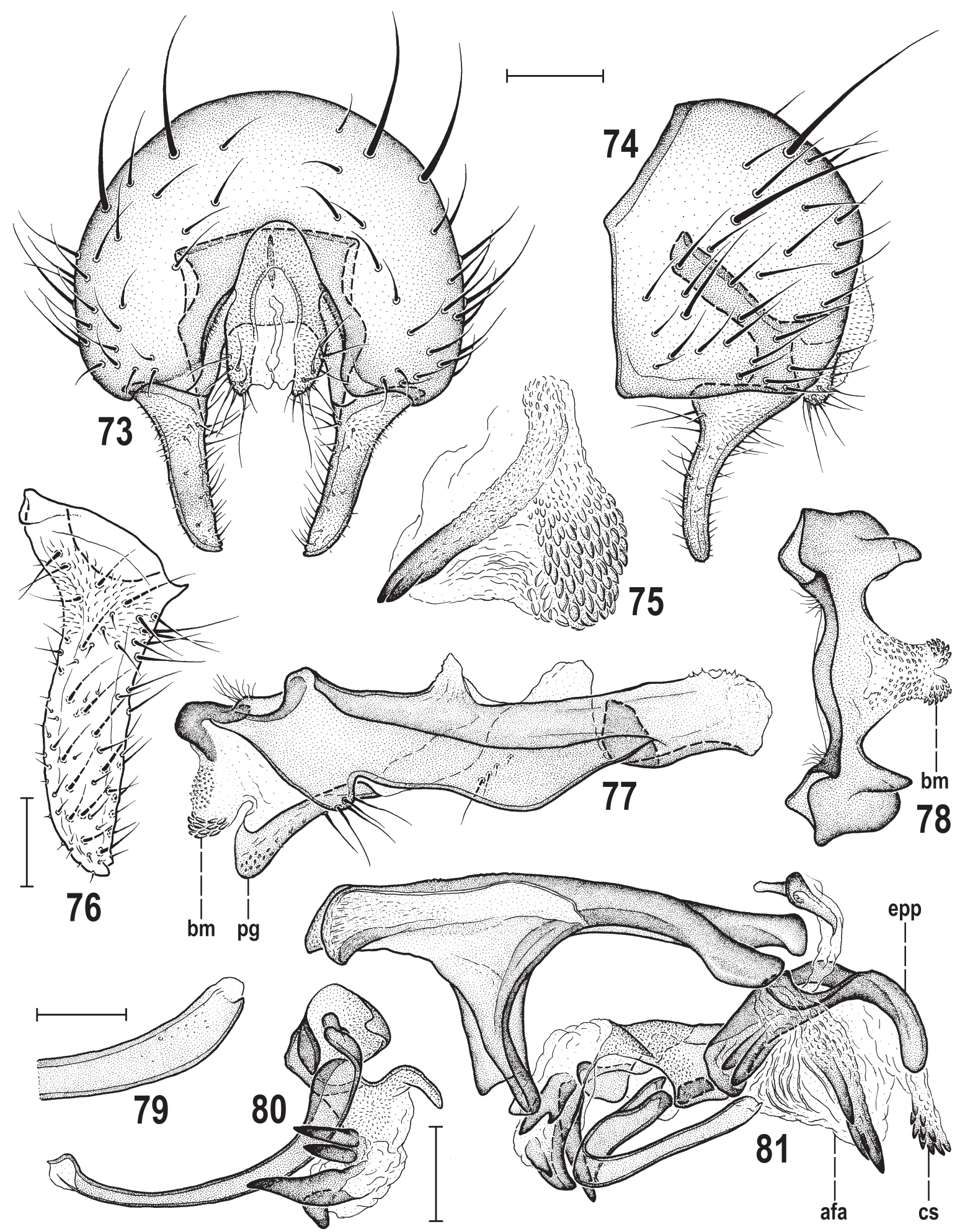

Figs 73-81. Epischnomyia tkoci sp. nov., male holotype (China: Sichuan). 73-74 - external genitalia (73 - caudally; 74 - laterally); 75 - right wall of aedeagal part of folding apparatus; 76 - gonostylus, subcaudally (widest extension); 77 - hypandrial complex (right side), laterally; 78 - transandrium, caudally; 79 - apex of filum, sublaterally; 80 - distiphallus, ventrally; 81 - aedeagal complex, laterally. Scales $=0.05 \mathrm{~mm}$ (Figs 76,79 ), $0.1 \mathrm{~mm}$ (others). For abbreviations see p. 37.

\& Roháček, 2003) and E. merzi Roháček, 2009 are closely related and very similar both in external and genital characters (cf. ROHÁČEK 2009) but this new Chinese species differs distinctly from both of them with its distally strongly tapered gonostylus having 2 small denticles on apex, differently formed medandrium, more setose pregonite, aedeagal part of folding apparatus with elongate robust spines on both sides, saccus armed with 4 (but 3 smaller) spikes distally and some additional subbasal projections and some other details in the male internal genitalia.

Epischnomyia tkoci seems to be generally darker than both relatives but considering the known colour variabi- 
lity, particularly in E. merzi (see ROHÁČEK 2009: 84), this dissimilarity is of limited diagnostic value, particularly as regards the dark form of $E$. merzi. The only distinct external difference has been found in the specialized chaetotaxy of the male hind femur where E. tkoci has more and very densely arranged thickened setae in the distal half (see Fig. 71). Etymology. The new species is named in honour of my friend Michal Tkoč (NMPC), a keen dipterist and specialist in Platypezidae, who collected this species in Sichuan.

Biology. Poorly known. The holotype was swept from rich herbaceous vegetation on a forested slope (see its habitat in Fig. 72 ) in a montane valley $(2050 \mathrm{~m})$, on 24 June (detailed information from M. Tkoč, personal communication, 2018).

Distribution. China: Sichuan.

\section{Anthomyza ornata sp. nov.}

(Figs 82, 83, 86-95)

Type material. HoLотуре: + , labelled: 'CHINA, Sichuan prov., Leshan, EMEISHAN, Leidonping, above cable car station, $2570 \mathrm{~m}, 29^{\circ} 32^{\prime} 02^{\prime \prime} \mathrm{N}$, $103^{\circ} 19^{\prime} 58^{\prime \prime}$ E, 10. vi. 2014, sweeping on veg., J. Hájek, J. Růžička \& M. Tkoč lgt.' and 'Holotypus + , Anthomyza ornata sp. n., J. Roháček det. 2017' (red label) (NMPC, genit. prep.).

\section{Description. Male unknown.}

Female. Total body length $2.78 \mathrm{~mm}$; bicolourous, yellow and dark brown (Fig. 83), with thorax longitudinally variegated, sparsely whitish grey microtomentose, subshining. Head yellow except for occiput and ocellar triangle, somewhat higher than long, in profile rounded anteriorly (frons not projecting in front of eye). Occiput dorsomedially concave, entirely dark brown, subshining due to sparse whitish grey microtomentum. Frons bright yellow, with only ocellar triangle brown, largely microtomentose and dull, only frontal (including ocellar) triangle subshining. Orbit anteriorly (up to posterior ors) lighter yellow, sparsely whitish microtomentose and slightly shining. Frontal triangle relatively broad, equilateral, reaching anterior two-fifths of frons, dark yellow to ochreous except for brown ocellar triangle. Frontal lunule small, orange yellow. Face narrow, weakly sclerotized and deeply concave, dull yellow and whitish microtomentose; parafacialia and gena whitish yellow, with dense silvery white microtomentum, both bordered by narrow ochreous marginal stripe; postgena whitish yellow to dirty yellow, sparsely whitish microtomentose and sharply delimited from adjacent dark brown ventrolateral part of occiput; mouthparts yellow with ochreous clypeus and yellowish white palpus. Cephalic chaetotaxy: all macrosetae very long (see Fig. 82) and hence most similar to those of $A$. sulphurea (see below); pvt relatively long and strongly crossed; vti extremely long, distinctly longest of cephalic setae (as long as longest eye diameter); oc subparallel, somewhat longer than vte and 2 (posterior) ors (these 3 subequal) but all also very long; 3 ors, posterior (more exclinate) and middle (slightly reclinate) subequal, anterior markedly shorter, only about one-fourth of the middle ors; 1 microsetula (about as long as medial microsetulae) in front of foremost (short) ors; 3-4 pairs of medial microsetulae between apex of frontal triangle and anterior margin of frons; 1 distinct inclinate setula (as long as uppermost postocular) behind vte; postocular setulae sparse (6) and relatively long (dorsal ones in particular), in single row; lateroventral part of occiput and postgena with a number of setulae, 1 longer but fine seta in posteroventral corner; 1 vi (distinctly shorter than both long ors); subvibrissa weak (or absent?), somewhat longer (on left) or shorter (on right) than longest peristomal setula; the latter sparse (6) and about as long as postocellars but finer. Palpus slender and rather long, with 1 relatively long and dark preapical seta and with 7-8 (all dark) ventral and lateral setulae; labella fleshy, broad and finely setulose (see Fig. 82). Eye larger than that of A. sulphurea, suboval to broadly reniform, with longest diameter slightly oblique and about 1.3 times as long as the shortest. Gena distinctly lower than in A. sulphurea (see Fig. 82), with shortest height 0.14 times as long as shortest eye diameter. Antenna dark yellow (scape, pedicel) to pale yellow (1st flagellomere); pedicel with dorsal seta longer than usual; 1st flagellomere elongately suboval, laterally flattened and with relatively long white cilia on anteroventral margin. Arista dark brown including thickened basal segment, about 2.2 times as long as antenna, distinctly brown ciliate although shorter than is 1st flagellomere.

Thorax slightly wider than head, yellow and dark brown striped (thoracic pattern most resembling that of Epischnomyia triarmigera), sparsely whitish grey microtomentose, subshining. Mesonotum largely yellow but with broad dark brown vittae between dc and prs-sa lines that are anteriorly fused (thus medial yellow area not reaching anterior margin of mesonotum) and posteriorly narrowly continuing on sides of otherwise yellow scutellum. Humeral and notopleural areas up to wing base whitish yellow. Pleuron dorsally with broad dark brown band extended from propleuron to base of abdomen (see Fig. 83); ventral part of pleuron pale yellow to yellowish white. Postscutellum bulging (Fig. 83) and dark brown; postnotum dark only medially, pale brown to ochreous laterally. Thoracic chaetotaxy rich, with most macrosetae unusually long (as in A. sulphurea): 1 hu (as long as anterior npl but finer); $2 \mathrm{npl}$ (posterior much shorter); 1 exceptionally long prs and 1 subequally long or slightly longer sa; 1 pa (shorter and thinner than sa); 3 postsutural dc: posterior extremely long and robust (together with apical sc longest thoracic seta), middle also very long (as long as or longer than sa), anterior fine and only about half length of middle dc; 6-7 dc microsetae in front of them $(1 \mathrm{dc}$ microseta can also be between anterior and middle dc); only 2 rows of relatively long ac microsetae; hindmost ac pair (situated slightly beyond middle dc) only slightly longer than others; $2 \mathrm{sc}$, laterobasal fine and only slightly longer than foremost dc, apical strong and very long; 1 relatively long upcurved ppl (reaching to dorsal margin of propleuron) and 1 downcurved microseta below it; 2 stpl, posterior long, anterior somewhat shorter; 1 setula in front of anterior stpl and 3 setulae below it; ventral corner of sternopleuron with 5-6 setae, 2-3 of them longer and curved. Scutellum rounded triangular, 


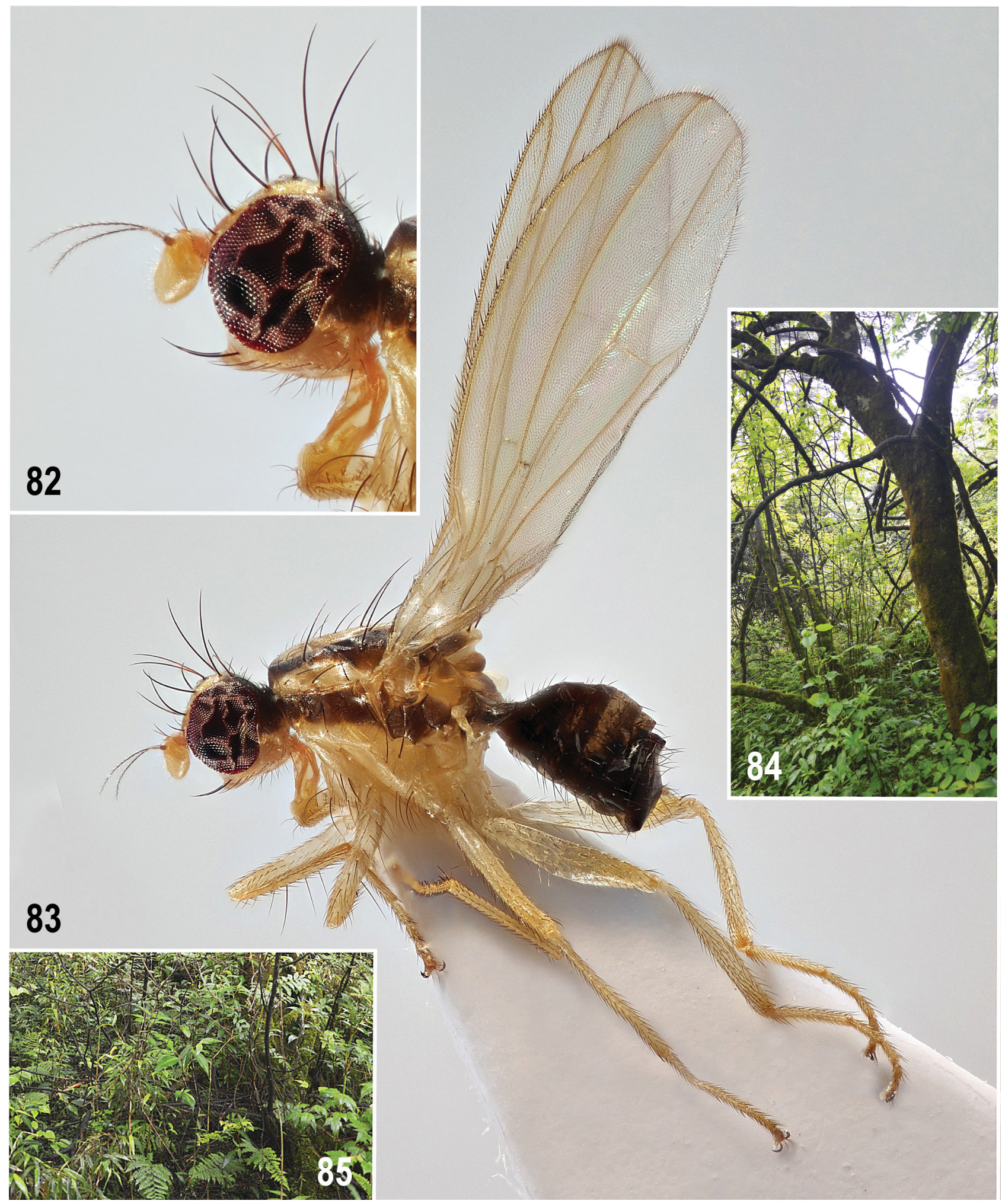

Figs 82-85. Anthomyza ornata sp. nov. and its habitat. 82-83-A. ornata sp. nov., female holotype (China: Sichuan): 82 - head, laterally; 83 - holotype before dissection, laterally (body length ca $2.8 \mathrm{~mm}$ ); 84 - habitat of $A$. ornata in the type locality; 85 - the same, detail of undergrowth. Photos by M. Tkoč.

very slightly convex to flat dorsally, about 1.7 times as wide as long. Legs uniformly yellow to yellowish white (coxae), at most apical half of last tarsal segment somewhat darkened, ochreous. $f_{1}$ (Fig. 88) with usual posterodorsal and posteroventral rows of long setae but ctenidial spine reduced though less so than that of $A$. sulphurea; $\mathrm{f}_{2}$ and $\mathrm{f}_{3}$ simply uniformly setulose, as are also all tibiae, except for $\mathrm{t}_{2}$ having a distinct ventroapical seta and a pair of anteroventral small setae on apex (Fig. 87); fore and hind basitarsus (Fig. 91) each with 3 pale-pigmented proximoventral setulae, mid basitarsus (Fig. 87) with 1 longer and 1 short dark proximoventral enlarged setulae. Wing (Fig. 83) long and relatively broad, with ochreous to pale yellow veins and pale ochreous hyaline 


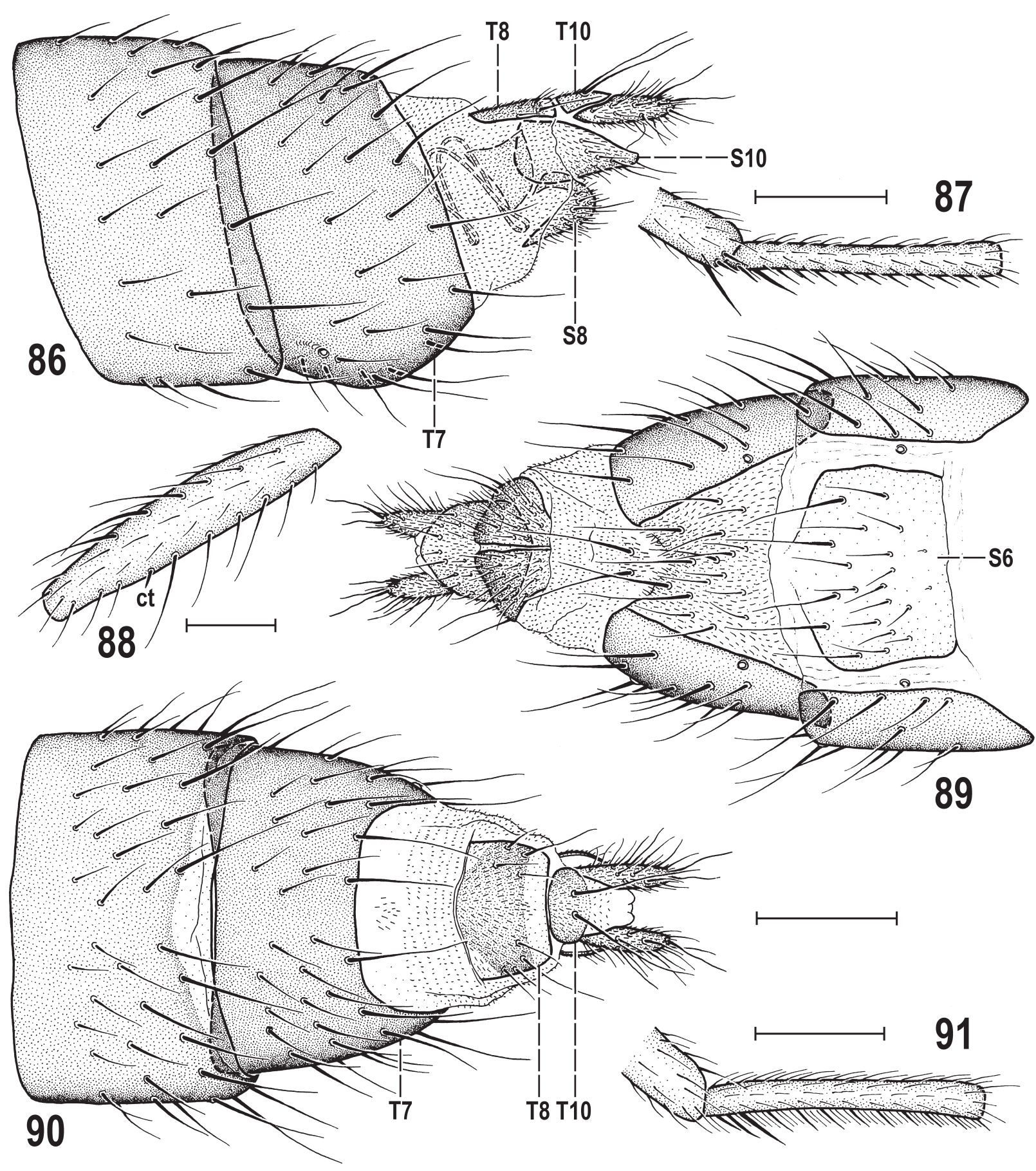

Figs 86-91. Anthomyza ornata sp. nov., female holotype (China: Sichuan). 86 - postabdomen, laterally; 87 - apex of $\mathrm{t}_{2}$ and mid basitarsus, anteriorly; $88-\mathrm{f}_{1}$, posteriorly; 89-90 - postabdomen ( 89 - ventrally; 90 - dorsally); 91 - apex of $\mathrm{t}_{3}$ and hind basitarsus, anteriorly. Scales $=0.2 \mathrm{~mm}$. For abbreviations see p. 37.

membrane. $\mathrm{C}$ with very distinct spine-like setae between apices of $\mathrm{R}_{1}$ and $\mathrm{R}_{2+3}$. $\mathrm{R}_{2+3}$ long, sinuous, parallel to $\mathrm{C}$ but apically upcurved to it; $\mathrm{R}_{4+5}$ slightly but distinctly bent, running paralellel to $\mathrm{C}$ but gradually converging with (almost straight) M. Discal (dm) cell large and long, with $r-m$ situated at basal two-fifths of cell. Apical portion of $\mathrm{CuA}_{1}$ slightly shorter than dm-cu and not reaching wing margin; $A_{1}$ short, ending far from it. Alula relatively large but narrowed and with apex rounded; anal lobe well developed. Wing measurements: length $3.69 \mathrm{~mm}$, width $1.19 \mathrm{~mm}, \mathrm{Cs}_{3}: \mathrm{Cs}_{4}=1.95, \mathrm{rm} \backslash \mathrm{dm}-\mathrm{cu}: \mathrm{dm}-\mathrm{cu}=$ 2.86. Haltere with dirty yellow stem and yellowish white, relatively small, knob.

Abdomen unusually narrower than high (laterally somewhat compressed). Preabdominal terga brown to blackish brown, very sparsely greyish microtomentose only medially, glabrous and lustrous laterally (as also is most of postabdomen). T1 and T2 partly (laterally) fused; $\mathrm{T} 1$ shorter and narrower than $\mathrm{T} 2$ and with a few short setulae laterally; T2-T5 subequal in length, very transverse 


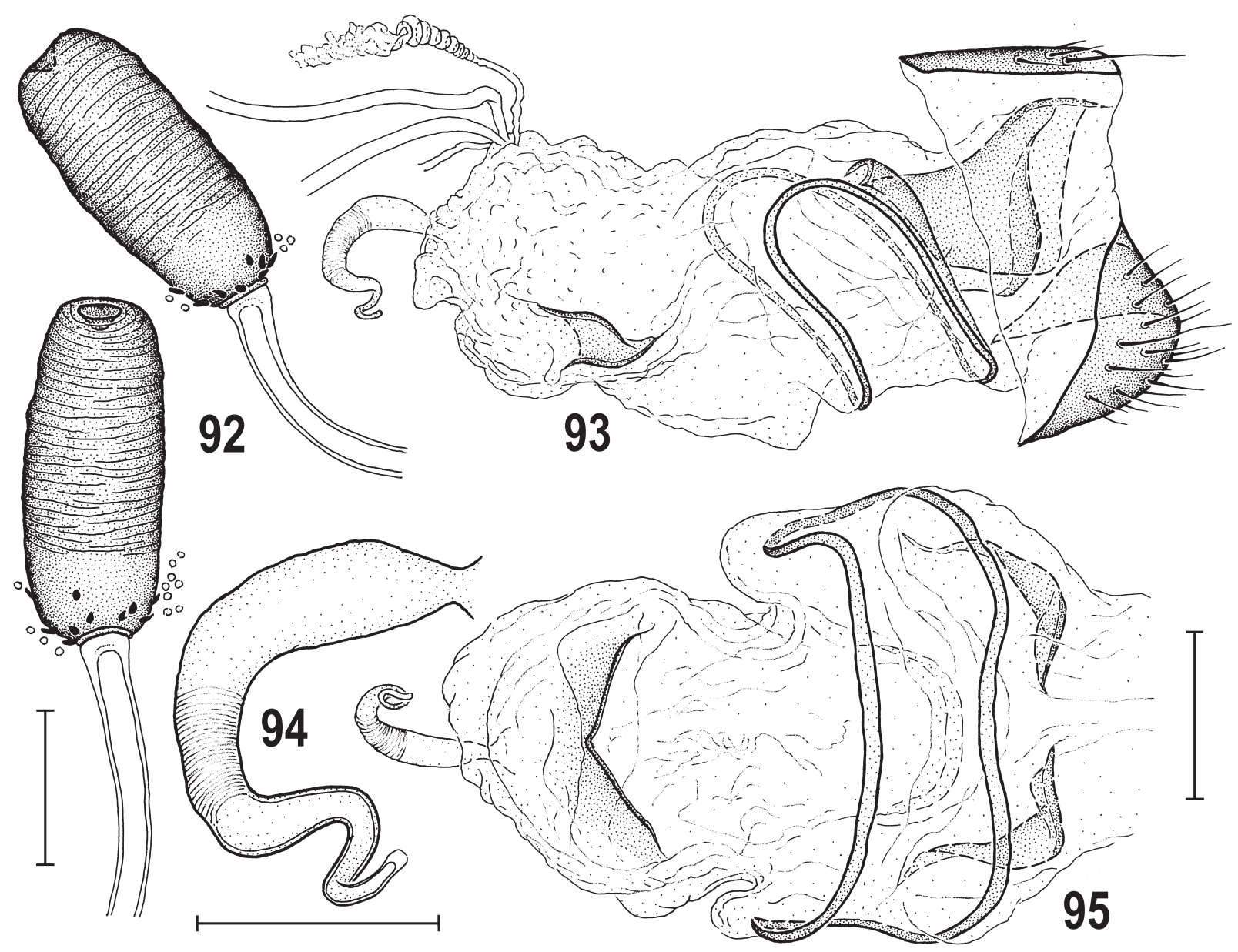

Figs 92-95. Anthomyza ornata sp. nov., female holotype (China: Sichuan). 92 - spermathecae; 93 - 8th abdominal segment and genital chamber, laterally (micropubescence omitted); 94 - ventral receptacle, laterally; 95 - genital chamber, ventrally. Scales $=0.05 \mathrm{~mm}$ (Figs 92,94$), 0.1 \mathrm{~mm}$ (others).

but overlapping, strongly bent far onto ventral aspect of abdomen and hence covering sterna in lateral view (cf. Figs 83, 86), all with relatively long but fine and dense setae (those at posterior margin longest). Preabdominal sterna whitish yellow, narrower, and hidden in ventral concavity of abdomen (but this probably is not true for gravid females). S2-S5 becoming somewhat wider posteriorly (S5 largest) but all as long as or longer than wide. S1 not observed; S2-S5 with long but fine setae being denser in more posterior sterna.

Postabdomen (Figs 86, 89, 90) medium long, tapered from 7th segment. T6 large, as wide as T5, dark brown (except for short pale posteromedial area, see Fig. 90) although lighter than T7, bent onto ventral aspect of segment as preabdominal terga, setose in posterior two-thirds, with setae at posterior margin long. S6 (Fig. 89) wider than S5 but similarly whitish yellow, weakly sclerotized but with longer setae posteriorly, hidden in ventral concavity between margins of T6 (cf. Fig. 86). T7 blackish brown (darker than T6), somewhat tapered posteriorly and dorsomedially shorter than laterally (Fig. 90), far expanded onto ventral aspect of 7 th segment and embedding 7th spiracles (cf. Fig. 89), with abundant setae including longer ones at posterior margin. S7 (Fig. 89) submembranous, unpigmented, lying in ventral conca- vity of 7th segment; it is tapered posteriorly but without delimited margins, distinctly micropubescent and longsetose, particularly posteriorly; moreover there is a pair of long setae in membrane behind S7 surrounded by some micropubescence (see Fig. 89). T8 small, flat, wider than long, brown-pigmented except for posterior pale band and anterolateral corners (Fig. 90), with only a few setae laterally. S8 about as long as T8, medially divided into 2 distinctly pigmented sclerites being posteriorly bent dorsally and anteriorly becoming somewhat invaginated (cf. Figs 86, 93); external side of S8 finely setose and micropubescent as is usual in Anthomyza. Genital chamber of medium length but relatively broad (Figs 93, 95) with 3 sclerotizations: a posterior pair of crooked sclerites, annular sclerite (large, broad, transverse and bent onto lateral surfaces of genital chamber as in A. sulphurea) and a transverse wing-like sclerite posterior to ventral receptacle (Fig. 95). Ventral receptacle (Figs 94, 95) not very long but tube-like and curved, membranous, composed of broader proximal part with plain surface, middle part with very finely ringed surface and distal part gradually attenuated, twisted several times and having blunt apex. Accessory gland small, on a distally dilated and ringed duct (Fig. 93). Spermathecae (1+1) also distinctive (Fig. 92 ), each elongately cylindrical, with shallow terminal 
invagination, surface with fine dense transverse rings except for basal fourth, several short spinulae proximally near duct insertion and cervix reduced to very short collar (this as in A. sulphurea); spermathecal duct very long, simple. T10 small, transversely oval, brownish pigmented (Fig. 90), with single medial pair of very long setae (much longer than those on cercus) in centre and some sparse micropubescence. S10 much larger than T10 (Fig. 89), somewhat longer than wide, finely setulose and densely micropubescent. Cercus of moderate size, relatively slender, with abundant but not very long setosity, apical and dorsopreapical setae only slightly longer than other long setae of cercus (Figs 86, 90).

Discussion. Although only a single female of this Anthomy$z a$ species was available for study I did not hesitate to describe it because the species is extraordinary in many features including colouration, chaetotaxy as well as postabdominal structures. Its distinctive longitudinal thoracic pattern (most similar to that of Epischnomyia species which differ in having wings with brown and white longitudinal pattern, cf. Fig. 69) is sufficient to distinguish $A$. ornata sp. nov. from all other Anthomyza species. When combined with very long cephalic (vti in particular) and thoracic macrosetae (especially the unusually long prs and sa, with only 2 rows of ac microsetae), proximoventral seta on mid basitarsus (all unusual in Anthomyza) and uniquely laterally compressed abdomen, the identification of the new species is unmistakeable. Also, some of the structures of the female postabdomen are species-specific: S7 desclerotized, submembranous without distinct margins; genital chamber with 3 sclerotized structures (paired posterior sclerites, unpaired anterior sclerite and transverse annular sclerite between them); spermathecae elongately cylindrical with small terminal invagination and a collar surrounding duct insertion.

This distinctive species seems to be most closely allied to $A$. sulphurea sp. nov. described below. This relationship is supported by the construction of the annular sclerite in the female genital chamber (transverse, bent onto sides of chamber) that is unique among the known species of the genus Anthomyza, the similarly structured spermathecae (including the ringed surface, small terminal invagination and rim-like collar of duct opening) but also by the enlarged macrosetae of the head and thorax. As discussed below under $A$. sulphurea these two species probably represent a further lineage of Anthomyza which could be related to the $A$. bellatrix group. However, to demonstrate this sister-group relationship definitively, more morphological data (including male genital characters of $A$. ornata) are needed.

Etymology. The species is named for its unusually bicoloured thorax by a Latin adjective ornatus $(-a,-u m)$, meaning decorated.

Biology. The holotype was swept in June from lush vegetation (mainly consisting of dicotyledons but also with a smaller bamboo component; M. Tkoč, personal communication, 2018) forming the undergrowth of a montane $(2570 \mathrm{~m})$ leafy forest (Figs 84, 85).

Distribution. China: Sichuan.

\section{Anthomyza sulphurea sp. nov. \\ (Figs 96-116)}

Type material. HoLотуре: $\hat{\alpha}$, labelled: 'China N Yunnan, Xue Shan nr. Zhongdian, 4200 m, 24.vi.1996, 27,49N/99,34E', 'collected by J. Farkač, P. Kabátek and A. Smetana' and 'Holotypus *m, Anthomyza sulphurea sp. n., J. Roháček det. 2017’ (red label) (SMOC, intact).

PARATYPES: $3 \approx 19$, with same label data as the holotype, only third

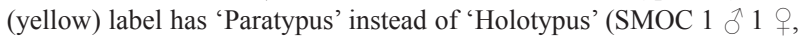
both genit. prep., and MBP $2 \hat{\jmath}, 1$ genit. prep.); 2 male paratypes (SMOC, MBP) have wings more or less damaged, and that in SMOC has one wing removed and preserved in glycerine together with abdomen. Note. The type locality lies in a mountain valley $12 \mathrm{~km}$ west of Zhongdian (Shangri-La), thus ca $27^{\circ} 49^{\prime} 13^{\prime \prime} \mathrm{N}, 99^{\circ} 35^{\prime} 19^{\prime \prime} \mathrm{E}, 4050 \mathrm{~m}$. The geographic coordinates and altitude given in the locality labels of the type specimens were obtained from an outdated map and are not precise (cf. TKOС̌ 2012: 290).

Description. Male. Total body length $2.14-2.30 \mathrm{~mm}$; general colour bright yellow but abdominal terga brown (Fig. 98), largely pale grey microtomentose and relatively dull. Head (Fig. 97) almost entirely yellow, distinctly higher than long, in profile rounded rectangular anteriorly (frons not projecting in front of eye). Occiput dorsomedially concave; its larger medial part pale yellow and all sparsely whitish microtomentose, lateral parts behind eyes darker, orange to orange ochreous. Frons bright yellow to orange yellow, with only small ocellar triangle brown, largely microtomentose and dull, only frontal triangle and orbits somewhat shining. Orbits lighter yellow than rest of frons, sparsely whitish silvery microtomentose and slightly shining. Frontal triangle relatively broad, equilateral, reaching anterior third of frons, also slightly shining except for brown ocellar triangle. Frontal lunule small, whitish yellow. Face narrow, weakly sclerotized and concave, dull yellow; parafacialia and gena whitish yellow and silvery white microtomentose, both bordered with an orange yellow marginal stripe; postgena whitish yellow as gena, whitish microtomentose and contrasting with adjacent orange ochreous ventrolateral part of occiput; mouthparts pale yellow with yellowish white palpus. Cephalic chaetotaxy: all macrosetae unusually long for Anthomyza species (see Fig. 97); also pvt relatively long, strongly crossed; vti usually longest of cephalic setae (sometimes as long as height of head); vte, oc and 2 (posterior ors) subequal, usually somewhat shorter than vti but also very long; 3 ors, posterior (more exclinate) and middle (reclinate, sometimes even longer than posterior) very long, anterior distinctly shorter, about one-third to half length of the posterior; 1 microsetula (about as long as medial microsetulae) adjacent to foremost ors but situated more medially; 2-3 pairs of medial microsetulae between apex of frontal triangle and anterior margin of frons; 1 distinct inclinate setula behind vte; postocular setulae sparse (5-6) and relatively long, in single row; lateroventral part of occiput and postgena with sparse setulae, 2 setae in posteroventral corner longest; 1 relatively short vi (only slightly longer than foremost short ors); subvibrissa reduced (or absent?), even slightly shorter than foremost peristomal setula; peristomal setulae sparse (3-5), becoming shorter posteriorly. Palpus of medium thickness, with 1 (rarely 2) dark preapical seta and with a series of ventral and lateral setulae; labella fleshy and broad, with abundant fine setulae 


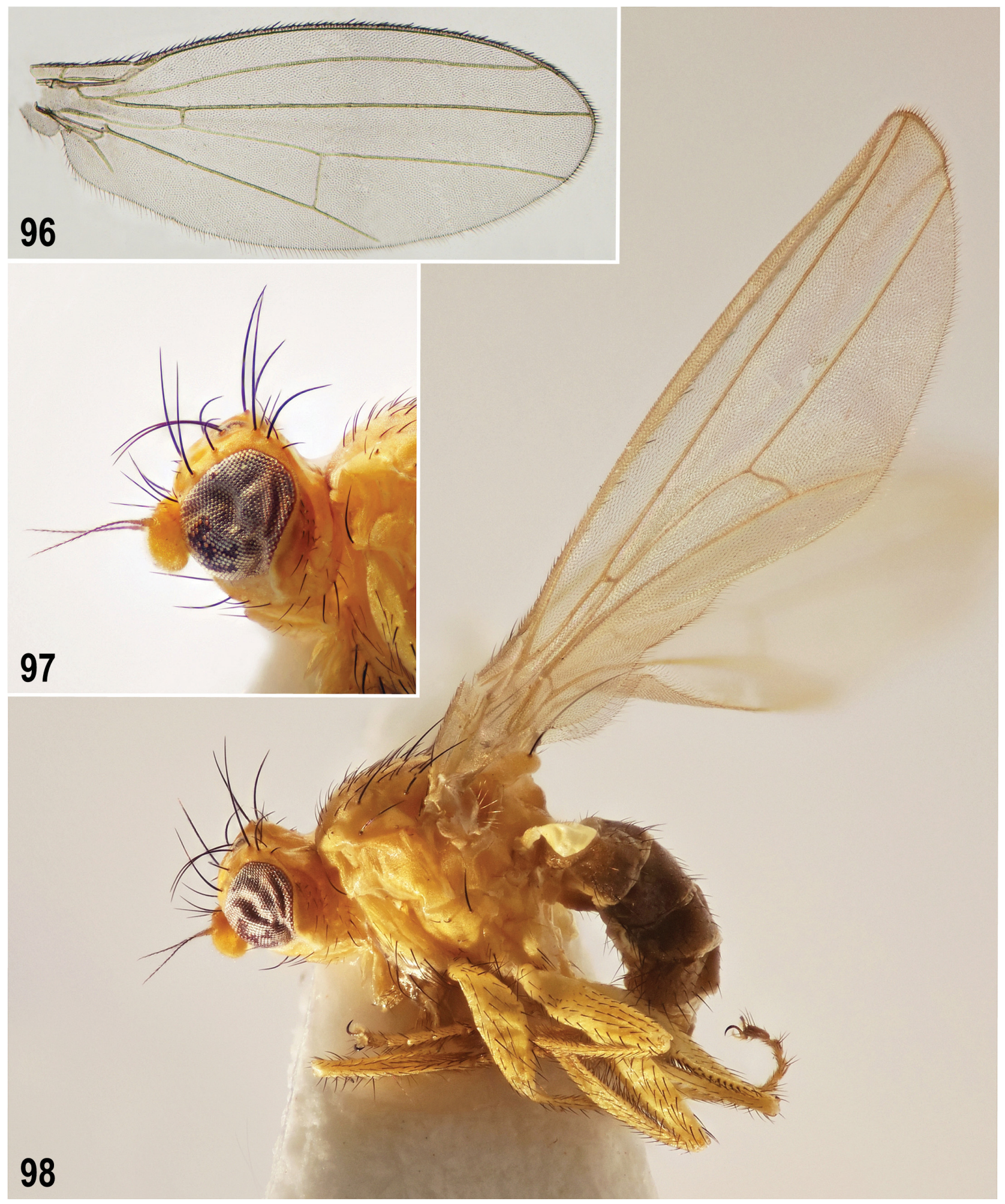

Figs 96-98. Anthomyza sulphurea sp. nov., male (China: Yunnan). 96 - wing (paratype, length ca $3.1 \mathrm{~mm}$ ); 97 - head, dorsolaterally (holotype); 98 holotype, laterally (body length ca $2.2 \mathrm{~mm}$ ). Photos by J. Roháček (96) and M. Tkoč $(97,98)$.

(slightly longer than those ventral on palpus). Eye not very large, suboval, with longest diameter slightly oblique and about 1.4-1.5 times as long as the shortest. Gena relatively high (deep) (see Fig. 97), with shortest height 0.27-0.31 times as long as shortest eye diameter. Antenna yellow to pale yellow, 1st flagellomere lightest; pedicel with dorsal seta longer than usual but fine; 1st flagellomere strongly laterally flattened and with relatively short white pilosity on anteroventral margin. Arista blackish brown (only its thickened basal segment pale brown), about 1.7 times as long as antenna and with yet shorter (and brown) cilia than those of 1st flagellomere.

Thorax not narrower than head, largely bright yellow (Fig. 98), dull and whitish grey microtomentose, only 


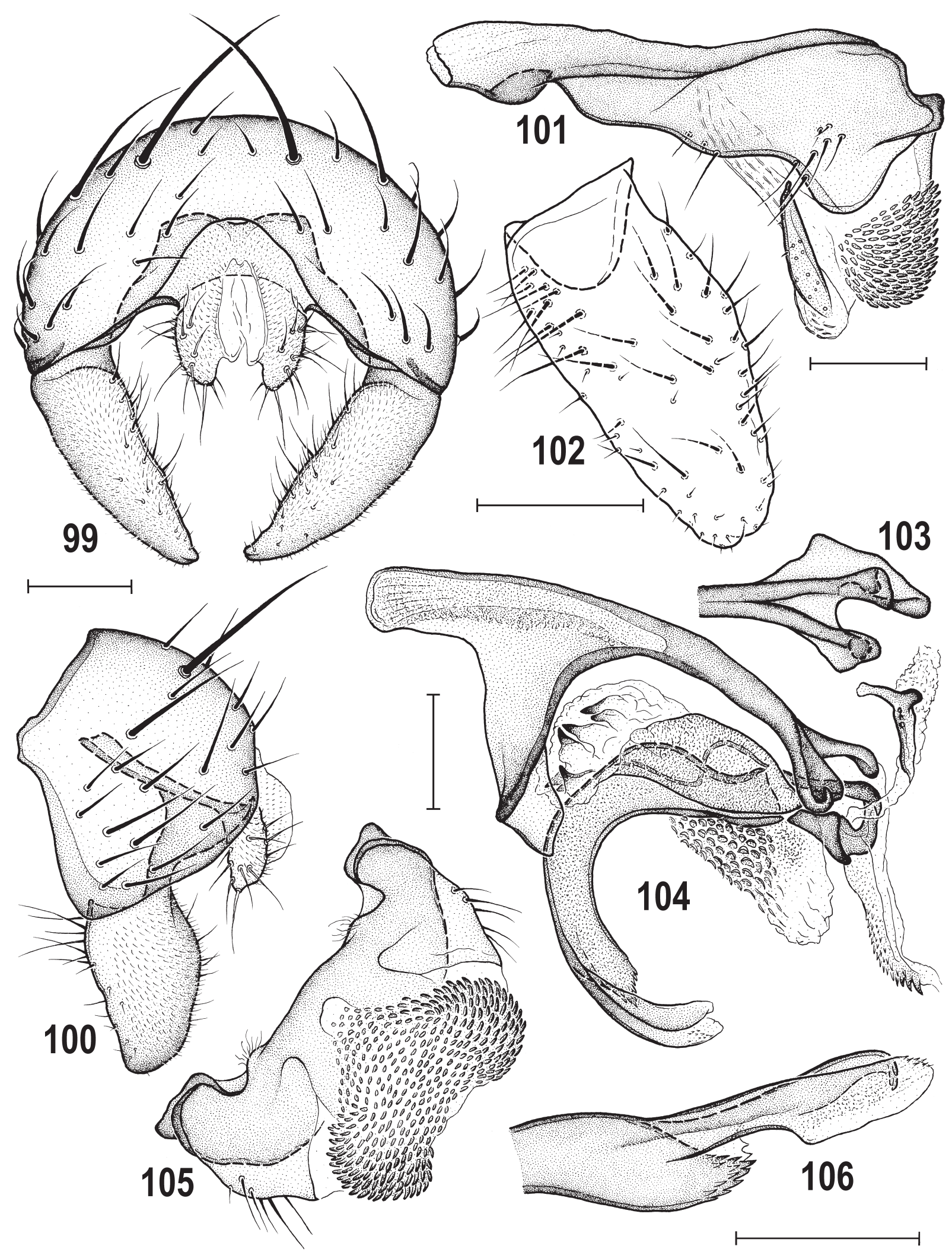

Figs 99-106. Anthomyza sulphurea sp. nov., male paratype (China: Yunnan). 99-100 - external genitalia (99 - caudally; 100 - laterally); 101 - hypandrial complex, laterally; 102 - gonostylus, lateroventrally (widest extension); 103 - basal end of phallapodeme, dorsally; 104 - aedeagal complex, laterally; 105 - transandrium, caudally; $106-$ apex of filum, ventrally. Scales $=0.1 \mathrm{~mm}$.

posterior half of mesonotum with pale ochreous brown (often faint to indistinct) medial and lateral (between $\mathrm{dc}$ and sa lines) vittae; also scutellum, postscutellum and postnotum more or less darkened medially. Thoracic chaetotaxy rich with macrosetae unusually long: $1 \mathrm{hu}$ (almost as long as anterior $\mathrm{npl}$ ); $2 \mathrm{npl}$ (anterior longer); $1 \mathrm{prs}$ (as long as anterior npl); $1 \mathrm{sa}$ (as long as prs); 1 pa (slightly shorter than sa); 2 postsutural dc, posterior extremely long and robust (together with apical sc longest thoracic seta), anterior as long as or longer than sa and up 


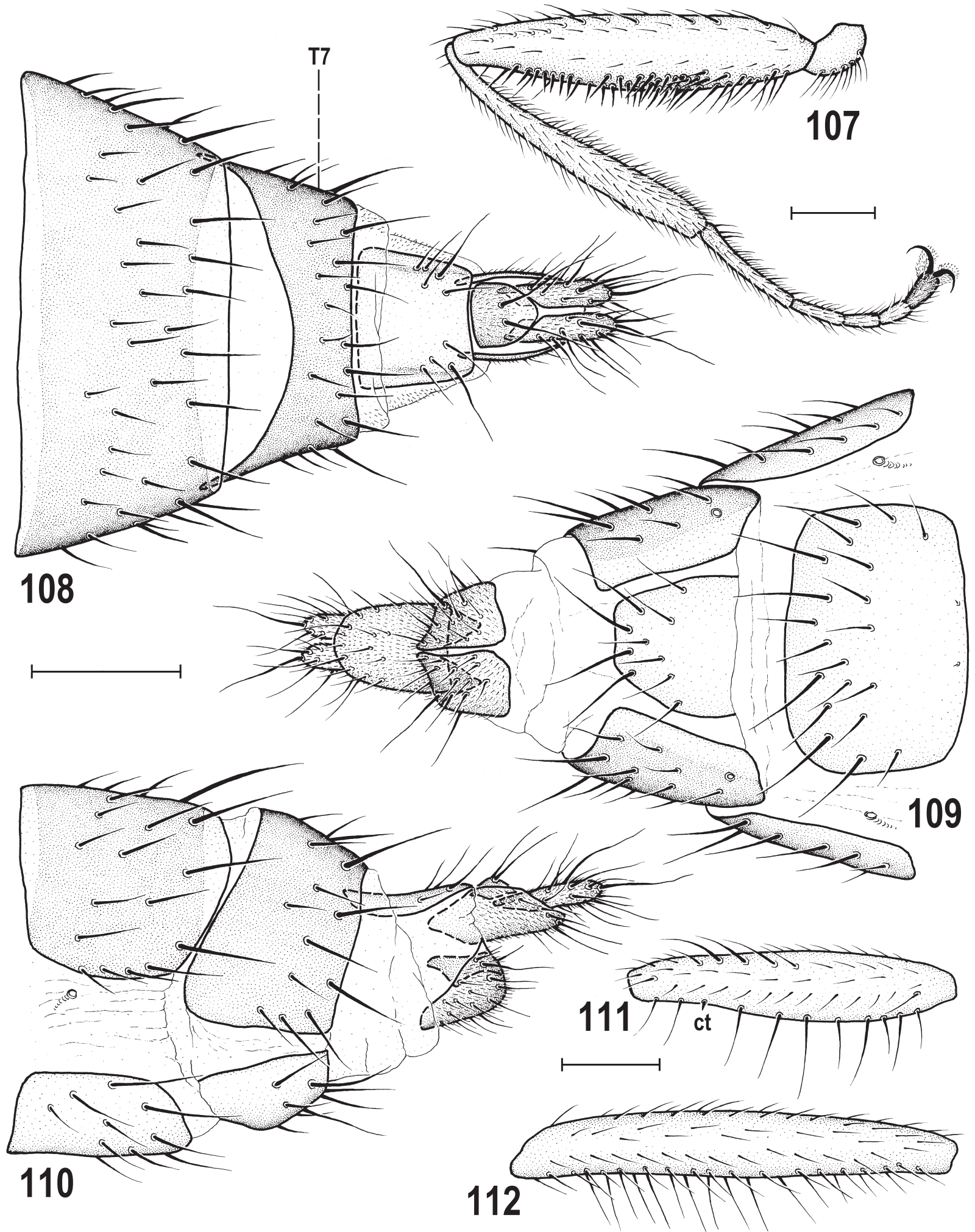

Figs 107-112. Anthomyza sulphurea sp. nov., male and female paratypes (China: Yunnan). 107 - male hind leg, posteriorly; 108-110 - female postabdomen (108 - dorsally; 109 - ventrally; 110 - laterally); 111 - male $\mathrm{f}_{1}$, posteriorly; 112 - male $\mathrm{f}_{2}$, anteriorly. Scales $=0.2$ mm. For abbreviations see p. 37 .

to $8 \mathrm{dc}$ microsetae in front of them, the hindmost twice as long as the others and sometimes resembling a small third $\mathrm{dc}$ macroseta; 4 irregular rows of ac microsetae on suture and also between anterior dc; hindmost ac pair (situated close to posterior dc) distinctly enlarged (at least 3 times as long as ac microsetae in front of it) to form prescutellar ac macrosetae; $2 \mathrm{sc}$, laterobasal about as long as hu (shorter than sa), apical very long (as long as posterior dc); 1 unusually strong upcurved ppl (see Fig. 97); 2 stpl, posterior long to very long, anterior somewhat shorter; 1 setula in front of anterior stpl and 2 or 3 setulae in dorsal half of sternopleuron; ventral part of sternopleuron with up to 7 setae (2-3 longer). Scutellum distinctly triangular, slightly convex dorsally, somewhat wider than long, with posterior 


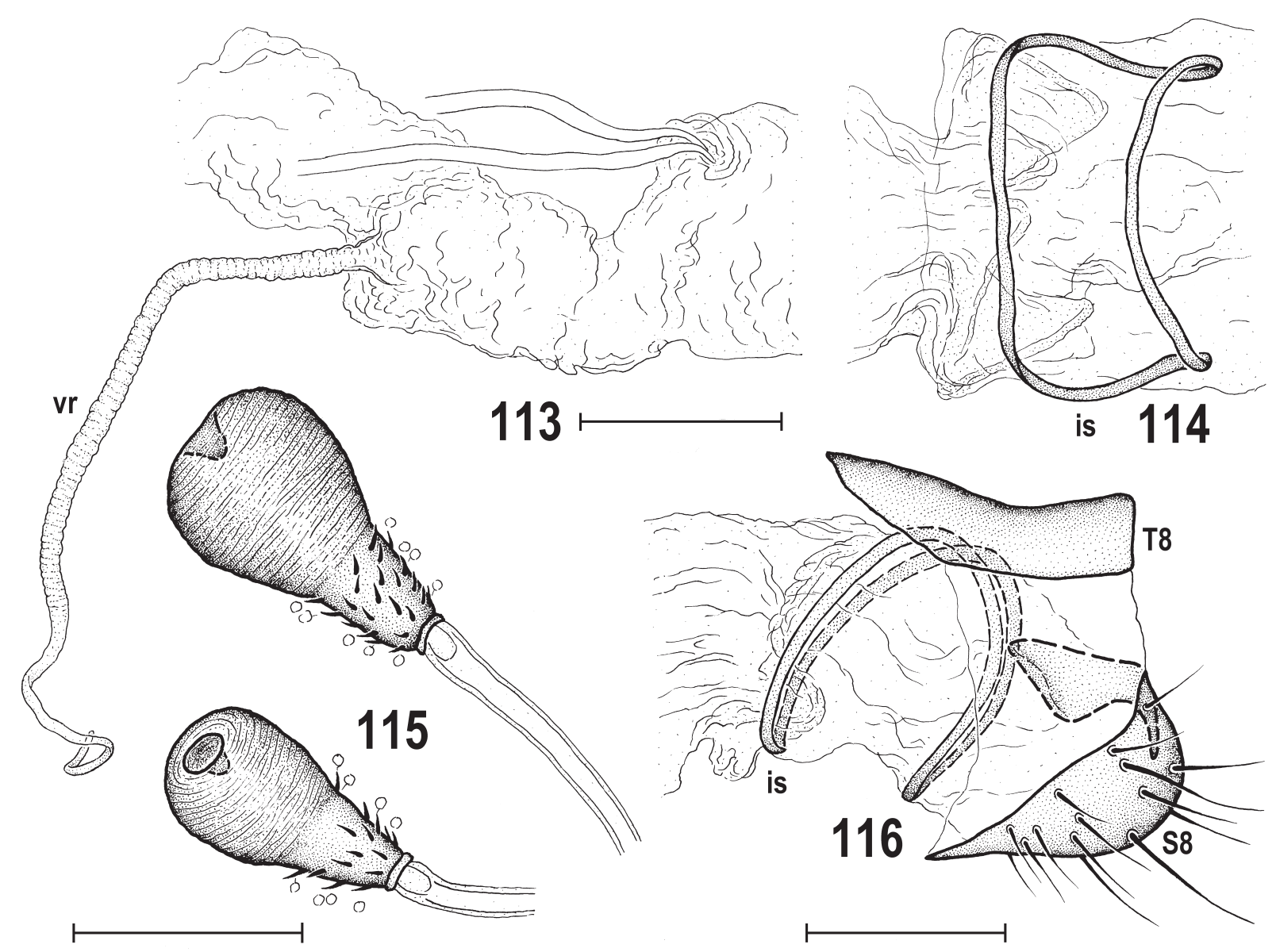

Figs 113-116. Anthomyza sulphurea sp. nov., female paratype (China: Yunnan). 113 - distal part of genital chamber with ventral receptacle, laterally; 114 - annular sclerite ventrally; 115 - spermathecae; 116 - 8th abdominal segment with proximal part of genital chamber, laterally (micropubescence omitted, also setae on T8 omitted). Scales $=0.1 \mathrm{~mm}$. For abbreviations see p. 37.

corner unusually acutely angled and, consequently, with apical sc arising close to each other. Legs uniformly pale yellow, only last segment of all tarsi darkened, pale brownish (that of hind tarsus darkest, see Fig. 107); all parts of legs more densely setose than those of other Anthomyza species. $f_{1}$ with usual posterodorsal and posteroventral rows of long setae but ctenidial spine extremely reduced forming a minute spine (Fig. 111); $\mathrm{f}_{2}$ with posteroventral row of fine and erect setae (Fig. 112), being longer than in relatives; $f_{3}$ with posteroventral row of dense setae, most of them (in distal two-thirds) thickened and shortened and those in middle third duplicated or even triplicated (Fig. 107); also hind trochanter with a clump of fine dense setae; tibiae densely finely setulose; $t_{2}$ with very short (only as long as maximum width of $\mathrm{t}_{2}$ ) ventroapical seta; fore and mid basitarsi with 1 , hind basitarsus with 3 ventral proximal setulae somewhat longer and thicker. Wing (Fig. 96) long and relatively broad, with pale brown veins and hyaline pale ochreous membrane. $\mathrm{C}$ with sparse but very distinct spine-like setae between apices of $\mathrm{R}_{1}$ and $\mathrm{R}_{2+3}$. $\mathrm{R}_{2+3}$ long, sinuous, running subparallel to $\mathrm{C}$ but with apex slightly upcurved; $\mathrm{R}_{4+5}$ slightly bent or with terminal part straightened, divergent from (slightly bent) M especially apically. Discal (dm) cell with $\mathrm{r}-\mathrm{m}$ situated at basal two-fifths to third of cell. Apical portion of $\mathrm{CuA}_{1}$ slightly longer than $\mathrm{dm}-\mathrm{cu}$ and almost reaching wing margin; $\mathrm{A}_{1}$ short, ending far from it. Alula small but not narrowed and with apex rounded; anal lobe well developed, as usual in Anthomyza species. Wing measurements: length 3.14-3.22 mm, width $1.07-1.15 \mathrm{~mm}, \mathrm{Cs}_{3}: \mathrm{Cs}_{4}=0.89-0.98, \mathrm{rm} \backslash \mathrm{dm}-\mathrm{cu}: \mathrm{dm}-\mathrm{cu}=$ 2.68-2.89. Haltere with yellow stem and yellowish white large knob (Fig. 98).

Abdomen. Preabdominal terga uniformly brown, with sparse light grey microtomentum, subshining. T1 fused with T2 although fusion line still discernible; T1 shorter and narrower than T2 and with only short setulae laterally; T2-T5 subequal in length, transverse and reaching far onto lateral aspect of abdomen but becoming somewhat narrower posteriorly (T5 narrowest); T2-T5 rather sparsely setose but setae at posterolateral corners relatively long. Preabdominal sterna pale ochreous brown, much narrower than associated terga but becoming wider posteriorly (S5 largest), S1 smallest, bare and with darker stripe at posterior margin; S2-S5 setose (S5 most densely), all slightly transversely subtrapezoidal (wider posteriorly than anteriorly).

Postabdomen. T6 transverse, bare, unpigmented, membranous, shorter than half length of T5. S6-S8 partly fused forming asymmetrical synsclerite as usual, with S6 and S7 situated left laterally and S8 dorsally. S6 pale brown, slightly shorter than S7, with thin, dark and sclerotized anterior ledge reaching onto ventral aspect and dorsally fused with that of S7; the latter darker brown and dorsally 
shortly fused with posterior margin of S8. S6 and S7 each with 2 distinct setae near posterior margin. S8 long (about 2.5 times as long as S7) and more symmetrical, with a series of short setae in posterior half.

Genitalia. Epandrium (Figs 99, 100) medium-sized but distinctly broader than high or long, with rather sparse setae including 2 pairs (dorsolateral and dorsomedial, this longer) of long and robust setae; anal fissure relatively small, rounded subtriangular (as in A. bellatrix Roháček, 1984). Cercus relatively small, sparsely and finely micropubescent, with relatively short setae, with apical seta only slightly longer than others. Medandrium (Fig. 99) rather broad and low, ventrally much wider than dorsally. Gonostylus (Figs 99, $100,102)$ simple, about as long as height of epandrium, with elongate suboval outline and convex outer side, with apex shortly broadly bilobed (Fig. 102), externally largely micropubescent and setose internally, with longest setae at anterobasal corner. Hypandrium (Fig. 101) robust, very broad (in dorsal view, cf. also caudal view in Fig. 105) but simple, without distinct leaf-like anterior internal lobes. Transandrium (Fig. 105) robust, more so than that of A. bellatrix, with short bilobed (medially incised) flat caudal process transilient to spinose basal membrane. Pregonite (Fig. 101) inconspicuous but elongate, completely fused with hypandrium, anteriorly low and with 3 (1 longer) partly internal setae, posteriorly conspicuously expanded ventrally but rounded and with a group of 6-7 setae inserted unusually dorsally on its external side. Postgonite (Fig. 101) relatively simple, moderate, proximally and distally tapered, with a few very short setulae (no longer anterior setula!) and sensilla on outer side. Basal membrane broad, most similar to that of $A$. bellatrix, densely spinose, finely dorsally, more coarsely ventrolaterally (Figs 101, 105). Aedeagal part of folding apparatus externally with dense wart-like adornment (Fig. 104) but lacking robust spines internally (in contrast to that of $A$. bellatrix and relatives). Connecting sclerite slender, submembranous, spinulose but apically with a few bigger and darker spines (see Fig. 104). Phallapodeme robust but less so than in A. bellatrix, with basal fork asymmetrical (Fig. 103) but not turned to the left, with very simple rounded apex without projecting corners. Aedeagus with short asymmetrical frame-like phallophore having dark ventral sclerite on the left. Distiphallus robust, composed of relatively small saccus and large filum. Saccus (Fig. 104) smaller than that of A. trifurca Sueyoshi \& Roháček, 2003, having proximal half sclerotized and pigmented and distal membranous part armed with about 6 dark-pigmented spines. Filum (Fig. 104) huge and formed by single robust curved sclerite terminating in 3 lobate, closely attached projections (see Fig. 106): 1 short, dark and with spinose apex and 2 longer, each having submembranous, flattened and pale apex with a few very minute spinulae at most. Ejacapodeme (in contrast to A. bellatrix group) well developed (Fig. 104), larger than that of most Anthomyza species, with slender pale digitiform projection and rounded dark protuberance.

Female. Similar to male unless mentioned otherwise. Total body length $3.10 \mathrm{~mm}$. Faintly darkened longitudinal stripes on mesonotum more distinct and longer, reaching to presutural area. $2 \mathrm{dc}$ microsetae in front of anterior dc enlarged. Sternopleuron with 1 additional microseta between stpl. Ctenidial spine on $\mathrm{f}_{1}$ similarly reduced to that in male but $\mathrm{f}_{2}$ with posteroventral erect setae shorter and less numerous; $\mathrm{f}_{3}$ posteroventrally simply setulose. Wing measurements: length $3.81 \mathrm{~mm}$, width $1.27 \mathrm{~mm}, \mathrm{Cs}_{3}: \mathrm{Cs}_{4}$ $=0.98, \mathrm{rm} \backslash \mathrm{dm}-\mathrm{cu}: \mathrm{dm}-\mathrm{cu}=2.51$. Preabdomen with T1-T5 wider, more transverse than in male and T4 the widest. Preabdominal sterna S2-S4 becoming progressively wider (S4 widest), S5 slightly narrower than S4 but wider than S6. S2-S5 distinctly wider than long, S2-S5 rounded trapezoidal, S5 suboblong.

Postabdomen (Figs 108-110) medium long, tapered from 7th segment. T6 large but narrower than T5, dark-pigmented (lighter than T7) but narrowly pale margined both anteriorly and posteriorly, sparsely setose in posterior two-thirds. S6 transversely suboblong with rounded corners, pale ochreous yellow and setose in posterior half. T7 blackish brown, dorsally short due to broad anterior incision (Fig. 108) and its larger lateral parts bent onto ventral aspect of postabdomen where lightened and embedding 7th spiracles (Fig. 109), setae restricted to posterior half of sclerite. S7 (Fig. 109) narrow, tapered posteriorly, separate although with lateral margins close to those of T7, very pale-pigmented and setose in posterior half (4 setae at posterior margin long). Membrane of 8 th segment narrow and without dense micropubescence. T8 pale-pigmented and weakly sclerotized, relatively large and long (Fig. 108), flat, posteriorly slightly tapered, with setae in posterior corners. S8 (Fig. 109) shorter than T8, medially divided into 2 dark-pigmented sclerites being posteriorly bent dorsally and anteriorly to form invaginated lobes (cf. Fig. 116); S8 externally finely setose and micropubescent. Genital chamber long but with sclerotization reduced and, consequently, markedly dissimilar to that of the $A$. bellatrix group. There is a large (almost as wide as 8th segment), dorsally bent and relatively symmetrical annular sclerite (Figs 114, 116) similar to that of $A$. ornata sp. nov. and only faintly darkened membrane anterior to it, but no other sclerites in genital chamber. Ventral receptacle (Fig. 113) very long, tube-like, membranous, having most of surface indistinctly ringed and its terminal third gradually attenuated with only apex simply twisted (resembling that of species of the Anthomyza macra group and some species of the genus Arganthomyza); accessory gland not observed in the only female examined. Spermathecae $(1+1)$ characteristic (Fig. 115), each elongately pyriform, with small terminal invagination, surface of distal broader part with fine dense transverse rings, spinulose proximal narrow part and cervix reduced to very short collar; spermathecal duct very long and plain. T10 small, rounded pentagonal (Fig. 108), with basal half dark-pigmented, single medial pair of long setae in centre and sparse micropubescence. S10 long and narrow (Fig. 109), about 2.5 times as long as T10, finely setulose and micropubescent. Cercus relatively long and slender, with rich setosity, and its longest apical and dorsopreapical setae almost as long as cercus (Fig. 110).

Discussion. This new Anthomyza species can be easily recognized by the following combination of external characters: largely yellow body with brown abdomen (Fig. 98); 
very long cephalic and thoracic macrosetae (Figs 97, 98) (resembling those of A. ornata and Epischnomyia species); dense setosity of legs but ctenidial spine on $\mathrm{f}_{1}$ extremely reduced (Fig. 111); male $\mathrm{f}_{2}$ and $\mathrm{f}_{3}$ with characteristic rows of setae ventrally (Figs 107, 112) and scutellum distinctly triangular.

The validity of $A$. suphurea sp. nov. is also supported by numerous distinctive characters in the male and female terminalia but revealing its relationships proved to be more difficult. The general formation of the male external genitalia (broad epandrium with small anal fissure, small cercus, simple gonostylus) and, particularly, some characters in the male hypandrial and aedeagal complexes seem to indicate relationship of $A$. suphurea with the East Palaearctic A. bellatrix group (as defined by RoHÁČEK 2006). They share the robust (and very broad) hypandrium and transandrium, densely spinose basal membrane, asymmetrical basal fork of phallapodeme and very robust filum of distiphallus terminating in 3 projections. However, the latter (probable) synapomorphies are contradicted by extensive dissimilarities in the female postabdomen, especially the separate $\mathrm{S} 7$, absence of paired asymmetrical internal sclerites (posterior to annular sclerite) in the female genital chamber, annular sclerite transverse (not elongate) and symmetrical, ventral receptacle not spirally coiled terminally and spermathecae elongate. In addition, some distinctive dissimilarities with synapomorphies of the $A$.bellatrix group can also be seen in the male internal genitalia, e. g. the aedeagal part of folding apparatus of A. sulphurea is devoid of strong spines, apex of phallapodeme is simply rounded (without projecting lateroventral corners) and ejacapodeme is not reduced. Moreover, the scutellum of A. sulphurea is not flattened dorsally and there are no whitish grey microtomentose stripes on its occiput. All these differences (lack of synapomorphies) prevent the inclusion of A. sulphurea in the A. bellatrix group directly but some shared apomorphies in the male genitalia (discussed above) indicate that they may be somewhat related. However, judging from the uniquely transverse annular sclerite in the female genital chamber, very similar structures of spermathecae, long cephalic and thoracic setae and similar fore leg chaetotaxy, A. sulphurea seems to be the nearest relative of $A$. ornata (described from single female above). These two species appear to represent a separate group of Anthomyza that cannot yet be formally described because the male of $A$. ornata is unknown. Provisionally (based on the shared apomorphies in the male genitalia of A. sulphurea, see above) this species-pair can be considered a sister group of the A. bellatrix group (composed of $A$. cuneata Roháček, 1987, A. bellatrix Roháček, 1984 and A. trifurca Sueyoshi \& Roháček, 2003). If so, the $A$. sulphurea + A. ornata pair carries more plesiomorphies than the $A$. bellatrix group (for synapomorphies of the latter see ROHÁČEK 2009 and ROHÁČEK \& BARBER 2016).

Etymology. The name is a Latin adjective (sulphureus, $-a$, $-u m$ ) and refers to the bright yellow (sulphur-yellow) head and thorax of the new species.

Biology. Nothing is known about the habitat of the new species. The type series was captured in June in a high- -montane valley (at $4200 \mathrm{~m}$, but according to Tкос̌ 2012: 290 , this altitude is incorrect; however, the type locality obviously lies slightly above $4000 \mathrm{~m}$, and is the highest site where Anthomyzidae have hitherto been collected).

Distribution. China: Yunnan.

\section{Anthomyza cuneata Roháček, 1987}

Material examined. CHINA: Sichuan: Pingwu Co., Laohegou Reserve, $32^{\circ} 29^{\prime} 3.20^{\prime \prime} \mathrm{N} 104^{\circ} 43^{\prime} 9.96^{\prime \prime} \mathrm{E}, 1400-2100 \mathrm{~m}, 13 .-17 . v .2016,1$ \%, O. Lonsdale leg. (CNCI, genit. prep.).

Remarks. Probably the most ancestral species of the Anthomyza bellatrix group (see RоHÁČEK 2009) characterized by less asymmetry in the male genitalia and internal sclerites of the female genital chamber (cf. RоНÁČEK 1987). The above specimen from Sichuan differs slightly in the shape of the apical projections of the filum of the distiphallus from that of Nepalese specimens but this small dissimilarity is surely within the variability of this character. Biology. Unknown. Habitat data are not indicated in the type series (RоHÁČEK 1987) nor in the specimen examined here. In Nepal, the species was collected at 2000-3500 m in April to June, therefore it is probable that the specimen from Sichuan was also collected at about $2000 \mathrm{~m}$ (cf. altitude range on its label data).

Distribution. Anthomyza cuneata was previously known only from Nepal (RoHÁČEK 1987). First record from China (Sichuan).

\section{Anthomyza trifurca Sueyoshi \& Roháček, 2003}

Material examined. CHINA: Sichuan: Pingwu Co., Laohegou Reserve, $32^{\circ} 29^{\prime} 3.20^{\prime \prime} \mathrm{N} 104^{\circ} 43^{\prime} 9.96^{\prime \prime} \mathrm{E}, 1400-2100 \mathrm{~m}, 13 .-17 . v .2016,7$ oิ 2 우, O. Lonsdale leg. (CNCI, 1 के 1 genit. prep.); Sichuan: Leshan: Emeishan, Leidonping, 29 $32^{\prime} 25^{\prime \prime} \mathrm{N} 103^{\circ} 19^{\prime} 52^{\prime \prime} \mathrm{E}, 2420 \mathrm{~m}$, around parking lot, shops and hotels, collected by aspirator, rainy weather, 10.vi.2014, 1 j, J. Hájek, J. Růžička \& M. Tkoč leg. (NMPC) (in ethanol); Sichuan: Wenchuan, $50 \mathrm{~km}$ W of Dujiangyan, Qionglai Mountains, $10 \mathrm{~km} \mathrm{SW}$ of Wolong vill.. Wolong NNR, Shaotang river valley, Yiangchanggou vill., area of earthquake damaged Panda centre, $30^{\circ} 58^{\prime} 31^{\prime \prime} \mathrm{N} 103^{\circ} 07^{\prime} 21^{\prime \prime} \mathrm{E}, 2100 \mathrm{~m}$, sweeping and individual collecting on vegetation close to stream and small pond, 24.vi.2014, 1 đ̊, J. Hájek, J. Rưžička \& M. Tkoč leg. (NMPC) (in ethanol); Sichuan: Wenchuan, Aba, Wolong, Wolong Nature Reserve, $31^{\circ} 01^{\prime} 32^{\prime \prime} \mathrm{N} 103^{\circ} 10^{\prime} 15^{\prime \prime} \mathrm{E}, 2050$ $\mathrm{m}$, forested slope, sweeping vegetation, individual collecting, 23.vi.2014, 1 †, J. Hájek, J. Růžička \& M. Tkoč leg. (NMPC, genit. prep.); Sichuan: Ya'an, $60 \mathrm{~km}$ N of Baoxing, above Qiaoqixiang lake, Zhaoxia vill., Nibagou Scenic Area, 30 $41^{\prime} 16^{\prime \prime} \mathrm{N} 102^{\circ} 42^{\prime} 41^{\prime \prime} \mathrm{E}, 2400 \mathrm{~m}$, sweeping close to stream, forest, 14.vi.2014, 2 đે, J. Hájek, J. Růžička \& M. Tkoč leg.

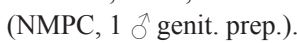

Remarks. This is the most derived representative of the Anthomyza bellatrix group. Its sister species, A. bellatrix Roháček, 1984 (known from adjacent North Korea, Japan: Honshu and Russia: Kuril Is., see RонÁČ́K 2006) is likely to be found in China.

Biology. Insufficiently known despite the species being common in Japan (see Sueyoshi \& ROHÁČEK 2003). In South Korea the species was most frequently swept from undergrowth of forests but it was also found in grassland and ruderal habitats (RонÁČEK 2006). Recent unpublished records from Japan (M. Tkoč leg.) indicate that the species is associated with larger grasses in forests. The flight period of adults is long (April-October). 
Distribution. The above first records from China (Sichuan) demonstrate that $A$. trifurca is apparently widespread in the E. Palaearctic area and reaches far to the south. It has otherwise been recorded only from Japan (Hokkaido, Honshu, Shikoku, Kyushu), North Korea and South Korea (ROHÁČEK 2006, 2009).

\section{Arganthomyza hyperseta sp. nov.} (Figs 119-128)

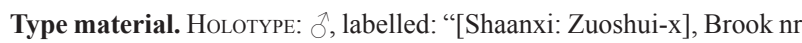
tunnel, He-taoping, 1650-1750m, 22 June 1997, A. NAKANISHI col." and "Holotypus O', Arganthomyza hyperseta sp. n., J. Roháček det. 2017" (red label). The holotype is now housed at the Saigusa Institute of Insect Natural History (SIINH, genit. prep.) in Fukuoka, and will eventually be donated to an authorized collection in China that is not yet determined.

Description. Male. Total body length 2.14-2.42 mm; general colour blackish brown, unusually lustrous (probably the shiniest species of Anthomyzidae) due to very reduced microtomentum (Fig. 119). Head somewhat higher than long, with frons only slightly produced in front of eye, thus relatively rounded anteriorly in profile. Occiput dorsomedially concave, entirely blackish brown, glabrous and shining, almost devoid of microtomentum. Frons also largely shining, with anterior half yellow to (posteriorly) orange, remainder blackish brown. Frontal triangle yellow anteriorly and dark brown posteriorly, bare and lustrous except for apex of anterior corner being whitish microtomentose and duller. Ocellar triangle small, shining, without microtomentum. Ocelli closely positioned, distance between them very slightly longer than ocellar diameter. Orbits anteriorly (from anterior margin of frons margin up to posterior ors) yellow and sparsely silvery white microtomentose, posteriorly blackish and polished; a very distinct silvery microtomentose stripe between posterior part of orbit and frontal triangle extending from posterior ors to vti. Frontal triangle very long, almost reaching to anterior margin of frons. Frontal lunule orange, small, narrow. Face very narrow, medially weakly sclerotized, deeply depressed and somewhat folded, dirty yellow and sparsely whitish microtomentose. Parafacialia and gena whitish yellow and densely silvery white microtomentose, having pale brown marginal stripe continued on ventral margin of gena and posteriorly dilated and connected with dark brown and relatively shining postgena. Mouthparts small, dirty yellow including palpus; clypeus not visible in the holotype. Cephalic chaetotaxy: macrosetae longer than in relatives (Fig. 119) but pvt relatively short, weak, but strongly crossed; vti very long (longer than shortest eye diameter), distinctly longest of cephalic setae; oc also long but shorter than vti, proclinate and parallel; vte and posterior ors subequal and slightly shorter than oc; 2 ors, anterior

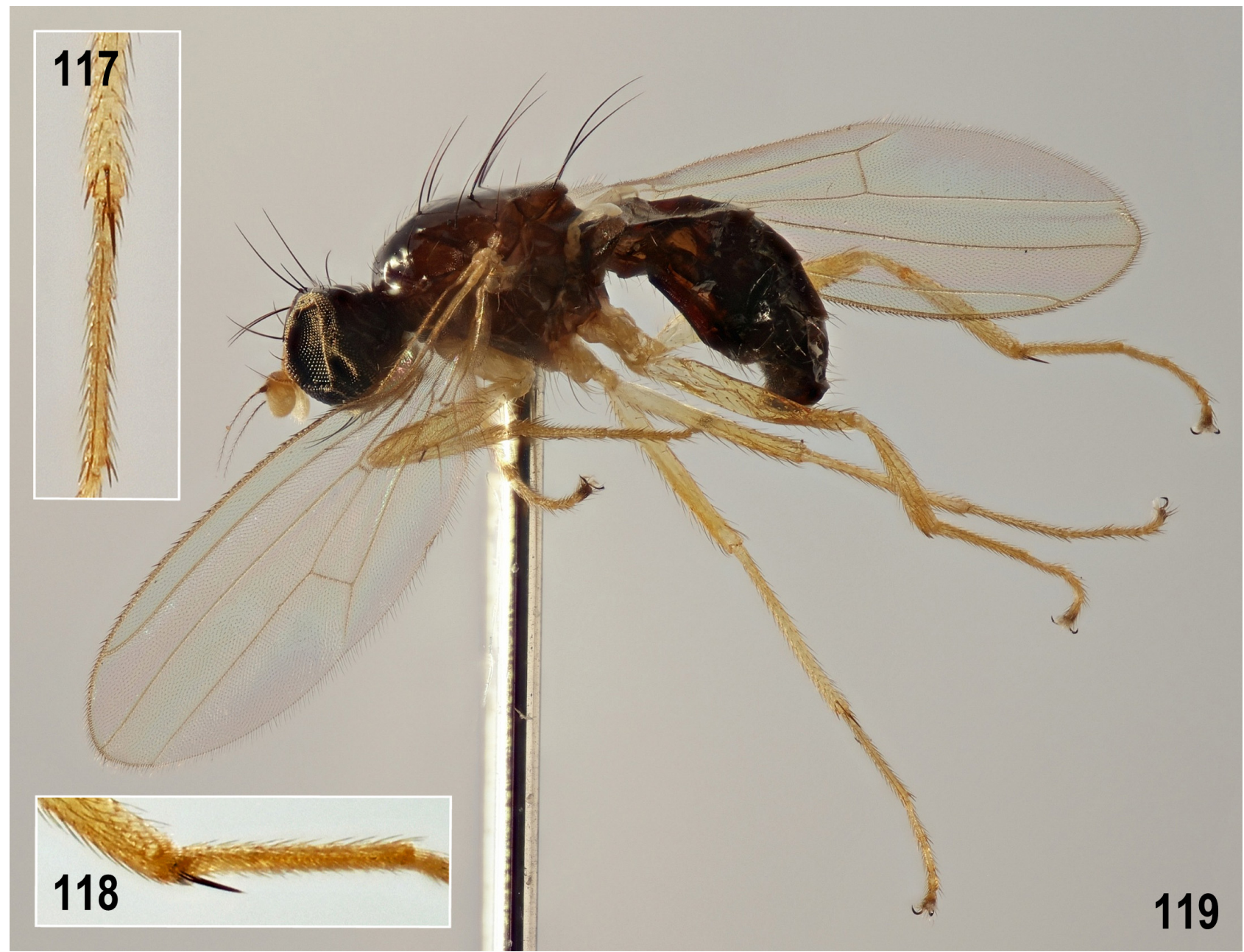

Figs 117-119. Arganthomyza hyperseta sp. nov., male holotype (China: Shaanxi). 117 - apex of $\mathrm{t}_{2}$ and mid basitarsus, ventrally; 118 - apex of $\mathrm{t}_{3}$ and hind basitarsus, posteriorly; 119 - holotype before dissection, laterally (body length ca $2.5 \mathrm{~mm}$ ). Photos by M. Tkoč. 


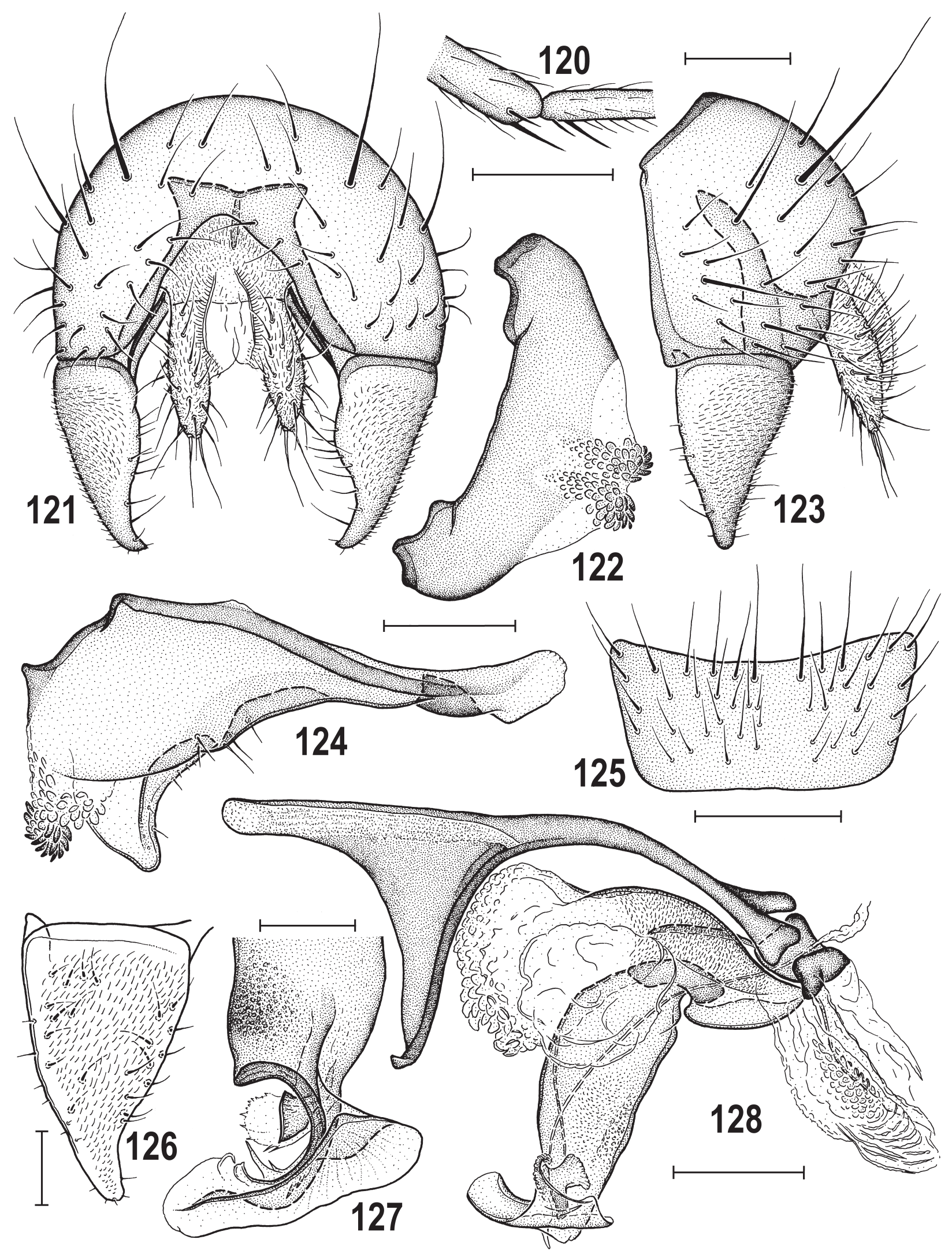

Figs 120-128. Arganthomyza hyperseta sp. nov., male holotype (China: Shaanxi). 120 - apex of $\mathrm{t}_{2}$ and base of mid basitarsus, anteriorly; 121 - external genitalia, caudally; 122 - transandrium, caudally; 123 - external genitalia, laterally; 124 - hypandrial complex (right side), laterally; 125 - 5th sternum, ventrally; 126 - gonostylus, laterocaudally (widest extension); 127 - apex of filum, anteroventrally; 128 - aedeagal complex, laterally. Scales $=0.2 \mathrm{~mm}$ (Figs 120, 125), $0.05 \mathrm{~mm}$ (Figs 126, 127), $0.1 \mathrm{~mm}$ (others). 
markedly shorter and weaker (less than third as long) than the long posterior (Fig. 119); 1 microsetula (rather far) in front of the anterior ors; 2 pairs of medial microsetulae at sides of anterior corner of frontal triangle; 1 inclinate setula behind vte distinct, as long as uppermost postocular setulae; the latter sparse (6-7) and dark, in single row; postgena with several setulae and 2 (1 longer) posteroventral setae; 1 long vi (as long as but weaker than posterior ors); subvibrissa reduced, not longer than anterior peristomal setula; only 5-6 fine peristomal setulae. Palpus slender, yellow, with 1 fine dark ventral preapical seta (distinctly longer than subvibrissa) and a few ventral setulae. Eye large, suboval, with longest diameter nearly vertical and about 1.5 times as long as shortest. Shortest genal height about 0.10 times as long as shortest eye diameter. Antenna slightly geniculate; scape and pedicel orange yellow; 1st flagellomere laterally flattened, largely whitish yellow, darker yellow only around base of arista (not brownish dorsally as in $A$. versitheca Roháček, 2009), with dense short pilosity but its anterior margin with comparatively long white ciliation. Arista brown including thickened basal segment, about twice as long as antenna, relatively long ciliate (cilia as long as those on 1st flagellomere).

Thorax slightly narrower than head, entirely blackish brown and largely strongly lustrous because of reduced microtomentum (Fig. 119). Mesonotum and most of humeral callus lacking microtomentum and glabrous, only ventral margin of the latter and of notopleural area, a small posterolateral spot (between posterior npl, sa, pa and base of scutellum) and scutellum with sparse grey microtomentum and subshining. Pleural part of thorax, postscutellum and postnotum completely blackish brown and sparsely pale grey microtomentose but also relatively shining. Thoracic chaetotaxy: mesonotum with reduced number of microsetae; macrosetae very long, some yet longer than those of relatives. $1 \mathrm{hu}$ (somewhat shorter than anterior $\mathrm{npl}) ; 2 \mathrm{npl}$ (posterior distinctly shorter); 1 very long prs (much longer than anterior npl); 1 very long sa (as long as prs); 1 pa (only about as long as anterior npl); 2 very long postsutural dc (posterior longest of thoracic setae, anterior shorter but also very long, slightly longer than sa or prs) and $5 \mathrm{dc}$ microsetae in front of them; ac microsetae almost absent (only 1 can be seen between anterior dc pair); 2 sc, laterobasal weak, shorter than pa, apical very long, almost as long as posterior dc; 1 medium long but very fine upcurved ppl; 2 relatively long but thin stpl, anterior only slightly shorter than posterior, and 2 upcurved pale setulae below them; ventral part of sternopleuron with 3 longer pale setae. Scutellum relatively narrow (only about 1.5 times as wide as long), rounded triangular, strongly convex dorsally. Legs yellow to pale yellow (Fig. 119), coxae and trochanters yellowish white, only distal half to two-thirds of apical tarsal segments dark brown. $\mathrm{f}_{1}$ with ctenidial spine slightly longer than maximum width of $t_{1}$ and with a row of very long posteroventral setae (longest twice longer than those in posterodorsal row). $\mathrm{f}_{3}$ with a row of posteroventral setae but only 4 in distal third shortened and distinctly thickened; $\mathrm{t}_{2}$ with 1 small anteroapical seta and 1 relatively short ventroapical seta; also $t_{3}$ with 1 short but distinct anteroapical seta; fore basitarsus with 2 longer proximoventral hair-like setulae; mid basitarsus with distinct proximoventral seta (Fig. 120) being subequal to ventroapical seta on $t_{2}$ (cf. also Fig. 117); hind basitarsus (Fig. 118) with a single robust proximoventral seta; $\mathrm{f}_{2}$, and $\mathrm{t}_{1}$ simply setulose. Wing (Fig. 119) about as long as body length (of air-dried specimen) and relatively narrow, with pale ochreous veins and hyaline membrane. $\mathrm{C}$ with small and sparsely arranged spinulae between apices of $R_{1}$ and $\mathrm{R}_{2+3}$. $\mathrm{R}_{2+3}$ long, slightly sinuous because it runs parallel to $\mathrm{C}$ with apex upcurved to $\mathrm{C}$; $\mathrm{R}_{4+5}$ very slightly bent, subparallel to $\mathrm{C}$ but converging preapically to (almost straight) M. Discal ( $\mathrm{dm}$ ) cell moderate, with r-m situated slightly in front of middle of $\mathrm{dm}$ cell. Apical portion of $\mathrm{CuA}_{1}$ somewhat longer than $\mathrm{dm}-\mathrm{cu}$, ending close to wing margin; $\mathrm{A}_{1}$ short, ending far from it; anal lobe not reduced; alula small, narrow, with apex rounded. Wing measurements: length $2.46 \mathrm{~mm}$, width $0.74 \mathrm{~mm}, \mathrm{Cs}_{3}: \mathrm{Cs}_{4}=1.69, \mathrm{rm} \backslash \mathrm{dm}-\mathrm{cu}$ : $\mathrm{dm}-\mathrm{cu}=2.80$. Haltere with yellowish white knob; stem yellow but basally darker, orange ochreous.

Abdomen (Fig. 119). Preabdominal terga blackish brown and shining despite very sparse grey microtomentum; sterna dark brown, more densely microtomentose and subshining. T1 and T2 largely separate, only laterally partly fused. T2 somewhat narrower and shorter than T3, T3-T5 subequal, broad, bent onto ventral aspect of abdomen, all relatively finely and sparsely setose. Preabdominal sterna relatively large, well sclerotized; S1 and S2 not studied; $\mathrm{S} 3-\mathrm{S} 5$ becoming wider posteriorly, S3 and S4 subequal in length, both wider than long; S5 (Fig. 125) widest but shorter than S4, transversely trapezoidal, with setae (those at posterior margin long) separated by a medial bare area. T6 very short, transversely band-like, bare, brown, undivided but with medial third unpigmented. S6-S8 dorsally fused together. S6 (as long as S7 but ventrally band-like) and S7 strongly asymmetrical, both with strongly sclerotized anterior ledge-like margin; S6 with 2 setae, S7 with 1 seta; S8 twice as long as than S7 (and about as long as epandrium), tapered posteriorly, with sparse setae in posterior half.

Genitalia. Epandrium (Figs 121, 123) dark brown, moderately broad, with relatively long but fine setae, including 2 (or 3) distinctly longer and thicker pairs, the dorsolateral being very long; anal fissure rather large, rounded triangular. Cercus relatively large, robust but pale-pigmented, densely finely setose, with 2 apical setae slightly longer than others. Medandrium (Fig. 121) relatively high, tapered dorsally with relatively acute dorsolateral corners. Gonostylus (Figs 121, 123, 126) slightly shorter than epandrial height, flat, bent medially, with ham-shaped outline as in relatives ( $A$. versitheca in particular) but narrower and with more tapered apex, finely micropubescent on most of outer side and relatively shortly setose on inner side. Hypandrium (Fig. 124) different from that of relatives, with distal (anterior) end slender, and posterior half gradually strongly dilated and posteriorly fused with relatively robust transandrium. Transandrium (Fig. 122) not separated from hypandrium, rather pale-pigmented except for very slender, 
more sclerotized and dark dorsal marginal ledge, without distinct caudal process, hence ventromedially transient to basal membrane. Pregonite (Fig. 124) reduced and fused to hypandrium, very low, hardly projecting ventrally but bent internally, with 3 relatively short anterior (internal) and 2 yet shorter posterior (external) setae (but both groups very close). Postgonite (Fig. 124) elongate, somewhat bent, distinctly pigmented and with apex transient to larger posterior submembranous lobe; its anterior margin with only a series of several minute setulae (2 slightly longer), without distinct seta. Basal membrane (Figs $122,124)$ with dense, flat, spine-like excrescences being smaller and pale dorsally and larger and darker ventrally. Aedeagal part of folding apparatus (Fig. 128) with only a group of small, inconspicuous flat and pale tubercles and some fine striae. Connecting sclerite indistinct, slender and membranous. Phallapodeme distinctly different from that of relatives, unusually slender including fulcrum and simple rod-like apex, although with basal end deeply forked as in relatives. Aedeagus with short, frame-like but heavily sclerotized phallophore (Fig. 128) and rather voluminous distiphallus. Saccus short but distally broad, with proximal part narrower and distinctly sclerotized and membranous distal part relatively voluminous, apically covered with numerous small hyaline tooth-like tubercles, otherwise unarmed. Filum yet more robust than that of $A$. versitheca, rather compact (with original longitudinal flat sclerites largely fused) but pale-pigmented and not strongly sclerotized; its apex (Fig. 127) widened, curved and partly membranous, with several flat lobe-shaped (some with fine spinulae) projections and a few acute teeth, distinctly different from both $A$. versitheca and $A$. carbo. Ejacapodeme not observed, probably lost during dissection of genitalia.

Female unknown.

Discussion. Arganthomyza hyperseta sp. nov. belongs to the A. setiplanta group as characterized by ROHÁČEK \& BARBER $(2013,2016)$. This group comprises A. setiplanta (Roháček, 1987) from Nepal, A. versitheca Roháček, 2009 from South Korea (also recorded from China: Shaanxi, Sichuan below) and A. carbo Roháček \& Barber, 2013 from Canada and USA. The new species is externally very similar to representatives of this group including the long macrosetae of head and thorax and colouration of all parts of body but differs distinctly from all of them in having the mesonotum extremely glossy, almost without microtomentum. Further (less striking) differences from these species can be found in the head colouration (with yellow anterior half of frons and orbits up to posterior ors, occiput without microtomentum) and chaetotaxy (pvt crossed, vti extremely long, anterior ors very small), thoracic chaetotaxy (prs, sa and dc longest of all relatives, Fig. 119), male $\mathrm{f}_{3}$ with only 4 short thickened setae in posteroventral row and hind basitarsus with only 1 robust proximoventral seta (Fig. 118).

Based on the construction of the male genitalia, $A$. $h y$ perseta seems to be the closest relative of $A$. versitheca sharing with the latter the narrower apex of the gonostylus and the broad filum of the distiphallus. However, there are several species-specific characters also in the male genita- lia distinguishing the new species from both $A$. versitheca and $A$. carbo (male unknown in $A$. setiplanta), particularly the epandrium with more triangular anal fissure and the very long dorsolateral setae (Fig. 121), apex of gonostylus most tapered (Fig. 126), hypandrium with anterior half narrow and posterior half unusually dilated (Fig. 124), transandrium more robust and gradually transient to basal membrane and the latter with somewhat bilobed spinose armature (Fig. 122), phallapodeme unusually slender and with simple apex (Fig. 128), saccus very broad and more tuberculate apically (Fig. 128), filum most robust and with complex and very distinctive apex (Fig. 127). Also the male pregenital sternum (S5) is distinctive in its chaetotaxy (Fig. 125). Because the female of $A$. hyperseta and the male of $A$. setiplanta remain unknown, the possibility that these two species could be more closely related cannot be excluded; however, the distinctly shorter frontal triangle, more ac microsetae and distinctly microtomentose mesonotum of $A$. setiplanta speak against this possibility and indicate that $A$. setiplanta is probably the most ancestral species of the group as hypothesized by RohÁČEK \& BARber $(2013,2016)$.

Etymology. The species is named for its strikingly long mesonotal macrosetae. The name is a Latin noun (composed of prefix hyper- and a noun seta) in apposition in nominative singular.

Biology. Habitat association of the new species is unknown. The holotype male was collected in June at 1650-1750 m. Distribution. China: Shaanxi.

\section{Arganthomyza versitheca Roháček, 2009}

Material examined. CHINA: ShaAnxi: Fuping-x, Banbianhe, $1.5 \mathrm{~km} \mathrm{~N}$ of Longcaoping, 1300-1360 m, 4.vii.1997, 1 §, T. Saigusa leg. (SIINH,

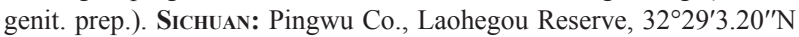

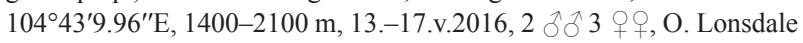
leg. (CNCI, $1 \precsim 1$ genit. prep.).

Remarks. Another representative of the Arganthomyza setiplanta group (delimited by ROHÁČEK \& BARBER 2013). As noted above it is obviously the nearest relative (sister species) of $A$. hyperseta sp. nov. (described above) while the Nearctic $A$. carbo Roháček \& Barber, 2013 is the next closest ally to this pair. The remaining (most ancestral) species of the group seems to be $A$. setiplanta (Roháček, 1987) from Nepal.

Biology. The type series was captured in montane forests of South Korea (750-1200 m) in June. The Shaanxi and Sichuan specimens expand both flight period (to May, July) and altitude range (1300-2100 m) of the species. The species is probably associated with the undergrowth of moist leafy forests (see RoHÁČEK \& BARBER 2013: Fig. 52). Distribution. South Korea (RoHÁčEK 2009), China: Shaanxi, Sichuan (first records).

\section{Discussion}

The eleven species of Anthomyzidae recorded here from China most likely represent only a small fragment of the total fauna of the family in this vast country. Of these only five, viz. Amygdalops bisinus, Epischnomyia 
merzi, Anthomyza cuneata, A. trifurca and Arganthomyza versitheca are known to be shared with neighbouring countries (cf. ROHÁČEK 2006, 2008, 2009), and the remaining six represent formerly unknown species. This ratio suggests that there should be a rich and very diverse fauna of Anthomyzidae that will include many more unnamed taxa.

There are 26 additional species (arranged alphabetically below) known from adjacent countries: Amygdalops abnormis Roháček, 2008, A. curtisi Roháček, 2008, A. cuspidatus Roháček, 2008, A. femorinus Roháček, 2009, A. nigrinotum Sueyoshi \& Roháček, 2003 (all largely Oriental), Anthomyza bellatrix Roháček, 1984, A. collini Andersson, 1976, A. decolorata Roháček, 2009, A. dissor Collin, 1944, A. drachma Sueyoshi \& Roháček, 2003, A. elbergi Andersson, 1976, A. flavosterna Sueyoshi \& Roháček, 2003, A. gracilis Fallén, 1823, A. macra Czerny, 1928, A. orineglecta Roháček, 2006, A. pallida (Zetterstedt, 1838), A. pleuralis Czerny, 1928, A. tschirnhausi Roháček, 2009 (all Palaearctic), Arganthomyza setiplanta Roháček, 1987, A. socculata (Zetterstedt, 1847) (Oriental and Holarctic), Epischnomyia triarmigera (Sueyoshi \& Roháček, 2003) (E. Palaearctic), Fungomyza cercata Roháček, 2009 (E. Palaearctic), Ischnomyia barbarista (Roháček, 2009) (E. Palaearctic), Stiphrosoma humerale Roháček \& Barber, 2005, S. grande Roháček, 2006 and S. fissum Roháček, 1996 (Holarctic and E. Palaearctic). It can be presumed that at least 20 of these species will be found in China. Consequently, together with 11 species known from China at the moment, 31 species occurring in China is a minimum estimate of the local fauna of Anthomyzidae. However, when considering the high proportion $(55 \%)$ of new species among those recorded here, the Chinese anthomyzid fauna must be much more diverse, possibly reaching 50-60 species, including up to 20 unnamed taxa. Such a rich biodiversity should be expected in this country when considering that its huge territory includes portions of both the Palaearctic and Oriental Regions and that it is extremely variable in its relief and climate which contribute to an enormous heterogeneity of ecosystems in the region.

The species of the diverse genus Amygdalops (with many undescribed taxa) are distinctly of Oriental origin and can therefore be expected mainly at lower altitudes in southeastern China. On the other hand, Anthomyza, another very rich genus, is most diverse in the Holarctic Region and, therefore, their representatives will occur mainly in the Palaearctic part of China but also in high-montane areas of the more southern provinces. The unnamed species can be expected particularly in montane ranges of the latter; Anthomyza ornata sp. nov., A. sulphurea sp. nov. and $A$. cuneata are good examples of such taxa. The discovery of Epischnomyia tkoci sp. nov. indicates that the small East Palaearctic genus Epischnomyia could also be more diverse in China. Similarly, Arganthomyza may be represented by several more species, of which the Holarctic $A$. socculata is to be expected in northern China with certainty as are also some additional unnamed species of the $A$. setiplanta group (being mainly East Palaearctic-Oriental) in montane valleys in southern China. Stiphrosoma species (hitherto unknown in
China) will also be found in the country but because they are more terricolous, living in tufts of graminoids, they must be sought through focused collecting in this microhabitat. Fungomyza species develop in rotting fungi but the biology of the East Palaearctic F. cercata is unknown (RoHÁČEK 2009). The latter species could perhaps be found in northeastern China as might Ischnomyia barbarista which is hitherto known only from the Far East of Russia and South Korea. Last but not least, discoveries of further unusual species belonging to new genera, such as Marshallya platythorax sp. nov. described above, cannot be excluded when considering the potential anthomyzid fauna of China.

\section{Conclusion}

The diversity of Chinese fauna of Anthomyzidae is predicted to be very high, containing approximately 50-60 species and including up to 20 unnamed taxa. The limited contemporary knowledge of their fauna in China has been mainly the result of a lack of material. Further collections and research of Anthomyzidae will surely contribute to interesting taxonomic, biogeographical and biological information on this family in China.

\section{Acknowledgements}

I would like to thank all curators and collectors who provided Chinese and other (type) material of Anthomyzidae for this study, namely M. Barták (MBP), M. Kotrba (ZSMC), O. Lonsdale (CNCI), S. A. Marshall and S. Paiero (DEBU), W. N. Mathis (USNM), L. Papp and Z. Soltész (HNHM), T. Saigusa (SIINH) and M. Tkoč (NMPC). I am particularly grateful to M. Tkoč (NMPC) for preparing all stacked macrographs for this paper, to S. A. Marshall (DEBU) for generous permission to use his photographs of living Chinese Anthomyzidae and to N. Burdíková, T. Sikora and J. Ševčík (Ostrava University, Czech Republic) for the molecular barcoding of anthomyzid adults and help with presentation of the results. O. Lonsdale, S. A. Marshall, J. Ševčík and M. Tkoč also kindly provided photographs of and/or information on habitats of Anthomyzidae from their field work. Both referees, K. N. Barber (Sault Ste. Marie, Ontario, Canada) and A. G. Irwin (Norwich, U. K), are specially thanked for very careful and contributing reviews of the manuscript. This study was financially supported by the Ministry of Culture of the Czech Republic by institutional financing of long-term conceptual development of research institution (the Silesian Museum, MK000100595), internal grants of the Silesian Museum Nos IGS201706/2017 and IGS201806/2018.

\section{References}

CUMMING J. M. \& WOOD N. D. 2010: 2. Adult morphology and terminology. Pp. 9-50. In: BROWN B. V., BORKENT A., CUMMING J. M., WOOD D. M., WOODLEY N. E. \& ZUMBADO M. A. (eds): Manual of Central American Diptera. Vol. 2. NRC Research Press, Ottawa, xvi + 715-1442 pp.

FOLMER O., BLACK M., HOEH W., LUTZ R. \& VRIJENHOEK R. 1994: DNA primers for amplification of mitochondrial cytochrome c oxidase subunit I from diverse metazoan invertebrates. Molecular Marine Biology and Biotechnology 3: 294-299. 
LETUNIC I. \& BORK P. 2016: Interactive tree of life (iTOL) v3: an online tool for the display and annotation of phylogenetic and other trees. Nucleic Acids Research 44: 242-245.

ROHÁČEK J. 1987: Two new species of the Anthomyza gracilis-group (Diptera, Anthomyzidae) from Nepal. Acta Entomologica Bohemoslovaca 84: 48-59.

ROHÁČEK J. 1993: Two new Afrotropical genera of Anthomyzidae (Diptera), with descriptions of seven new species. Annals of the Natal Museum 34: 157-190.

ROHÁČEK J. 1998: Taxonomic limits, phylogeny and higher classification of Anthomyzidae (Diptera), with special regard to fossil record. European Journal of Entomology 95: 141-177.

ROHÁČEK J. 2004: Revision of the genus Amygdalops Lamb, 1914 (Diptera, Anthomyzidae) of the Afrotropical Region. African Invertebrates 45: 157-221.

ROHÁČEK J. 2006: A monograph of Palaearctic Anthomyzidae (Diptera) Part 1. Časopis Slezského Zemského Muzea, Opava (A) 55(supplement 1): 1-328.

ROHÁČEK J. 2008: Revision of the genus Amygdalops Lamb, 1914 (Diptera, Anthomyzidae) of the Oriental, Australasian and Oceanian Regions. Acta Zoologica Academiae Scientiarum Hungaricae 54: $325-400$.

ROHÁČEK J. 2009: A monograph of Palaearctic Anthomyzidae (Diptera) Part 2. Časopis Slezského Zemského Muzea, Opava (A) 58(supplement 1): $1-180$.

ROHÁČEK J. 2013: New amber fossil Anthomyzidae (Diptera): an unexpected Eocene diversity. Journal of Systematic Palaeontology 11: $431-473$

ROHÁČEK J. \& BARBER K. N. 2011: Quametopia, a new genus of Nearctic Anthomyzidae (Diptera), with description of two new species, immature stages and life history. European Journal of Entomology 108: 287-326.

ROHÁČEK J. \& BARBER K. N. 2013: A worldwide review of the genus Arganthomyza Roháček, with revision of the Nearctic species (Diptera: Anthomyzidae). Zootaxa 3604(1): 1-72.
ROHÁČEK J. \& BARBER K. N. 2016: Nearctic Anthomyzidae: a monograph of Anthomyza and allied genera (Diptera). Acta Entomologica Musei Nationalis Pragae 56(supplement): 1-412.

ROHÁČEK J. \& BARRACLOUGH D. 2003: Margdalops, a new African genus of Anthomyzidae (Diptera), comprising six new species. African Invertebrates 44: 157-190.

ROHÁČEK J. \& PRZHIBORO A. 2016: Anthomyzidae (Diptera) of Iturup Island (Russia: Kuril Islands). Acta Musei Silesiae Scientiae Naturales 65: 203-213.

ROHÁČEK J. \& TÓTHOVÁ A. 2014: Morphology versus DNA - what will bring clarity to the relationships of phylogenetically unclear genera of Anthomyzidae (Diptera)? Arthropod Systematics and Phylogeny 72: 165-176.

ŠEVČÍK J., KASPŘÁK D., MANTIČ M., FITZGERALD S., ŠEVČÍKOVÁ T., TÓTHOVÁ A. \& JASCHHOF M. 2016: Molecular phylogeny of the megadiverse insect infraorder Bibionomorpha sensu lato (Diptera). PeerJ 4(e2563): 1-30. doi:10.7717/peerj.2563

STAMATAKIS A. 2014: RAxML version 8: A tool for phylogenetic analysis and post-analysis of large phylogenies. Bioinformatics 30: 1312-1313. http://bioinformatics.oxfordjournals.org/content/ early/2014/01/21/bioinformatics.btu033.abstract

STUCKY B. J. 2012: SeqTrace: A graphical tool for rapidly processing DNA sequencing chromatograms. Journal of Biomolecular Techniques 23: 90-93.

SUEYOSHI M. \& ROHÁČEK J. 2003: Anthomyzidae (Diptera: Acalyptrata) from Japan and adjacent areas. Entomological Science 6: 17-36.

TKOČ M. 2012: A new species of the flat-footed fly genus Callomyia (Diptera: Platypezidae) from South China. Acta Entomologica Musei Nationalis Pragae 52: 289-296.

ZATWARNICKI T. 1996: A new reconstruction of the origin of eremoneuran hypopygium and its implications for classification (Insecta: Diptera). Genus 7: 103-175. 